\title{
Development of a Multi-Scale Stormwater Management Modelling Methodology
}

\author{
by
}

\author{
Preetha Haque
}

BSc Eng (WRE), Bangladesh University of Engineering and Technology, 2012

\author{
A thesis \\ presented to Ryerson University \\ in partial fulfillment of the \\ requirements for the degree of \\ Master of Applied Science \\ in the program of \\ Civil Engineering
}

Toronto, Ontario, Canada, 2019

(C) Preetha Haque, 2019 
AUTHOR'S DECLARATION

I hereby declare that I am the sole author of this thesis. This is a true copy of the thesis, including any required final revisions, as accepted by my examiners.

I authorize Ryerson University to lend this thesis to other institutions or individuals for the purpose of scholarly research.

I further authorize Ryerson University to reproduce this thesis by photocopying or by other means, in total or in part, at the request of other institutions or individuals for the purpose of scholarly research.

I understand that my thesis may be made electronically available to the public. 


\title{
Development of a Multi-Scale Stormwater Management Modelling Methodology
}

Master of Applied Science, 2019

Preetha Haque

\section{Civil Engineering, Ryerson University}

\begin{abstract}
The evaluation process of the land development project becomes complicated, as the simulation results of Fine-Scale Models (FCM) of lands proposed for development cannot be easily transferred to the watershed Coarse-Scale Models (CSM) due to parameterization problem. In this research study, a Multi-Scale Modelling (MSM) methodology was developed to minimize the difficulty in transferring the result into the different spatial scales of the models. The developed MSM methodology was tested on Ganatsekiagon Creek's sub-watershed, simulating several scenarios. The analyses of model results show that the CSM is generating a lower Peak Flow Rate (PFR) and Flow Volume (FV) than the MSM, while the increasing level of development with BMPs leads to a rise in FV and a decrease in PFR. The comparison results of with and without BMPs show that the stormwater management ponds are effective in PFR reduction and the implementation of LID practices can be effective in FV reduction.
\end{abstract}




\section{Acknowledgments}

I would first like to thank my supervisor, Dr. Darko Joksimovic, whose expertise was invaluable in the formulating of the research topic and methodology in particular. His guidance helped me in the research and writing of this thesis. I could not have imagined having a better advisor and mentor for my MASc Studies.

I would like to acknowledge the support of my colleagues Tara Razavi, Tim Van Seters, Christy Graham and Jenny Hill from my internship at TRCA for their wonderful collaboration. You supported me greatly and were always willing to help me. I would also like to mention the support of TRCA and the City of Pickering by providing me with all the necessary data needed for the analysis of the study.

In addition, I would like to thank my parents and my husband for their wise counsel and sympathetic ear. You were always there for me. Finally, I would like to mention the support of my

little daughter who was so understanding at her young age and providing happy distractions to rest my mind outside of my research. 


\section{Table of Contents}

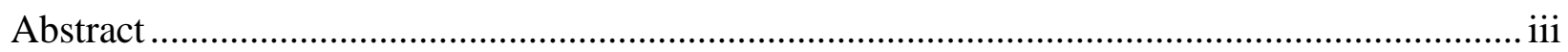



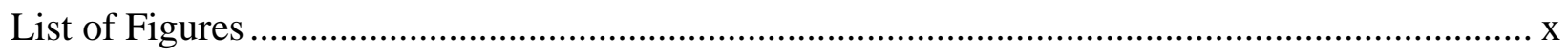

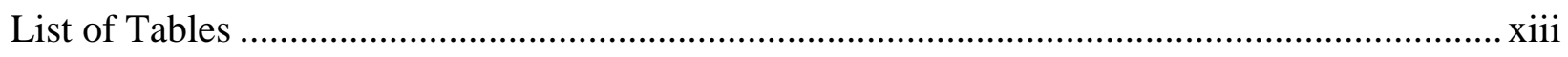

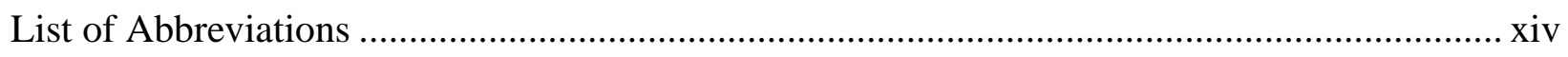





1.2 Stormwater Management Approaches ................................................................ 4

1.3 The problem of spatial modelling scales in current practice..................................... 5



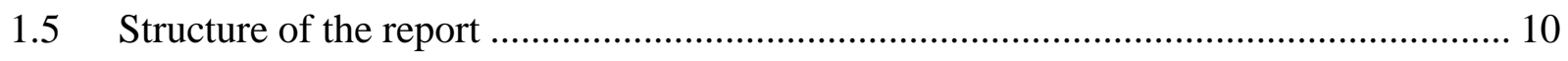

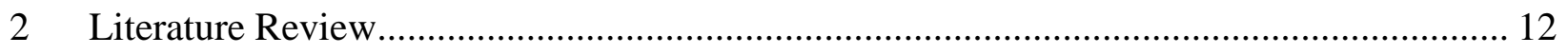

2.1 History of Watershed Planning in Ontario ...................................................... 12

2.2 Stormwater Management Facilities (SWMF) ................................................... 15

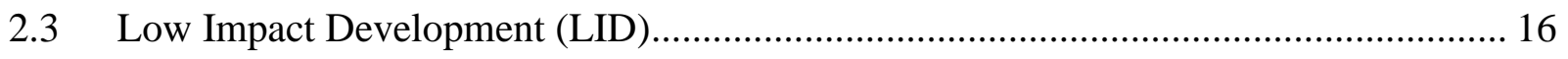




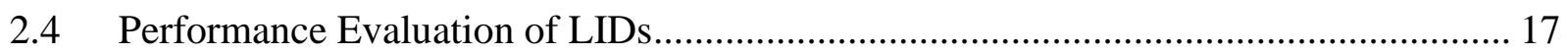

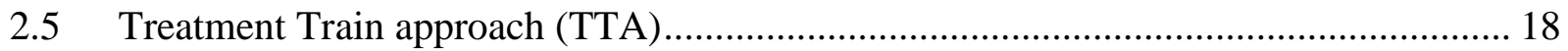

2.6 Importance of Catchment-Scale BMPs evaluation ................................................... 19



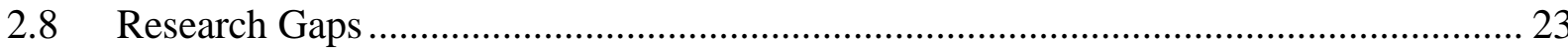



2.9.1 Spatial Discretization of the Models .................................................................. 25

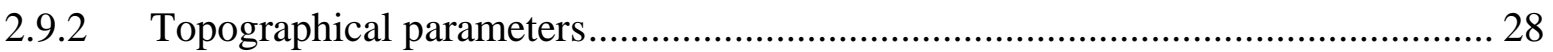

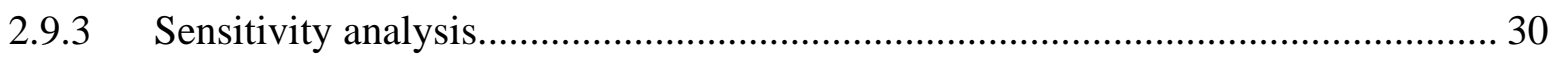

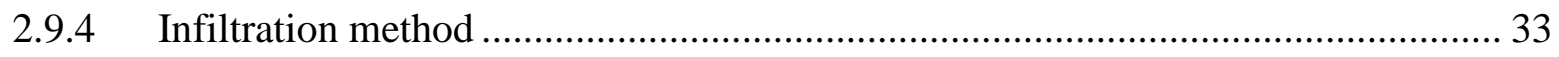

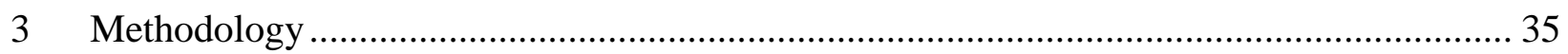



3.2 Coarse-scale Pre-development model set up............................................................. 38



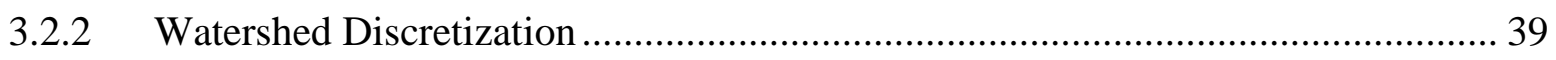




3.2.4 General Model Settings..................................................................................... 40

3.2.5 Sensitivity test of the model........................................................................... 41

3.2.6 Calibration and validation of the Predevelopment model........................................ 41

3.3 Coarse-scale Post-development model set up ............................................................. 42

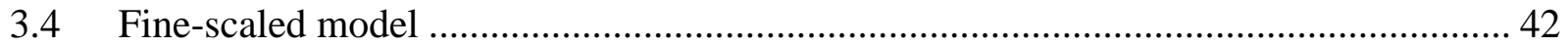

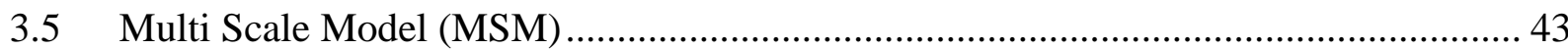



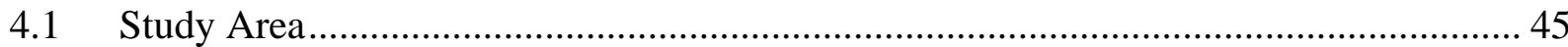

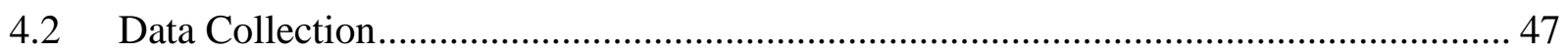

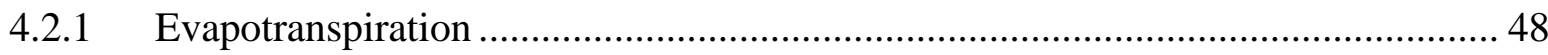

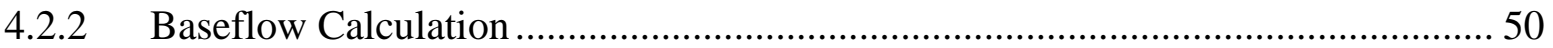

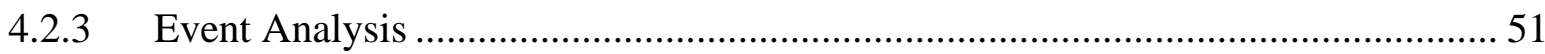

$4.3 \quad$ Pre-development model setup ………………………............................................ 55

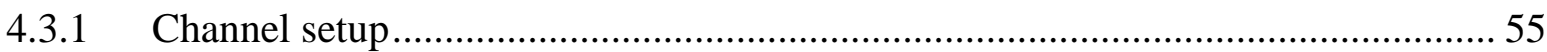

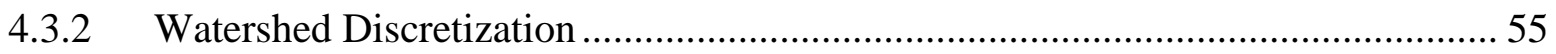

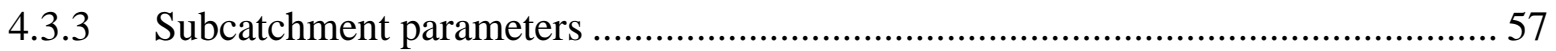




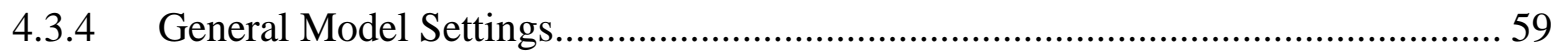

4.3.5 Sensitivity test of the model............................................................................... 59

4.3.6 Calibration and Validation of The Pre-development Model.................................... 60

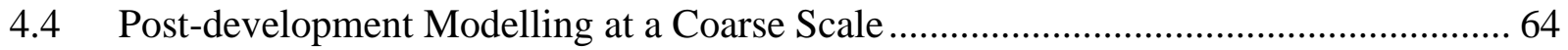

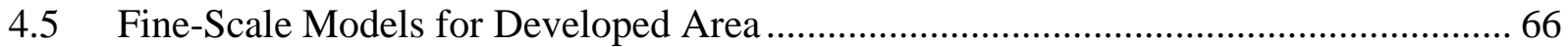

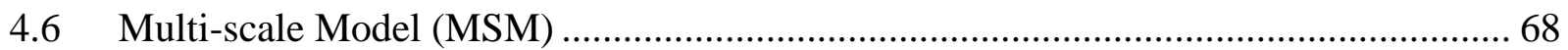

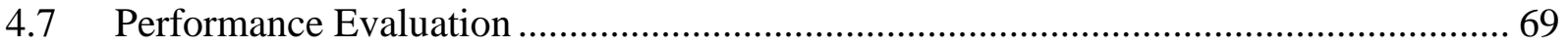

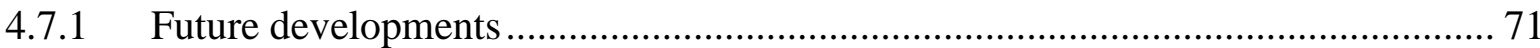

4.7.2 Best Management Practices .............................................................................. 76

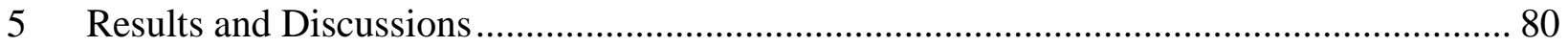

5.1 Calibrated Pre-development Model's Performance ...................................................... 80

5.2 Calibrated Post-development CSM's Performance........................................................ 81

5.3 Comparison of Coarse-scale Pre and Post-development Models.................................... 82

5.4 Comparison of CSM and FSM for Developed Area ................................................... 84

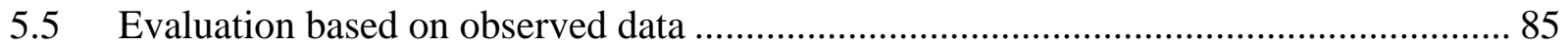

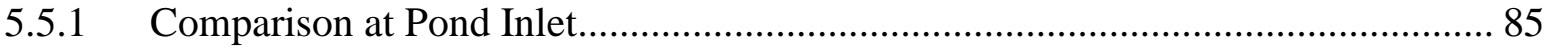


5.5.2 Comparison at Watershed Outfall........................................................... 87

5.6 Results of the Future Development Scenarios ......................................................... 90

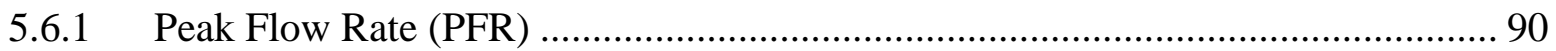

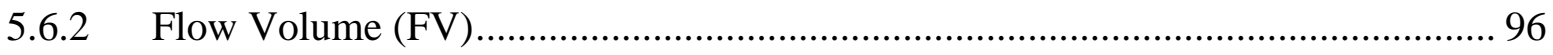



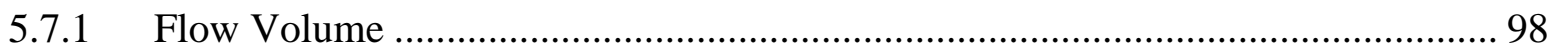

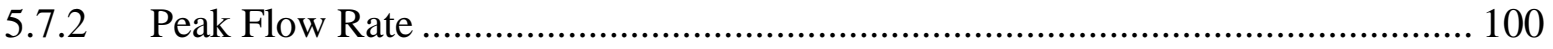

6 Summary and Conclusions ..................................................................................... 102

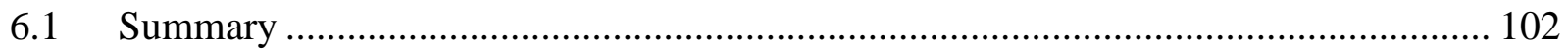

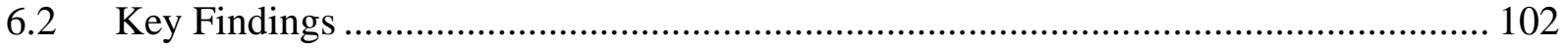

6.3 Limitations and Future Recommendations .............................................................. 104

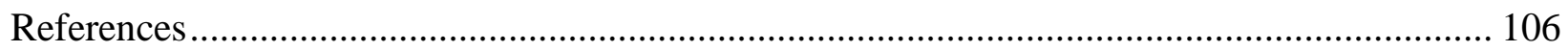




\section{List of Figures}

Figure 1: Comparison of Drainage Pattern Due to Urbanization ................................................ 2

Figure 2: Typical Urban and Rural Runoff Hydrograph ........................................................ 3

Figure 3: Scale Differences in Stormwater Management Planning and Modelling ....................... 7

Figure 4: Process of Generating Stormwater Management Plans ................................................ 14

Figure 5: Typical Example of Treatment Train Approach .......................................................... 18

Figure 6: Flow Chart Presenting the Methodology of This Study ………………….................. 35

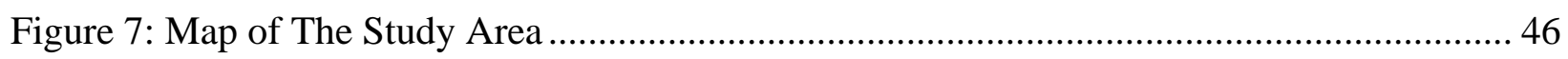

Figure 8: Estimated Baseflow of Urfe and Ganatsekiagon Creek …………................................ 51

Figure 9: Three Different Levels of Discretization of The Ganatsekiagon Sub-watershed ......... 57

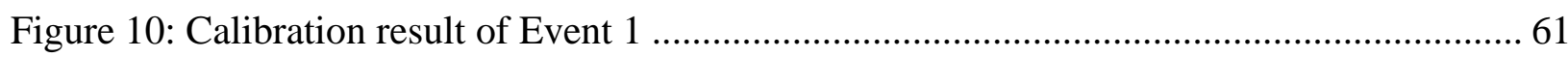

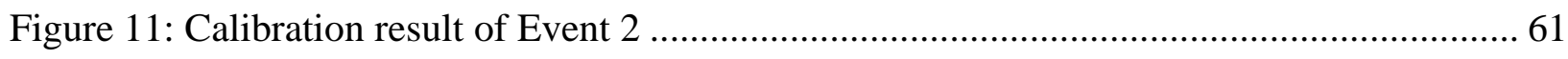

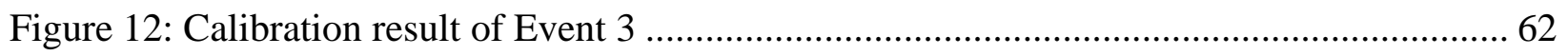

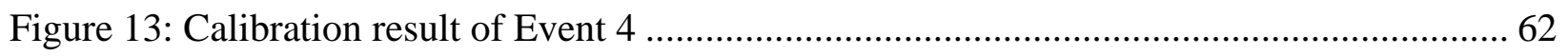

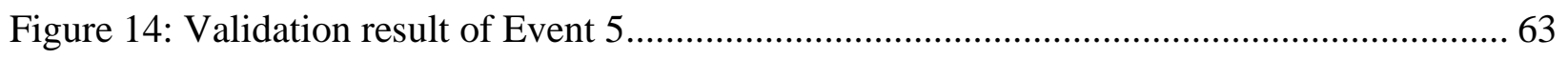

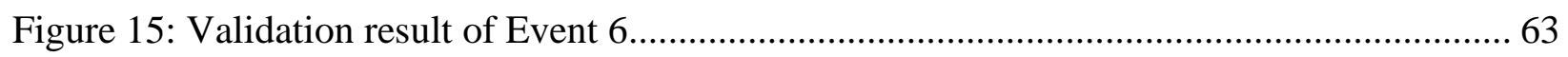


Figure 16: Duffin Heights in CSM 65

Figure 17: Detailed Post-development Model of The Duffin Heights in Fine-Scale 67

Figure 18: Difference of a Multi-scale and a Coarse-scale Model of the Ganatsekiagon Creek Subwatershed 68

Figure 19: Map of The Approved Future Development Projects in The Subwatershed 69

Figure 20: Models of the 25\% of Future Development Scenario A) Coarse and B) Multi Scale 72

Figure 21: Models of the 50\% of Future Development Scenario A) Coarse and B) Multi Scale 73

Figure 22: Models of the 80\% of Future Development Scenario A) Coarse and B) Multi Scale 74

Figure 23: Models of the $100 \%$ of Future Development Scenario A) Coarse and B) Multi Scale 75

Figure 24: Multi Scale Model of The 100\% of Future Development A) with and B) without LID

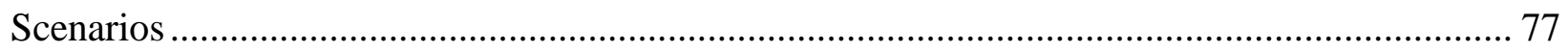

Figure 25: Multi Scale Model of the 100\% of Future Development A) With and B) Without SWM

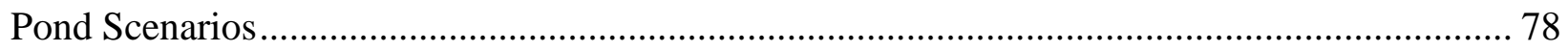

Figure 26: Multi Scale Model of the 100\% of Future Development A) With and B) Without BMPs Scenarios 79

Figure 27: Performance of the Calibrated Ganatsekiagon Creek Sub-watershed Model in All the Selected Events 81 
Figure 28: Performance Evaluation of the Ganatsekiagon Creek Sub-watersheds Post-development Model 82

Figure 29: Comparison of Coarse-scale and Fine-scale Post-development Model of Duffin Heights area 84

Figure 30: Comparison of Modelled Peak Flow Rate at Duffin Heights SWM Pond Inlet ..... 86

Figure 31: Comparison of Modelled Flow Volume at Duffin Heights SWM Pond Inlet. 86

Figure 32: Event Comparison Results of Pre-development Model, CSM, and MSM of the PostDevelopment scenario of Ganateskiagon Creek Watershed...... 88

Figure 33: Comparison of Maximum Flow Rate in the Future Development Scenarios with a) Short Duration b) Long Duration Events 92

Figure 34: Map Showing of the Nodes to Compare the Peak Flow Rate Propagation..... 94

Figure 35: Comparison of the Peak Flow Rate Propagation from the CSM and MSM with $80 \%$ Future Development. 95

Figure 36: Comparison of the FV in Different Future Development Scenarios with a) short duration and b) Long Duration Events 97

Figure 37: Comparison of The Flow Volume of All the BMPs Scenario with a) Short Duration and b) Long Duration Events 99

Figure 38: Comparison of the Peak Flow Rate of the BMPs Scenario 101 


\section{List of Tables}

Table 1: Collected stream and Pond monitoring data ............................................................... 48

Table 2: Average Monthly Evapotranspiration Values ............................................................. 49

Table 3: Calibration and Validation Events for The Ganatsekiagon Creek Models...................... 53

Table 4: Selected Events for Duffin Heights FSM .................................................................... 54

Table 5: Estimated Dstore for Permeable and Impermeable Areas .............................................. 58

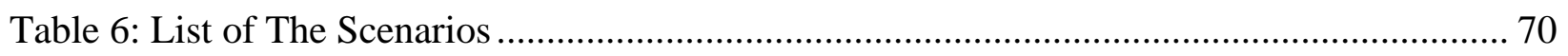

Table 7: Comparison of Pre- development and CSM Ganatsekiagon Creek Sub-watershed Models

Table 8: Selected Post Development Events (2017) for The Ganatsekiagon Creek Sub-watershed

Table 9: Comparison of Peak Flow Rate from The Models at The Ganatsekiagon Creek........... 89

Table 10: Comparison of Total Flow Volume from the Models at the Ganatsekiagon Creek ..... 89

Table 11: List of the Selected Design Storms for the Simulations ............................................... 90 


\section{List of Abbreviations}

\begin{tabular}{ll} 
AES & Atmospheric Environment Service \\
BMP & Best Management Practice \\
CN & Curve Number \\
CSM & Coarse Scale Model \\
CVC & Credit Valley Conservation \\
DEM & Digital Elevation Model \\
DH & Duffin Heights \\
Dstore & Depression storage \\
E & Efficiency \\
EMP & Environmental Management Plan \\
FSM & Fine Scale Model \\
FV & Flow Volume \\
Gana & Ganatsekiagon \\
GIS & Geographical Information System \\
LID & Low Impact Development \\
LSRCA & Lake Simcoe Region Conservation Authority \\
MSM & Multi Scale Modelling \\
NSE & Nash Sutcliffe Efficiency \\
PCSWMM & Personal computer Stormwater management model \\
PET & Potential Evapotranspiration \\
PFE & Peak Flow Error \\
PFR & Peak Flow Rate \\
Pre-dev. & Pre-development \\
SCS & Soil Conservation Service \\
SRTC & Sensitivity-based Radio Tuning Calibration \\
SWM & Stormwater Management \\
SWMF & Stormwater Management Facility \\
SWMM & Stormwater Management Model \\
TRCA & Toronto and Region Conservation Authority \\
TTA & Treatment Train Approach \\
TTT & Treatment Train Tool \\
US EPA & United States Environmental Protection Agency \\
VE & Volume Error \\
WDT & \\
& Watershed Delineation Tool \\
\hline &
\end{tabular}




\section{Introduction}

World population is increasing every year, and more and more people are moving to urban areas. Population projection shows that by the year 2050, the world's urban population will increase by more than 50\% (United Nations 2018). In 2035, more than $87 \%$ of people in Toronto will be living in the urban area of Toronto, and the total population will rise by 15\% from 2018 (Toronto Population 2019). This high rate of the increased urban population needs accommodation, workplace, and other civic infrastructures. So, the growing population is ultimately leading to increasing urban area with a lot of concrete and asphalt structures, which are generally impermeable in nature. Therefore, the development is converting the natural land surface areas into impermeable urbanized surface areas. This increasing imperviousness is known to exacerbate the deterioration of urban watercourses.

\subsection{Effect of Urbanizations}

Urbanization of any natural catchment means converting a portion of the permeable surface into an impermeable surface. The increase of impervious surface is not only an indicator of urbanization, but it is also an indicator of environmental impact from land development (Arnold and Gibbons 1996); because impermeable surfaces decrease infiltration and evapotranspiration; as a result, most of the precipitated water becomes surface runoff (Figure 1). Decreasing infiltration and evapotranspiration and increasing surface runoff are disturbing the natural balance of the water cycle, which is affecting the environment hugely. As discussed in this section, urbanization changes surface permeability not only by introducing impermeable surface but also by changing the topsoil of the porous surface. According to the study of Xiao et al. (2006), the development of 
their study area replaced the existing loam soil of the area near the development, with clay soil, which resulted in a $63 \%$ increase in storm runoff volume. Additionally, during the construction activity, the urban soil experiences compaction to increase the stability of the structure, which also decreases the infiltration capacity of the soil.

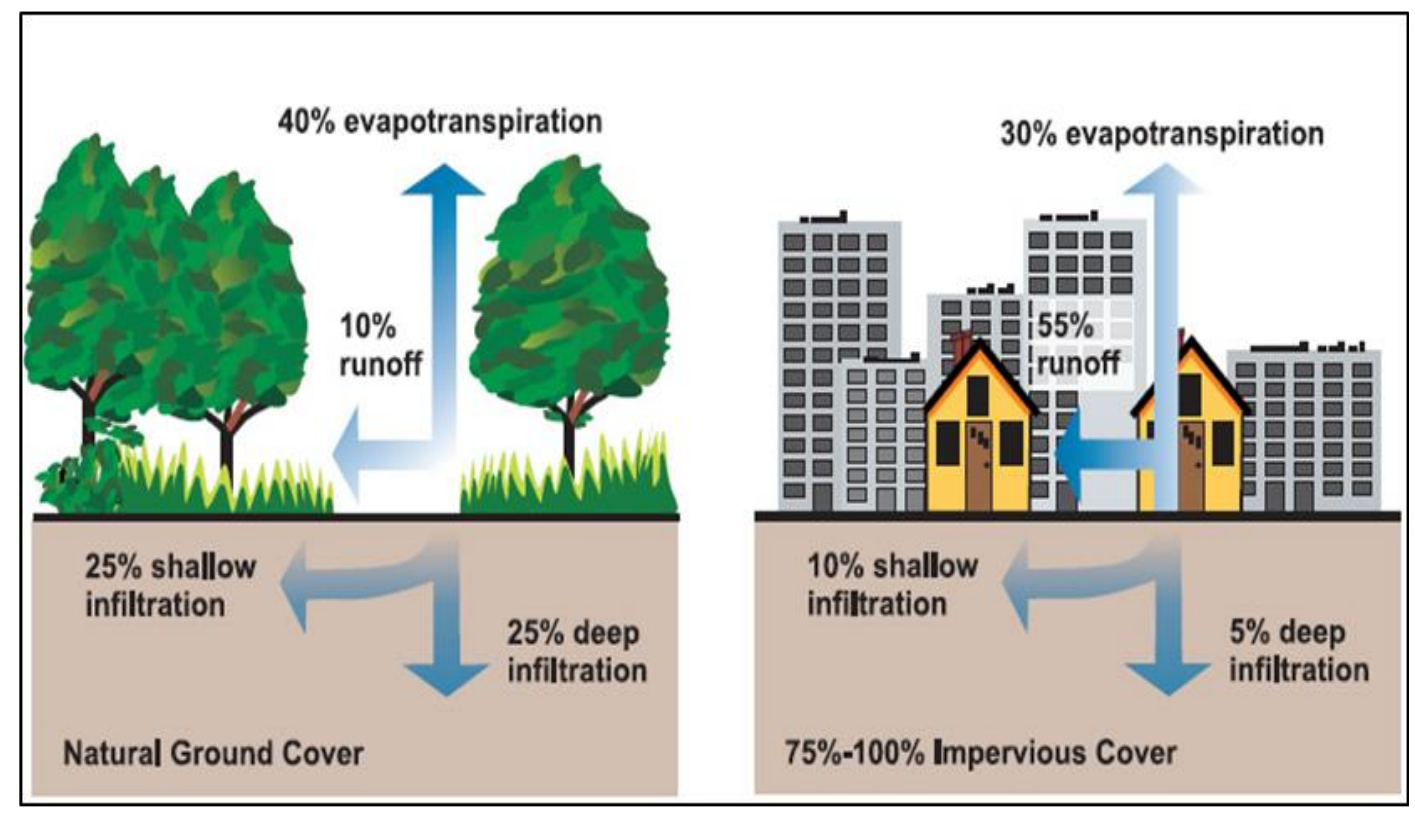

Source: (Wikipedia n.d.)

\section{Figure 1: Comparison of Drainage Pattern Due to Urbanization}

Urbanization increases temperature locally, which also affects the precipitation pattern. Studies have shown that seasonal changes in precipitation increased locally by $5 \%-15 \%$ after urbanization (Huff and Changnon 1972; Shepherd 2006; Shepherd et al. 2002; Taha 1997).

The catchments response time to precipitation also decreases due to urbanization (Salvadore et al. 2015). In an urban area, the peak of the streamflow due to a rainfall event come faster, and an urban area also drains more quickly than a rural area (Figure 2). Urbanization converts most of the precipitation to surface runoff, and the rapid surface runoff causes more frequent floods with a higher magnitude of peaks from a relatively small rainfall event than in natural areas. This change 
eventually disturbs the hydrological cycle and degrades the water resources (Arnold and Gibbons 1996).

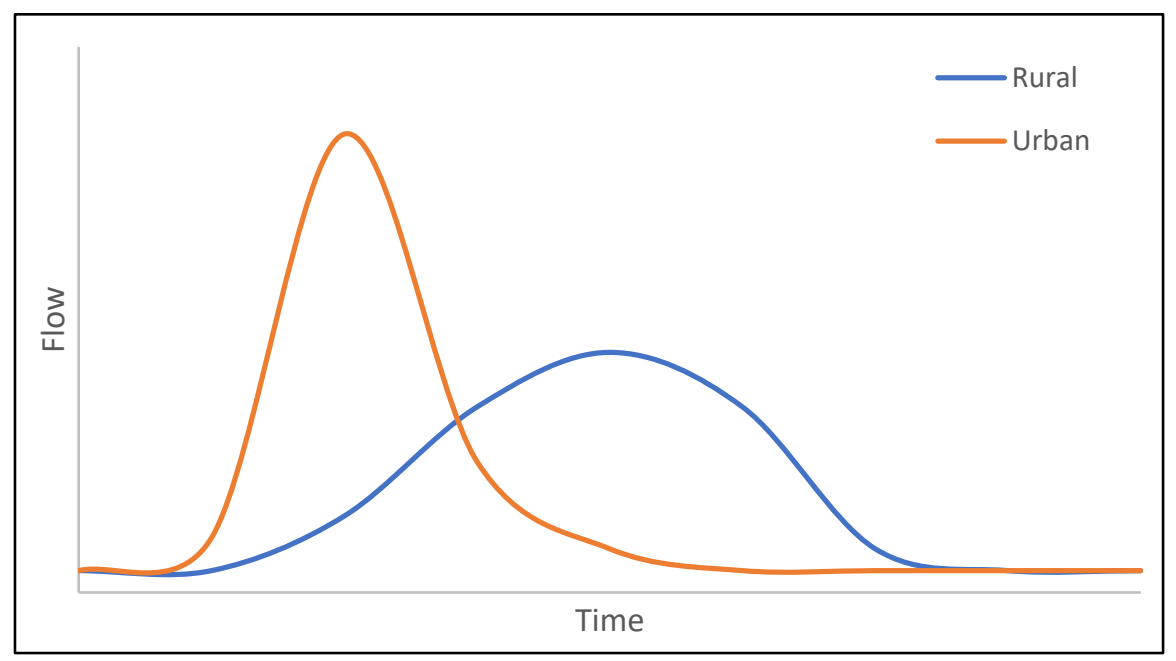

Figure 2: Typical Urban and Rural Runoff Hydrograph

Additionally, the hydraulically efficient stormwater pipes of the urbanized area, which are directly discharging into streams, also change the stream condition (Booth et al. 2005; Li et al. 2017; Walsh et al. 2005). Natural channels can adapt to changed situation naturally by changing its course shape and area. Urbanized channels that are lined do not have that adaptability, and the changed situation increases floods in both frequency and magnitude (Salvadore et al. 2015). These changes of the flow condition also result in erosion, scour, increase of pollution and eventually affect the biodiversity and ecology of the streams ( $\mathrm{Li}$ et al. 2017).

On the other hand, the reduced infiltration decreases the groundwater recharge, lowering the groundwater table and eventually reducing base flow to the streams (Arnold and Gibbons 1996; Li et al. 2017; Walsh et al. 2005). However, according to some other studies, urbanization can also increase the groundwater recharge. The urbanized areas need underground water utilities. Only a 
few water utilities worldwide can claim, they were able to reduce leakage to less than $10 \%$. In developed countries, expected leakage of water utilities is $20-30 \%$ while it is about $30-60 \%$ in developing countries (Garcia-Fresca and Sharp 2005; Lerner 1990). This water utility leakage contributes to the groundwater table and rises the groundwater level. The potential groundwater recharge may rise to $100-300 \mathrm{~mm} / \mathrm{yr}$. in average condition, and in the extreme condition, it can be about 3000mm/yr. in permeable soils (Lerner 1990). Whether the groundwater recharge increases due to leaky water distribution or decreases due to reduced infiltration, it is ultimately changing the natural condition.

The changes mentioned above due to urbanization affect stream health. According to the study of Schueler (1994), an increase of impermeability as low as $10 \%$ can result in degradation of stream health. Many studies have been done to quantify urbanization effects on a watershed. For example, Guan et al. (2015) have studied the hydrological changes due to the urbanization of a coniferous forest. This study shows that the urbanization accelerated the hydrological response, rose the peaks ten times, doubled the runoff volume, increased the low-frequency flowrates considerably, and in contrast, the high-frequency-low flows reduced quickly.

\subsection{Stormwater Management Approaches}

Various approaches have been developed to manage the increased stormwater resulting from an urbanized watershed. The oldest measure is a conveyance to move the stormwater from the urban area to the streams rapidly. These conveyances transfer the problems related to excess stormwater to the downstream, which is not a real solution. 
In the 1960s, the detention-based stormwater management approach was introduced. In this approach, the urban stormwater was stored in a basin for a while and then released the water with a low flow rate to the streams. This detention approach is a modified version of a conveyance system. The problem with this solution is that the excess runoff was still contributing to the downstream, and the failure of the detention approach was causing flooding and erosion. Moreover, the problem of water quality and groundwater replenishment could not be addressed by the detention approach (Dannowski 2013).

Recently, many types of Best Management Practice (BMP) have been introduced. The purposes of BMPs are to reduce the total volume of surface runoff, reduce the peak flow, improve the water quality, and increase the groundwater recharge. These BMPs reduce the effects of urbanization at the source of generation and maintains the pre-development (pre-development) flow condition, which is the main concept of sustainable development or low impact development.

\subsection{The problem of spatial modelling scales in current practice}

The current development approach in many parts of the world is moving toward the concept of sustainable development. In the province of Ontario, all the Government levels, have the policy to preserve the pre-development condition of natural water resources and ensure sustainable development. As the degree of the development effects cannot be quantified before the accomplishment of the development through monitoring, a hydrological simulation of the proposed development and associated BMPs is prerequisite of the approval of any development project. The effects of BMPs can only be shown in a detailed fine-scale model (Khin 2015). Generally, government policies and plans, as well as approval (e.g. Ontario ECA), are developed 
based on a watershed scale and sub-watershed scales modelling results (Figure 3). These watershed and sub-watershed models hereafter referred to as Coarse-Scale Models (CSM), are typically developed using a relatively coarse model discretization in space and time. This is done because the fine-scale model simulations need a longer run-time and detailed input data, which is not necessarily available. However, the models for development proposals are done with a fine spatial scale, only considering the developed and the upstream external areas. These are referred to as Fine-Scale Models (FSM) in this research. Although more detailed and including the proposed stormwater infrastructure, these FSMs only show the impact of the development and associate BMPs at the outfall of the developed area. However, the effect on the downstream channels of the watershed can not be readily understood from the result of these FSM. Results from these FSMs cannot be transferred to the watershed scale due to enormous uncertainty in the process of parameterization (Jefferson et al. 2017).

The spatial scale differences of watershed, sub-watershed and site scale modelling are shown in Figure 3. In current practice, this scale variation makes the evaluation process of the land development project complicated as there is no established standard approach to evaluate the impact of the proposed development on the downstream channels. Moreover, most of the recent developments incorporate multiple BMPs to manage increased stormwater runoff. In present practice, the developed area is incorporated into the watershed scale model with lumped parameters for the subcatchment and grossly aggregated BMP parameter to represent all the BMPs of the developed area combinedly. But the cumulative effect of multiple BMPs associated with development can not be estimated as a simple additive (Jefferson et al. 2017). Developing a modelling methodology to combine the FSM of proposed development sites with the CSM of the 
watershed is very important; to establish a standard approach for evaluating the impact of any proposed project on the downstream part of the watershed's natural watercourses, with more confidence. This newly developed modelling methodology should also minimize the existing parameterization problems due to the scale difference between the current modelling approaches.

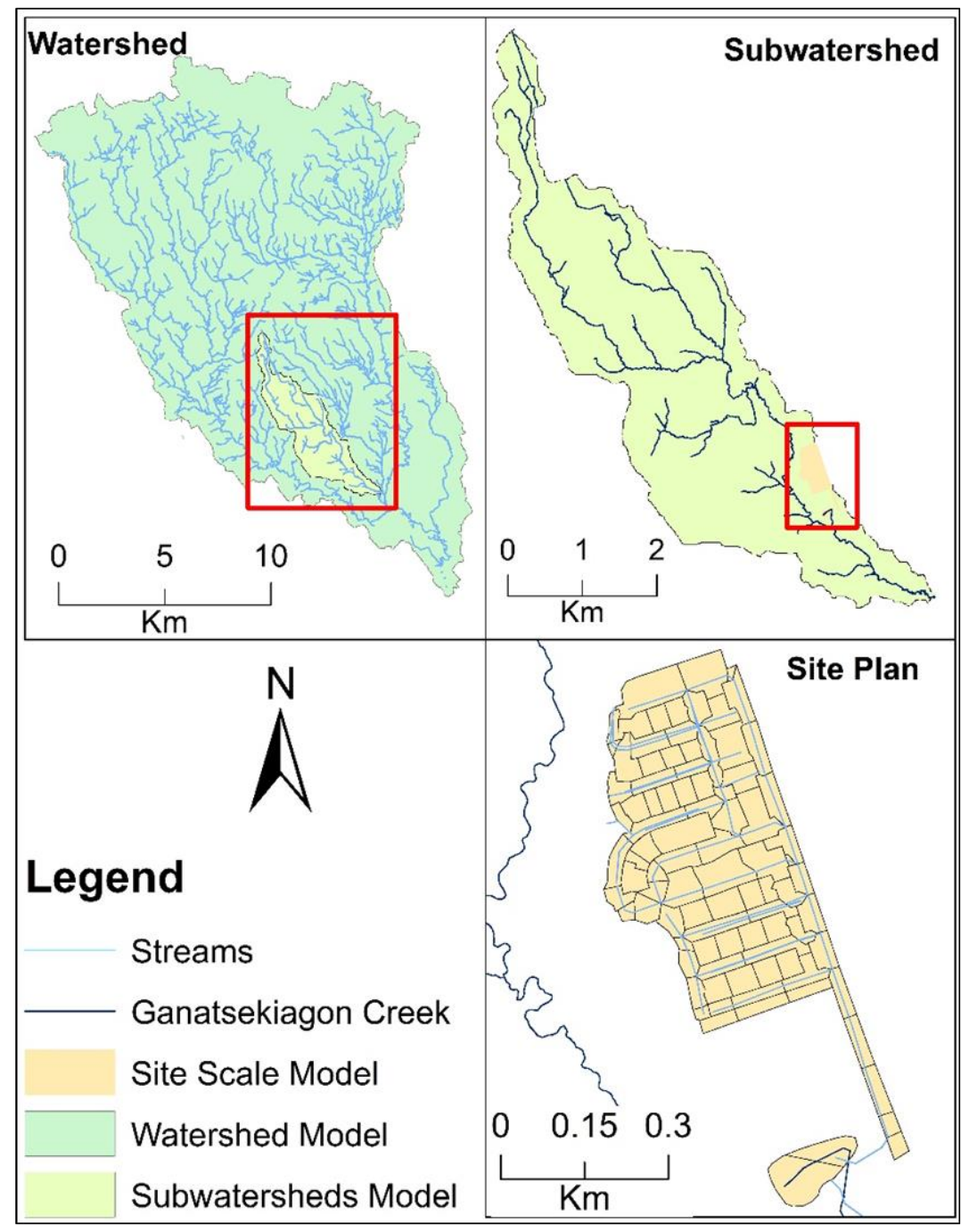

Figure 3: Scale Differences in Stormwater Management Planning and Modelling 


\subsection{Research Objective and Scope}

The objective of this study is to develop and test a Multi-scale modelling approach that links the different spatial scales, traditionally used in models for watershed, sub-watershed, and stormwater management plans. The term of Multi-scale means that the developed model will have higher spatial resolution for the developed portion of the watershed, including the proposed stormwater management infrastructure, as normally captured by FSMs. The undeveloped portion of the watershed will have lower spatial resolution, typical of the CSM used in watershed and subwatershed planning. The newly develop modelling methodology is aimed at being used to simulate both the fine-scaled part and the coarse-scaled part together and represent the development effect on the downstream natural channels more accurately and minimize the problem related to scaling differences in the present practice.

The developed modelling methodology will be able to show the effect of the development and the associated BMPs on the downstream portions of the watershed. This process will be very helpful to compare the pre-development condition and the post-development condition at any point of the downstream channels as required. As both the fine-scale and the coarse-scale part of the model will be simulated as one integrated model, the problem with the parameterization due to transferring the result into any other scale will be eliminated and can be considered as a standard practice to evaluate models of different spatial scales.

The developed methodology will also be tested in a developing area to understand the difference between the performance of the newly developed modelling methodology and the present modelling practice of CSM. The developed modelling methodology will also be tested on some 
assumed development scenario to understand the effect of extensive land development on the downstream portion of the watershed.

The approving agencies want to ensure that all the proposed development and the associated stormwater management features will preserve the predevelopment flow condition of the streams. The stormwater management features are designed in such a way that the Flow Volume (FV) and Peak Flow Rate (PFR) after the development is not higher than the pre-development condition. This newly developed modelling methodology will be able to show the changes in FV and PFR, due to the developments on the stream without much effort. So, this methodology will be helpful for the approving agencies to understand the effects of the proposed development and guide future development to maintain the pre-development FV and PFR.

In this study, the model will be prepared, considering only the FV and the PFR difference as these performance measures are considers as the indicator of the effectiveness of the BMPs. The change in erosion rate due to urbanization depends on the changes in flow duration curves. As the timing of the flow are not considered in this research, the change in erosion was not analyzed in this research. The water quality aspect of the pre and post-development scenario is not considered in this research because it is assumed that the pond was sized accurately to reduce the Total Suspended Solids (TSS) to the allowable range and maintain the water quality standards. In winter when the ground is frozen the infiltration capacity of land surface reduces and at that time sudden temperature drop melts the accumulated snow and rain makes massive flow to the stream but, the flow conditions of the winter seasons were also not included in this research study because of the 
complexity of winter hydrology. The summary of the activities carried out to achieve the stated objective is given below.

1. To develop a Multi-Scale Modelling (MSM) methodology for minimizing the problem related to the current practice of different scales in modelling.

2. To demonstrate the performance of the developed multi-scale modelling methodology in a developing area as a case study.

3. To understand the effect of extensive land development on the downstream portion of the watershed with some hypothetical scenario using the developed modelling methodology.

\subsection{Structure of the report}

In this thesis, Chapter 1 contains the introduction of the study and includes the background and study objectives and scope. The overall idea of the full dissertation is also concisely presented here to guide through the entire thesis.

In Chapter 2, the previous studies on BMPs are presented to identify the existing research gaps. After identifying the research gaps, a review of relevant research papers is also presented, which helped to finalize the methodology of this study.

Chapter 3 presents the detailed methodology to develop a Multi-scale watershed model, which can evaluate any proposed BMP's performance on a watershed scale.

In Chapter 4, a case study is presented to demonstrate the application of the developed methodology on an urbanizing sub-watershed. 
Chapter 5 presents the performance of the developed Multi-scale model on the urbanizing subwatersheds. The effects of the expected future developments in the case study area are also simulated with $25 \%, 50 \%, 80 \%$ and $100 \%$ of the already approved development projects in the study area. These future development scenarios have been simulated with $2 \mathrm{yr}, 5 \mathrm{yr}$ and $10 \mathrm{yr}$ design rainfall events to understand the impacts of the development on the downstream part of the watershed, and the difference of the between the MSM and the CSM results.

Finally, Chapter 6 presents the overall study, conclusions, and recommendations for future research. 


\section{Literature Review}

This chapter presents a summary of research studies done previously on BMPs to identify the research gaps. The history of watershed planning in Ontario is first discussed briefly, followed by an introduction of BMP and Low Impact Development (LID). The performance of different LID features and, the current practice of BMPs in Ontario are also discussed for a better understanding of the basis of the research. Then the research gaps are identified, reviewing the latest researches in the field of BMPs performance evaluation. Relevant studies are reviewed, to address the identified research gaps, and to determine the most crucial considerations for developing the MSM methodology.

\subsection{History of Watershed Planning in Ontario}

The Ontario Government has recognized and addressed the importance of watershed planning several decades ago. To develop the watershed management framework in Ontario, the "Conservation Authority Act" had been established in 1946. At present, there are 31 Conservation Authorities in southern Ontario and five in northern Ontario. In the 1980s, Master Drainage Plans were developed, mainly to manage the development impacts on the watershed. These plans addressed issues like floodplain management, runoff quantity control, erosion and flood control works, major/ minor system design, and culvert improvements.

In between the 1980s and 1990s, the objectives of environmental management shifted toward a sub-watershed approach. The main goal of this approach was to maintain and enhance natural system without ignoring the development impacts. Issues like watershed quality consideration, 
enhancement opportunities and aquatic habitats were started to get importance through this approach. In 1991, the ministry of environment published "Stormwater Quality Best Management Practices"; this report suggested that structural and non-structural Stormwater Management Practices (SWMPs) should be included in urban developments. Guidance and procedure of selecting appropriate SWMP were documented in this report (Ontario Ministry of the Environment. 2003). Since 1993, the province released a trilogy of documents to guide the overall watershed planning. These documents are: Watershed Management on a Watershed Basis: Implementing an Ecosystem Approach, Sub-watershed Planning, and Integrated Water Management Objectives into Municipal Planning Documents. All the development projects had to ensure the alignment with the planning mentioned above.

At present, the overall land use planning system is guided by policies. The province sets the legislative and policy frameworks, and the municipalities implement them with the help of conservation authorities. The watershed plan and official municipal plan ensure the protection of water resources and manage human activities, land, water, aquatic life, and resources; these plans provide a basis for municipalities to evaluating growth and servicing options. On the other hand, the sub-watershed plans identify specific criteria, objectives, actions, thresholds, targets, and best management practices for development, water and wastewater servicing, stormwater management, managing and minimizing impacts related to severe. Figure 4 represents the overall process, how the watershed plan and sub-watershed plan contributes to the Municipal planning process to eventually guide the land use development, protect the natural water resources and minimize the development impacts on the water resources (Ontario 2018). 


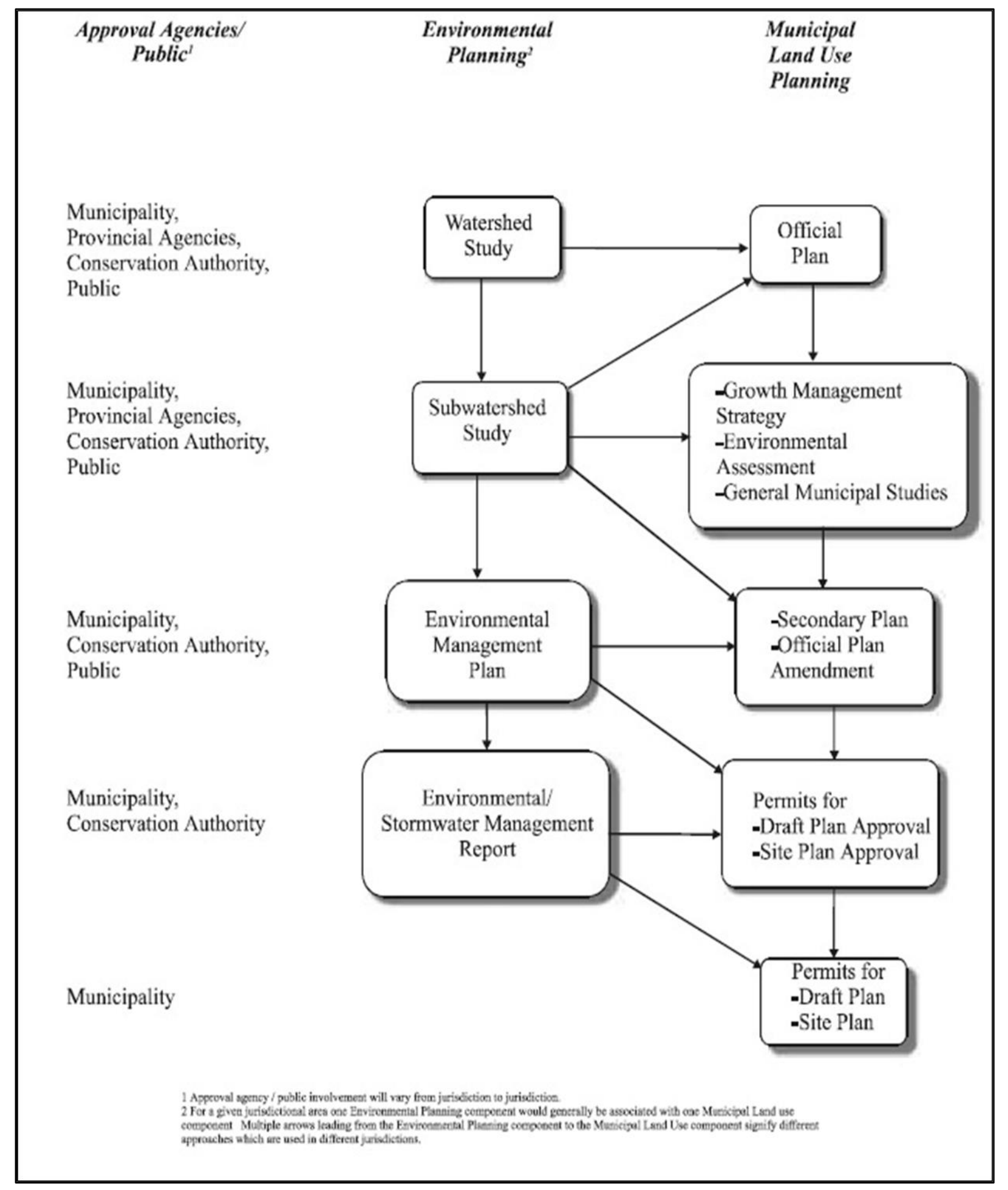

(Source: Ontario Ministry of the Environment. 2003)

Figure 4: Process of Generating Stormwater Management Plans 
The watershed plan provides the base of formulating the official plans like water and wastewater and stormwater master plans. The watershed plan also guides the development of the subwatershed plan. Based on the sub-watershed plan, the type of land development, acceptable SWMF categories and the performance level of the SWMF are decided in Stormwater Management (SWM) plans. This SWM planning is integrated into the Environmental Management Plan (EMP) of a site. This EMP is typically done before the approval considerations of a development projects draft plan. Based on the submitted EMP, the approval authorities take their decision whether to approve the proposed development project or not. The EMP contains the detail design of SWMFs and the expected effects of the land development developed area (Ontario Ministry of the Environment. 2003). The land developers must follow the plans and policies of the government and apply for the land development project, to the decision-making authority. The approval authorities review the application to check the consistency with the existing plans and policies before approving the project (Ontario 2018).

\subsection{Stormwater Management Facilities (SWMF)}

In Ontario, the stormwater management ponds are also known as Stormwater management Facilities (SWMF). Though the concept of SWMF developed decades ago, it has changed its objective over time. Initially, the purpose of the SWMF was flood mitigation and attenuation of peak (Ahiablame et al. 2012). This first-generation SWMFs were mainly detention ponds; these ponds store the excess storm runoff and slowly releases to the mainstream. Several terms are used to refer to this approach, such as conventional development (CD), traditional approach, regional approach, centralized approach, end-of-the-pipe practice (Ahiablame et al. 2012). These Management facilities were designed to reduce the peak only, but it was not designed to reduce 
the volume or improve the water quality and neither to routed the water to the centralized municipal facility or nearest stream (Ahiablame et al. 2012; Jefferson et al. 2017). Later, SWM ponds were designed to control water quality as well as quantity at the same time. Although the majority of new development in the 80s and 90s included SWM ponds for quality and quantity control, monitoring in the Greater Toronto Area had shown continual degradation of stream health over that period (TRCA 2009).

However, nowadays, the design consideration of the SWMFs has shifted towards the water balance and stream health. The primary purpose of the SWMF is to maintain the streams of a watershed to its predevelopment condition (Damodaram et al. 2010; Krebs 2017; Leimgruber et al. 2018; Li et al. 2017). Since the early 1990 s, the treatment train approach has been suggested, which combines

lot level, conveyance, and end of pipe SWMFs as a line of the last defence. This approach is targeted to control the stormwater at its source (Jefferson et al. 2017).

\subsection{Low Impact Development (LID)}

The lot level stormwater management features are also known as Low Impact Development (LID) or Best Management Practices (BMP). The difference of LID and BMP is only on the size; LID is designed for a small area, and BMP can manage stormwater from a large area compared to LID. LIDs and SWMFs both can be referred as BMP. Over the last decade the activities related to LID or BMP as Stormwater Management (SWM) approach, have intensified through pilot projects, guidance manuals, modelling tools and updates to guidelines. LID or BMP are land development strategy for managing stormwater at its source with decentralized micro-scale control measures (Ahiablame et al. 2012). LID reduces the need of centralized approach and promotes processes 
such as infiltration, filtration, onsite storage and detention, evapotranspiration, absorption, adsorption, precipitation, biodegradation, phytoremediation, and percolation (Ahiablame et al. 2012). Some examples of LID or BMPs are green-roof, Bioswale, Infiltration trench, permeable pavements, dry and wet ponds. Consequently, applications for new land developments are increasingly using a wide range of BMPs in SWM plans, including widespread implementation of LIDs.

\subsection{Performance Evaluation of LIDs}

As the practice of LIDs started a long time ago, many studies have evaluated the performance of LIDs, and these studies have shown the benefits of implementing this LID practice. Hager et al. 2018, have reviewed 250 research studies on performance evaluation of commonly used nine types of BMPs. The authors have classified the BMPs, on the functions, as infiltration-based and retention-based. Many other microscale studies have shown an excellent performance of LIDs (Ahiablame et al. 2012; DeBusk and Wynn 2011; Dreelin et al. 2006; Hoghooghi et al. 2018; Hunt et al. 2008; Li et al. 2017; Palla et al. 2008; Salvadore et al. 2015; Di Vittorio and Ahiablame 2015; Xiao et al. 2006), some studies have mentioned that rather than individual LID the combination of LIDs perform better (Joksimovic and Alam 2014; Palla et al. 2008). However, a generalization of the results of LID from those studies is difficult because of the variability of the performance of the various LIDs (Ahiablame et al. 2012). 


\subsection{Treatment Train approach (TTA)}

The Treatment Train Approach (TTA) was introduced in the "Stormwater Management Planning and Design Manual" published by The Ontario Ministry of the Environment in 2003. Figure 5, shows a typical example of a TTA. This approach refers to a systematic stormwater management strategy, which is a combination of appropriate LIDs, conveyance system, and end of the pipe system. The use of this approach is advocated to mitigate the urbanization effects on natural hydrology. The LIDs reduce the stormwater runoff at the lot level. Conveyance system carries the remaining runoff, and then the end of the pipe system receives the discharge from the conveyance and transfer it to the receiving waters with a delay and reduced discharged rate.

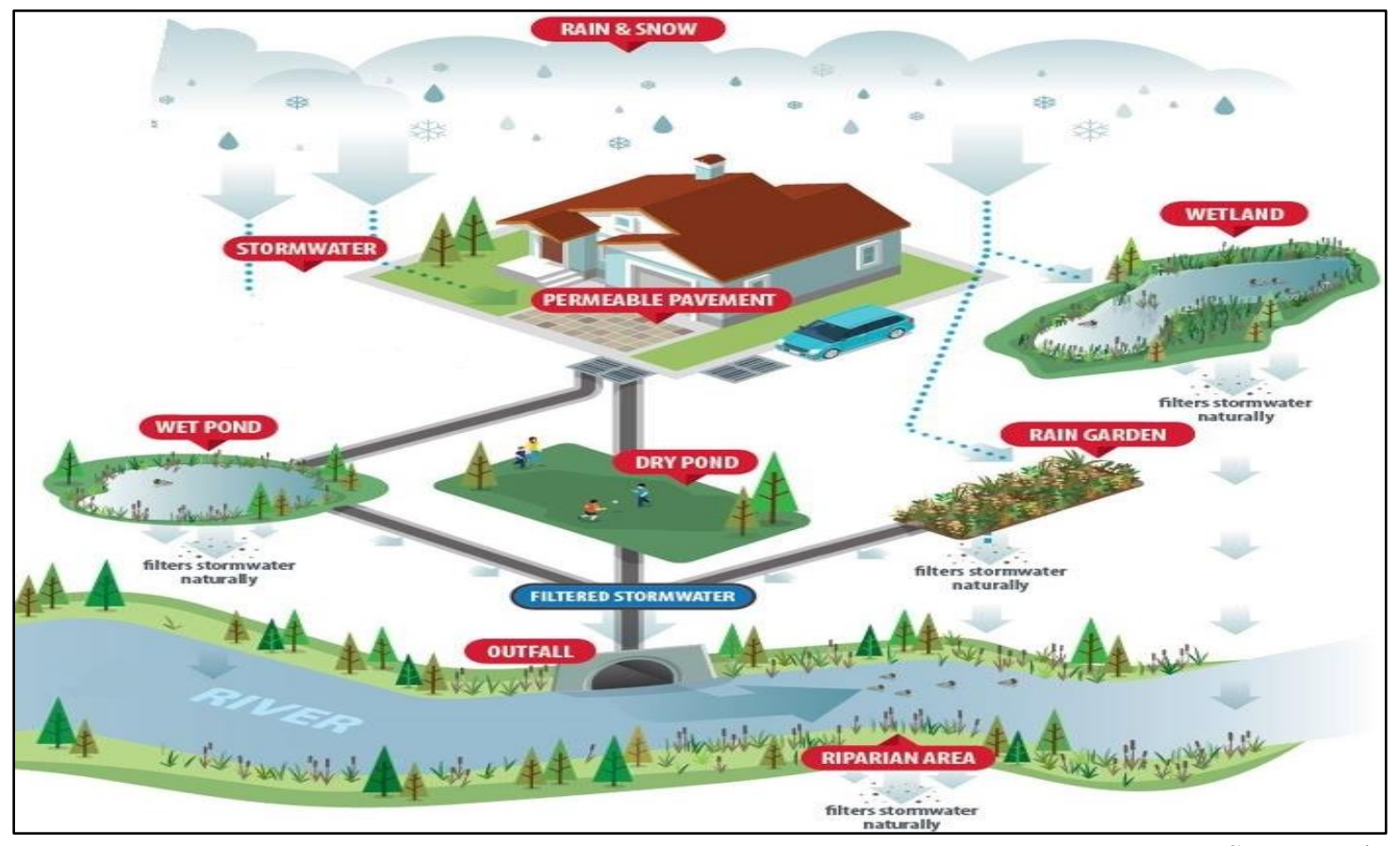

Source: calgary.ca

Figure 5: Typical Example of Treatment Train Approach

Currently, the land developers submit the details design of BMPs with the Environmental Management Plan (EMP) of a land development project for assessment by the project approving 
authority. Recently, Lake Simcoe Region Conservation Authority (LSRCA), Credit Valley Conservation (CVC) and Toronto and Region Conservation Authority (TRCA) have jointly developed a tool named "Treatment Train Tool" (TTT). The primary purpose of this tool is to simulate and evaluate the performance of the BMPs according to the designs submitted with EMP of a proposed land use development. This tool provides a water budget of pre and postdevelopment scenarios. Usually, the BMPs are designed to mitigate the urbanization effects for only the considered sites. Performance evaluation of these designed BMPs on the watershed is not possible from these site scale simulations.

\subsection{Importance of Catchment-Scale BMPs evaluation}

Assessment of the performance of BMPs requires hydrological and hydraulic modelling. However, spatially distributed hydrological modelling of an urban area, which has a high degree of heterogeneity is complicated (Salvadore et al. 2015). The scale of interest of this kind of model can vary from the individual site to as large as the whole watershed. Most of the pre-development BMP models are showing the effect for the individual sites (Ahiablame et al. 2012), but the impact on the whole watershed is not represented by those models (Jefferson et al. 2017). The change of baseflow, peak flow, watersheds respond to rainfall or lag time of a stream cannot be observed in site scale or subcatchment-scale studies. So, it is essential to evaluate the effect of the BMPs in catchment-scale to ensure the health of the stream ( $\mathrm{Li}$ et al. 2017). 


\subsection{Evaluation of BMPs in the urban catchment}

Salvadore et al. (2015) have reviewed the existing hydrological modelling studies of urban watersheds and tried to find out the gaps and outlined the future advances of this kind of modelling. According to the authors, so far, there is no universal methodology for simulating catchment-scale urban water system. The urban catchments have a highly heterogeneous land cover and a hydrological process. Whereas the natural catchments generally have homogeneous land cover, with a natural hydrologic process. The understanding of the interaction between natural and urban catchment is not very developed yet. This incomplete understanding of the interaction between the urban and natural hydrological process presents a high degree of uncertainty in modelling. Salvadore et al. (2015) have selected 43 urban hydrological modelling studies among them $36 \%$ was using the spatially distributed approach with a spatial resolution of $3 \mathrm{~m}$ to $10 \mathrm{~m}$, and $90 \%$ of these studies used temporal resolution less than one day. The most used time step is one hour, which may not accurately characterize the components of urban fluxes. They suggested that for the fast dynamics of the urban hydrological process and high heterogeneity, models with a higher spatial-temporal resolution is required. They have seen that through all the modelling studies considered the overland flow routing, only $28 \%$ incorporates river routing, and only one-fourth of them used hydrodynamic concept. Moreover, the storm drainage system is not considered in most of the modelling. The authors have also identified that data limitation is still a problem, and in many cases, due to unavailability of data, proper calibrations and validations are unfeasible.

Pennino et al. (2016) have studied the cumulative impact on a watershed over space and time, by assessing the long-term hydrologic changes and water quality metrics, with and without the Stormwater Green Infrastructure (SGI). This analysis shows that basin with more than 10\% BMPs 
shows $26-44 \%$ reduction in hydrological flashiness metrics, compared to the watersheds without any BMPs. It also shows that a high percentage of BMP resulted in lower peak and less frequent peak runoff with longer hydrograph duration, lower coefficient of variation for runoff and higher volume-to-peak ratio.

Li et al. (2017) investigated and provided an analysis of modelling and monitoring results for several catchment and subcatchments. The objective of the study was to observe the difference in FV and PFR with and without BMPs. This study typically summarized that as expected, implementation of BMPs reduced surface runoff volume and peak discharge, increased hydrograph lag times and base flow magnitude, and decreased storm recession rate. The site-scale monitoring study presents an excellent performance of BMP. However, in the catchment-scale study, the result of the model's prediction and monitoring report had a considerable difference. This difference is because of the uncertainty of the surface and subsurface flow paths, monitoring measurement limitations, and in some cases may be the measurement errors were more than the effects of BMP implementation. One other problem is that, in the modelling studies, usually the analysis was done considering the highest expected efficiency over the whole study period, but due to the practical limitations such as siltation and clogging, the highest efficiency cannot be continuously achieved (Fletcher et al. 2007; Petrucci et al. 2013). One other limitation of modelling studies is that in modelling usually the flow routing simulation is done in a very simplified approach, but there is much uncertainty involved in these processes. On the other hand, monitoring studies are also challenging, because most of the BMP covers a small portion of the developed area and the effects of BMPs, on catchment-scale streamflow regimes, may be small relative to measurement errors and the consequences of variability in other factors such as climate change. 
Jefferson et al. (2017) have reviewed 100 watershed-scale studies evaluating SWM effectiveness using empirical and modelling approach. In these studies, the primary attention was on PFR and FV. According to their review, both the urbanization and the associated BMPs, affect the natural hydrology of the catchment, and it is complicated to identify the source of the effects to quantify the benefits of BMPs. The BMPs are designed considering small sites, and these are supposed to manage only a portion of the increased runoff, and the rest of the runoff remained unaddressed. The urbanization also changes the hydrology beyond the impervious surface, which BMP cannot manage. Because of these problems, the cumulative effect of these BMP is not a simple additive. The cumulative impact of the multiple BMPs on a watershed is very critical to quantify because the process of translating the results from small scale to the watershed scale is very uncertain. So, the authors suggested that the restoration of the watershed functions to its predevelopment condition may not be possible, even with multiple BMPs. According to the authors, the watershed systems behave like hysteresis and the BMPs may reduce the effect of urbanization on the system but it shifts the system to a new trajectory which may not return to its initial pre-development state.

The watershed characteristics of an urbanizing watershed are more uncertain than an urbanized one. Urbanizing watershed has all kind of land uses. It can have a natural forest, agricultural land, urban residential or industrial area, among others. So due to this high level of topographical heterogeneity, the evaluation of BMPs through simulation is much more complicated than a fully urbanized catchment. Hoghooghi et al. (2018) have analyzed the effects of BMPs with mixed land cover. This analysis shows that with the highest possible implementation level, the only modest reductions were achieved, which indicated a potential limitation of BMPs efficiency in a mixed land cover watershed. 


\subsection{Research Gaps}

The literature review shows that all the performance evaluation studies of BMPs were done after the urbanization, to observe the impact that has already been done. All the site scale modelling studies have shown a positive effect of the BMPs. However, the catchment scale studies have shown that the implementation of the BMPs is not able to maintain the predevelopment flow rate and volume, though this is the main objective of BMPs. Currently, all the developments work must submit the design of the BMPs with targeted reduction efficiency to the approving authorities, but these predevelopment simulations are always done considering only the small lots and detailed parameters. Because the detailed distributed models are required to show the benefits of BMPs (Khin 2015). As the effects of these BMPs are not easily transferable from this small-scale simulation to the watershed scale simulations, the impact on the watershed remains unknown during the approval of the development projects.

Hellmers and Fröhle (2017) pointed out that the reason behind the deficits in current catchmentscale hydrological modelling practice, to simulate the effectiveness of small-scale predevelopment models, is that the current catchments scale models are developed for large drainage area and based on lumped parameters. These models do not allow for incorporating detailed development setup and precise placement of local BMPs. The physical phenomena are represented very weakly in these models. These models show a lack of Geographical Information System (GIS) friendly and a user-friendly interface. These deficits illustrate the need for improved understanding of how fined scale BMPs can be addressed on the catchment scale in numerical models. Guan et al. (2015) suggested that the complexity of a catchment scale model, the uncertainty of future conditions, and the lack of a good quality dataset might limit the understanding about past, current, 
and future hydrological behaviours of the developing urban catchments. So, it is crucial to develop a methodology to combine the small lot scale simulations with the watershed scale simulations to have a better understanding of the effects of the designed BMPs before approval and systematically guide the future developments.

In this study, an attempt will be made to understand the interactions by modelling Natural, Urban and BMP hydrology together and develop a Multi-scale modelling methodology to integrate smallscale pre-development models with the large-scale watershed model easily. This Multi-scale modelling approach will be able to simulate the effects of proposed land development and associate BMPs on the streams of the downstream part of the watershed. The results of the study are providing guidance to the approval authorities for future land development sustainably.

\subsection{Modelling considerations}

In this study, to understand the cumulative effect of the BMPs and urbanizations on the stream, simulations will be done using a Multi-scale modelling approach. Selection of an appropriate model is essential for this kind of complex study. The problem of the scale difference discussed earlier will be addressed in the newly developed modelling methodology by incorporating different scales in one model. The newly developed model will be a semi-distributed model, as it can address different levels of spatial variability with different model resolution (Hellmers and Fröhle 2017). In the semi-distributed model, a catchment is divided into small subcatchments based on the geographical characteristics and drainage network. So the variability of the topography and the

drainage network will better represent the actual catchment, but within one subcatchment, the spatial distribution will be represented by lumped parameters (Petrucci and Bonhomme 2014). 
This study will need an integrated hydrologic and hydraulic simulation because it will have dendritic natural channels as well as the minor system of developed areas. This simulation will need several hydraulic structures and BMPs to represent the urbanized hydrology accurately. There can be backwater flow in the channels and pipes so the model will have the dynamic flow routing option. The model will also have appropriate options to simulate the infiltration processes. This modelling study will have a high temporal and spatial resolution too, to accurately simulate the overall hydrological process. All these criteria can be fulfilled by US EPA Storm Water Management Model (SWMM) (Kaykhosravi et al. 2018; Rossman 2017; Rossman and Huber 2016), it will be used in this study. The other reason to choose the EPA SWMM model is that it can be linked with the "Treatment Train Tool" easily.

\subsubsection{Spatial Discretization of the Models}

Spatial discretization refers to separating the watershed into some homogeneous computational units or subcatchments. Appropriate spatial discretization is essential for hydrological modelling, especially for the urbanized land use (Salvadore et al. 2015), because the hydrological properties across the watershed will vary, due to its spatial heterogeneity (Anselin 2010). Discretization is done to accurately represent the characteristics of spatial heterogeneity of the basin (Liu et al. 2016). Spatial discretization should be detailed enough to capture the dominant processes and natural variability of the watershed. On the other hand, it should also be concise enough to save computation time and respect data availability (Booij 2003; Liu et al. 2016). It has been shown

previously that CSM results in rapid catchment response to rainfall and exaggeration in peak flow (Krebs et al. 2014). Previous hydrological models have also shown that spatial resolution can affect 
the simulated peak flow result, though the runoff volume is less sensitive to the spatial resolution (Elliott et al. 2009; Ghosh and Hellweger 2011; Krebs et al. 2014)

Liu et al. (2016) have done a study to develop an approach to identify the appropriate spatial resolution of a modelling study by quantifying the relative information loss. The authors emphasized that maintaining a balance between data aggregation, information loss and computational complexity is the main difficulty in choosing the appropriate spatial resolution or discretization process. Because the CSM lumps the data and creates a smaller number of subcatchments, it may cause significant information loss. On the other hand, an FSM will represent the drainage area with many subcatchment needing all the necessary data in fine resolution to represent the real world with much computational complexity. Results of this study show that with coarser discretization, the loss of information increases.

According to Liu and Gupta (2007) and Ludwig et al. (2009), the impact of information loss due to low spatial resolution is worse compared to the information loss because of data uncertainty. The study of Liu (2016), has also shown that a models performance for a uniform discretization over the whole catchment is worse than a non-uniform discretization approach which can preserve spatial heterogeneity with the same computational complexity.

Ichiba et al. (2018), performed a study to observe the effect of spatial resolution on the model result of urban hydrology. In this study, they observed the impact of scale to describe the catchments heterogeneity by analyzing the structure of the sewer network and distribution of impervious area. They have done a modelling to observe the scaling effect on hydrological model performance at 17 spatial resolutions ranging from $100 \mathrm{~m}$ to $5 \mathrm{~m}$ on a 2.45 sq.km study area. They 
have observed that up to a certain level, the model performance increases with increases in spatial resolution, after which the difference is insignificant. However, small scale models require more computation time. The authors recommended that medium spatial resolution gives better performance and fast computation time. In their study, they choose the $15-30 \mathrm{~m}$ resolution as the best resolution for their study area. The authors also pointed out that an appropriate spatial resolution can simplify the calibration process, but the model scale depends on data availability.

For modelling of a large area with an appropriate scale, finer data and a wide range of field measurement data are required (Krebs et al. 2014). However, usually due to lack of required data, modelling of a large ungagged natural or urban watershed is complicated. Krebs et al. (2014) have compared the simulation results of FSM and CSM of the same study area. They developed the CSM by truncation of the smaller sewer pipes. The difference between the FSM and CSM in their study was that the CSM had coarser drainage network. They observed that the CSM shows rapid catchment response to rainfall and exaggeration in peak flow because in the CSM the effective impervious area was increased considerably due to lack of drainage network and it routed all the flow directly to the outfall neglecting the sewer networks.

All the studies mentioned above have shown that spatial discretization can affect the simulation result significantly. Therefore, the appropriate spatial resolution will be analyzed carefully in this research study. Instead of following the method used by Krebs et al. (2014), of aggregating the drainage area according to drainage pipe size, in this research the catchment delineation tool available in PCSWMM will be used to discretize the subcatchments (Rossman and Huber 2016). 


\subsubsection{Topographical parameters}

Another critical criterion to develop a model is choosing the appropriate topographical parameter to replicate the actual land cover. Nowadays, useful topographic data are readily available, but very few modelling approaches correctly use these data (Salvadore et al. 2015). Many necessary parameters can be extracted from the geographical data, but the inclusion of these data increases model complexity, and this can lead to overparameterization problems (Krebs et al. 2016; Kuczera and Mroczkowski 1998). A semi-distributed model has many parameters which may change for each subcatchment. Therefore, calibrating this wide range of parameters based on very little available information often leads to the low predictive capability of a calibrated model; this phenomenon is termed as overparameterization (Jakeman and Hornberger 1993; Petrucci and Bonhomme 2014).

Petrucci and Bonhomme (2014) tried to investigate the effect of using geographical data with highfrequency long time-series hydrological data in catchment-scale hydrological modelling. The authors did this analysis on $2.5 \mathrm{~km}^{2}$ study area with high temporal resolution (5 min time steps). They developed six different configurations of the model with the increasing use of geographical information of the same area. The results of this study show that using primary geographical data such as land cover can improve the model's performance. Even an uncalibrated model with proper land use data can perform like a calibrated model. So appropriate use of geographical data can increase the model's performance if calibration is not possible. However, after a marginal limit, the benefit of geographical data decreases. The authors pointed out that overparameterization will produce a similar result for all the calibration scenarios, but it will cause a high variability in the validation simulations. However, their study did not show high variability in the validation 
simulations for the water quantity analysis, like many other semi-distributed modelling studies. The authors suggested that the assumption of overparameterization of hydrological models for more than a few parameters should be reconsidered because the use of high-frequency long time series and the combined use of hydrological and geographical data can reduce the risk.

Digital Elevation Model (DEM) is a good source of topographical data, although DEM may not correctly represent the small-scale features and the minor drainage infrastructures of the urban landscape. Therefore, describing the actual flow pattern in the fine-scale for the urban area is difficult. So, the analyzed geographical data should be tested against hydrological data (Kuczera and Mroczkowski 1998; Petrucci and Bonhomme 2014). The network data may not contain some small conduits; these missing small conduits may result in disconnected network sections (Krebs et al. 2014). For ungagged catchment, the parameters from a similar calibrated subcatchment model can be used (Kokkonen et al. 2003; Krebs et al. 2016). This process of using parameter form similar catchment model is called model regionalization. Krebs et al. (2016) have evaluated the regionalization approach using three subcatchments with three different imperviousness. They calibrated the model of the three catchments separately and got similar parameters after calibration, and then they interchanged the parameter sets among the models to replicate the monitored runoff data and got good results. This study shows that for an urban area, hydrological model regionalization is more manageable, and with high temporal resolution and accurate rainfall data, urban runoff response can easily be described in regionalization.

In this research, the DEM and land use data will be used to obtain the essential geological data for the model setup. As the observed hydrological data will also be used in this study, it is expected 
that the problem of overparameterization will not occur as mentioned by Petrucci and Bonhomme 2014. To minimize the problem of not capturing small features by DEM, a relatively highresolution DEM will be used in this research and the design drawing of the urbanized area will be used to set up the urbanized area in the model. The natural catchment area in the model can be set up by using the regionalization technique but finding a similar gagged catchment for regionalization is tough because the data for fine-scale is scarce. In that case, coarse-scale can be a good option for accurate modelling of the ungagged natural catchment. In the Multi-scale approach, the natural area will be of coarse-scale, and the urban area will be of fine-scale.

\subsubsection{Sensitivity analysis}

The sensitivity of the model result, to the model's parameters, is also a vital issue for modelling and planning process of LIDs (Leimgruber et al. 2018). Krebs et al. 2013, tried to simulate an urbanized catchment of 5.87 ha with $86 \%$ imperviousness and attempted to mitigate the effect of urbanization with LID (green roof) approach. As the study area was mostly impervious the author's developed model was not sensitive to the impervious percentage, but it was sensitive to the depression storage depth, and the Manning's roughness coefficient for the conveyance flow.

A later study by Krebs et al. (2014), which involved three subcatchments with $86 \%, 54 \%$ and $19 \%$ imperviousness, performed sensitivity analysis considering the Nash-Sutcliffe Efficiency (E) (Nash and Sutcliffe 1970), the percentage of Peak Flow Error (PFE) and the Volume Error (VE). They observed that subcatchment slope have a significant influence on the model performance if the watershed is flat in nature; otherwise, its effect is minimal. Flow width of the subcatchment mainly affects the PFE of the simulations. According to their analysis for large resolution model, 
the width of subcatchment can be calculated as $(0.7 * \sqrt{\text { drainage }}$ area $)$. Percentage of imperviousness and depression storage also have a significant influence on the model's output. The model of an urban sub-catchment is more affected by the Manning's $\mathrm{n}$ for the conduit flow $\left(\mathrm{n}_{\mathrm{c}}\right)$, while the natural subcatchment model is more affected more by the Manning's $\mathrm{n}$ for the overland flow $\left(\mathrm{n}_{\mathrm{o}}\right)$. The authors also showed that the model performance degrades if the distance of rainfall gauge and flow measurement station is greater than $2 \mathrm{~km}$ because of the spatial variation of rainfall.

Leimgruber et al. (2018) investigated the sensitivity of runoff volume to the LID parameters for both single events and long-term rainfall data. The authors observed that the storm event characteristics, precipitation depth and antecedent dry period can affect the performance of LIDs in terms of runoff volume. More extended antecedent dry period results in less sensitivity to the LIDs performance because the LIDs may have time to regain its full runoff retention capacity. The authors, therefore, suggested that a minimum inter-event time should be considered in modelling and planning of LIDs. Though this study gives an idea of the sensitivity of runoff volume, it does not include the peak flow and the time to peak flow, which are also significant factors in evaluating LIDs performance.

Salvadore et al. (2015) also analyzed the sensitivity of the model parameters. They observed that for depression storage is a critical parameter for low-intensity rainfall events. However, for heavy storms, the depression storage does not have any effect on the stormwater runoff volume and peak. The authors also suggested that for capturing the fast-dynamic hydrological processes of urban areas, the model should use a high temporal resolution. 
The sensitivity analysis of Guan et al. (2015) showed that Manning's n can affect the magnitude and occurrence time of peak flow at the outlet. Depression storage can affect the storm runoff for small storms and for large storms it affects only at the starting period of the storm after that it can not change the runoff. As the amount of surface runoff depends on the imperviousness, it has the highest sensitivity on the simulation result. Flow width and slope of this study area also affect the model result. This study also pointed out that model rarely overestimates peak flow in calibration analysis, but it underestimates peak flow in the validation process.

Rossman and Huber (2016) have mentioned the sensitivity of runoff volume and peak flow to the surface runoff parameters. According to the authors, the total area of subcatchment and imperviousness have a significant effect on both runoff volume and peak. Increase of area and imperviousness increases volume and peak runoff. While the width, slope and roughness affect the shape of the resulted runoff hydrograph. Increase of width and slope increases the peak of the hydrograph but decreases the runoff volume. However, the increase in roughness has the opposite effect on the hydrograph. It increases the runoff volume but decreases the peak flow. Depression storage has a significant effect on the simulation result only for low-depth storms.

As the above literature review showed that parameter sensitivity has a significant effect on the simulation result, sensitivity analysis will be done in this research carefully. In the sensitivity analysis, spatial attention will be given to the subcatchments width, slope, area, roughness, depression storage, drying time, channels roughness and flow area. The literature review also shows that the intensity of rainfall and inter-event time are critical input data for the models because the result of low and high-intensity rainfall will have very different results. 


\subsubsection{Infiltration method}

One of the principal purposes of implementing BMPs is to increase the infiltration in the urban area to minimize the adverse effects of urbanization on the natural watersheds. Therefore, infiltration should be calculated accurately in the simulations of BMPs performance, and the method used for calculating infiltration is an important feature (Kaykhosravi et al. 2018).

Infiltration can be calculated using several methods such as Green-Ampt, Horton's method, Modified Horton's method, Curve Number method, etc. Horton method is based on empirical equations and considered as the best-known infiltration equations, although applied only for that event where the rainfall intensity exceeds the infiltration capacity. The Modified Horton's Method was developed to overcome this problem. This modified method can provide comparatively a more accurate result for low rainfall intensities. In recent years, Green-Ampt Equation is getting popularity because of its applicability in both steady and unsteady rainfall situations. The only and most crucial problem with this method is, it requires some soil parameters which are not readily available and estimation of which increases model uncertainty.

The Curve Number $(\mathrm{CN})$ method is based on the Soil Conservation Service (SCS) curve numbers. It is used very frequently because of its familiarity among the most practicing engineers and tabulated CNs are available for a wide range of soil groups, and land uses (Rossman and Huber 2016). The CN method was first developed in 1954 (Rossman and Huber 2016), at which time the concept of LID was not introduced, so the available CNs may not represent the actual scenario of a LID (Ahiablame et al. 2012). Some research studies have tested and modified the CNs for different LIDs. For example, Damodaram et al. 2010, have identified that green roofs have a CN 
ranging from 84 and 90 instead of 98 , which is the $\mathrm{CN}$ of a regular impermeable roof. Sample et al. 2001, have provided a table of CNs for different land covers of a developed area based on measured initial rainfall abstraction.

In this research, $\mathrm{CN}$ method will be used because this method needs fewer data compared to the other mentioned methods, and that implies less uncertainty related to data unavailability. Moreover, the Treatment Train Tool also uses CN Method. 


\section{Methodology}

The objective of this research is to minimize the problem to the scale differences in current practice by developing a MSM methodology, and to demonstrate the performance of the developed model in a developing area. The development of the MSM methodology involved several steps, as presented in Figure 6.

C Collect necessary data such as streamflow, rainfall, land use etc.
Collection and
processing

Figure 6: Flow Chart Presenting the Methodology of This Study 
The first step is to collect the necessary watershed data for the analysis, such as streamflow data, rainfall data, channel network information, land use, etc. The collected data should be analyzed and processed as required for use in setting up the models of the watershed.

In the second step, a CSM should be developed and calibrated, representing the pre-development conditions, typical of the modelling efforts done at watershed and sub-watershed planning studies. The purpose of this CSM is to represent the watershed model, based on which the planning of required stormwater management to achieve regulatory requirement are developed. This CSM will be used to simulate the flows under the pre-development condition of the watershed, and all the development scenarios will be compared with the result of this model to evaluate the impacts of the developments and associated BMPs on the downstream channels of the developed area.

For the present state of watershed development, a CSM should be developed and calibrated to represent the post-development conditions in the third step. The purpose of this CSM of the postdevelopment scenario is to represent the current practice of comparing the stream response under post-development alternatives with a pre-development scenario on a watershed scale. This postdevelopment watershed should have the SWM ponds and the lumped parameters to represent development on a coarse-scale and will include any LID features in a lumped way.

The fourth step involves the development of an FSM to represent the developed area only. This FSM should have all the storm sewers, as well as LIDs and SWM ponds to represent all the SWM features as it is designed in the developed area. The subcatchments of the FSM should be created considering the drainage outlet of the lots, which will make the subcatchments size about 40 to 50 times smaller than the smallest subcatchment of the CSM. These smaller subcatchments will also 
have finer parameters to represent the drainage characteristics and the runoff conditions more accurately compared to the CSMs. Moreover, this FSM should have all the LIDs with details that are not captured or represented in the CSM due to relatively small size of the LIDs. The FSM can be calibrated if only the pond level observed data is available.

In the fifth step, the FSM should be integrated into the CSM to develop the MSM approach. In the MSM, the developed area should have all the parameters of finer resolution, and the rest of the area of the watershed will have the coarse-scaled parameters. This MSM can transfer the result of the BMPs of the developed area to the downstream part of the watershed to compare the postdevelopment scenario with the pre-development scenario with more confidence by using the observed data of a well-established stream gauging station.

Finally, a MSM should be utilized to represent all planned urban developments in the watershed. The model output of the MSMs representing different stages of development should also be examined by comparing the model output of a CSM approach. All the modelling works in this study were done using the USEPA SWMM (Rossman 2017). The detailed methodology of the model development and data used for the setup are discussed in the rest of this chapter.

\subsection{Data collection and processing}

For the model setup, topographical information is required. The Digital Elevation Model (DEM), land use and the hydrological soil type data should be collected, to provide the necessary topographical information of the watershed in the model setup. The cross-section of the channels in the watershed should also be collected to setup the channel networks. Meteorological data such 
as rainfall, evaporation, and wind speed should also be collected for the model setup. Any previously developed models of the watershed or any part of the watershed can be collected to gain further understanding of the characteristics of the watershed. The calibration and validation of the model will require the streamflow data and rainfall data. Some events should be selected for the required calibration and validation of the developed model by analyzing the collected rainfall data and the streamflow data.

\subsection{Coarse-scale Pre-development model set up}

The coarse-scale pre-development model can be developed using the Digital Elevation Model (DEM), land use and the hydrological soil type data for topographic information. The details of the pre-development model setup are given below.

\subsubsection{Channel network setup}

The conduits and junctions should be added manually according to the DEM, or in case of the previously available model of the same area, the shapefile of the junction and conduits can be imported directly in the SWMM model. In case of manually adding these model elements, the collected cross-section of the channels should be provided into the model or in the case of unavailability of cross-section data, tools such as the "Transect creator" of PCSWMM software can be used to collect cross-section data from the DEM. Appropriate Manning's $\mathrm{n}$ should be assigned for the channels according to the literature recommendations for different channel types. All the conduit and junction depths and invert elevations should be checked according to the DEM for consistency, as a quality control step. In this way, the channel network of the model can be 
prepared accurately. It is the most crucial step of developing the model because the watershed delineation depends largely on this channel network.

\subsubsection{Watershed Discretization}

After setting up the channel network, the subcatchments should be created using the Watershed Delineation Tool (WDT) of the PCSWMM. In this process, the DEM of the modelled area, the channels network of that area and the outfall point of the watershed should be specified to discretize the subcatchments because the subcatchments will be created based on the channels, outfall, and the topography. The WDT will calculate the flow directions, slope, contributing area to the stream, stream threshold, flow paths, and creates sub-watersheds automatically. The number of subcatchments will depend on the provided target of discretization level. That means if the aim is to generate subcatchments with less area, then the number of subcatchment will be higher. With

the change of the number of subcatchment, the widths and flow lengths will also experience a change which affects the model results (Liu and Gupta 2007; Ludwig et al. 2009; Elliott et al. 2009; Ghosh and Hellweger 2011; Krebs et al. 2014; Liu et al. 2016 and Ichiba et al. 2018). Watershed discretization should be done carefully with several trials to capture the actual scenario with less uncertainty due to data unavailability and to minimize the possibility of data loss. The WDT automatically calculates and assigns the area, slope, width, flow length and outlet attribute for each subcatchment by extracting data from the DEM.

\subsubsection{Sub-catchment Parameters}

The necessary parameters, such as imperviousness, roughness coefficient, depression storage, $\mathrm{CN}$, should be provided in this step. These parameters specify the characteristics of the sub-catchment. 
Literature reviews have shown that in surface runoff simulations Imperviousness, depression storage, Manning's $\mathrm{N}$ are critical parameters for both permeable and impermeable areas, especially for the natural watershed (Section 2.9.3). SWMM manuals have a guide for choosing appropriate values for these mentioned parameters. The data of the percentage of the impervious area can be obtained from the land use data. The area weighting tool can be used to calculate the total percentage of impervious area in each subcatchment appropriately. Appropriate $\mathrm{CN}$ should also be assigned for each of the subcatchments according to the collected hydrological soil type and the land use of the area.

The rainfall data should be specified in the model, by assigning one rain gauge to each subcatchment. If multiple rain gauges are available for the area, Thiessen polygon can be created using the available rain gauge locations, to select an appropriate rain gauge for each subcatchment.

\subsubsection{General Model Settings}

This methodology is developed, considering the $\mathrm{CN}$ method for infiltration, firstly, because the $\mathrm{CN}$ method requires fewer parameters so reduces uncertainty. Secondly, $\mathrm{CN}$ for a wide range of soil type and land use are readily available in tabulated form and lastly and more importantly, TTT uses $\mathrm{CN}$ approach to estimate infiltration amount.

In this methodology, the simulations can be done only for rainfall generated runoffs and flow routing. Dynamic wave approach should be chosen as the routing method in this research because the dynamic wave approach can address channel storage, backwater effects, the losses in the

entrance and exit of the conveyance. This approach can also consider the reversal flow and 
pressurized flow. In general, the channel network will have some hydraulic structure (e.g. culverts at road crossings), and backwater effects are expected to occur. The dynamic wave method requires a small time step to calculate the routing accurately and to minimize numerical stability (Rossman 2017). Therefore, an appropriate time step should be chosen for the routing calculation.

\subsubsection{Sensitivity test of the model}

The developed model should be tested for the sensitivity of model outputs to the provided input parameters. For this process, the built-in Sensitivity-based Radio Tuning Calibration (SRTC) tool of the PCSWMM software can be used. As discussed in Chapter 2, the previous studies have shown that rainfall-runoff models are sensitive to the impervious percentage, depression storage, Manning's n, subcatchments slope, width, and flow length (Section 2.9.3)

\subsubsection{Calibration and validation of the Predevelopment model}

The pre-development model should be calibrated and validated using several selected rainfall events. Analyzing the collected rainfall data and the observed streamflow data, the events which show a consistency in the rainfall and the streamflow was should be selected. Few of the selected events should be used for calibration, and validation can be done using the rest of the events. The calibration of the model should be done using different parameters based on the sensitivity of the model result on a trial and error basis. The percentage change of the individual parameters, of the parameter sets, to represent the best match with the observed streamflow should be chosen and used to change the previously assigned parameter set. Thus, the obtained calibration model should be tested with the validations event to verify the performance of the model by comparing with the observed streamflow and finalized as validated pre-development model. 


\subsection{Coarse-scale Post-development model set up}

The pre-development model should be used as the base developing the post-development model. In the predevelopment model, the $\mathrm{CN}$ should be changed only for the developed area to replicate the post-development scenario. The BMPs of the developed area should also be included in the model with lumped parameters. The post-development model should also be calibrated and validated with a separate set of calibration and validation event in the same way as described for the pre-development model's calibration and validation process. After calibration and validation, the post-development CSM should be finalized as the post-development model.

\subsection{Fine-scaled model}

A fine-scale post-development model for only the developed area should be prepared separately. For the preparation of the Fine-Scale model (FSM), the subcatchments area, shape, stormwater pipe size, slope, flow direction and the details of the LIDs can be incorporated from the design drawings of the proposed developed area manually. The invert elevation can be determined using the DEM of that area. The detailed data of the stormwater management ponds should be used from the stormwater management reports of the respective developed areas. The CNs of the subcatchments of this model should be considered according to the hydrological soil type and the percentage of imperviousness and the guidance of the Soil Conservation Service 1986. The outfall of the FSM should also be incorporated, as designed. The detailed model should have all the stormwater sewers, LID and the SWM ponds according to the design of the proposed development. In case of a proposed development, the FSM should be verified under a loading from design storm event of different return periods (as required), and in case of an existing development, the model 
should be verified with the pond monitoring data to check the consistency between the modelled pond discharge and the observed pond discharge to finalize the FSM.

\subsection{Multi Scale Model (MSM)}

After preparing the FSM, it should be incorporated into the coarse scaled pre-development model, to form the MSM. After incorporating the FSM, only the developed area should have fine-scaled parameters, but the rest of the area will be modelled using the same coarse-scaled parameters as the pre-development model. The following steps need to be performed to prepare a MSM of the entire watershed.

- The name of the sub-catchments, Conduits, Junctions, Weir, Orifice, Storage and Outfalls of the FSM should be checked and changed if required, to eliminate the risk of having the same feature name in the CSM and the FSM.

- The portion of the developed area should be split and deleted from the subcatchments of the CSM according to the shapefile of the developed area.

- The subcatchments, conduits, junctions, weirs, storages, orifices and the outfalls from the detailed developed model should be imported into the CSM of the watershed, using the "Import GIS shapefile" of the PCSWMM software, with the "Import New Entities only" option checked in.

- The proposed LID options should be incorporated manually in the combined model, as the FSM.

- The outfall of the imported FSM should be replaced with the existing junctions of the watershed model, in which the developed area is designed to discharge. 
Following the steps mentioned above, the fine-scale developed area model and the large scale watershed model can be combined. The combined Model will be an MSM of the watershed, which will be used to assess various post-development scenarios. 


\section{Case Study}

This chapter documents how the developed methodology of MSM was applied on the Ganatsekiagon Creeks sub-watershed and includes a comparison of the simulated runoff of the CSM and MSM of the sub-watershed as well as comparisons to the observed runoff in the study area.

\subsection{Study Area}

The developed methodology of MSM was tested on the Ganatsekiagon Creek sub-watershed located in the City of Pickering, Ontario, Canada. This sub-watershed is a part of the Duffin Creek Watershed, which is experiencing urban growth in recent years and slated for extensive development in the coming years. However, only $10 \%$ of the lands are currently urban, $19 \%$ are urbanizing, and $71 \%$ of the watershed still has a predominantly rural landscape (TRCA 2019). According to Aquafor Beech Ltd. 2013, the major tributaries of Duffin Creek watershed do not need storm controls, but the small branches like Ganatsekiagon (Gana) Creek needs stormwater control measures. The model prepared for the Duffin Creek watershed had 54 subcatchments among which the entire Ganatsekiagon creeks sub-watershed was one subcatchment. Figure 7, is showing the study area. This study area has several beaver dams, and frequent blow out of these beaver dams results in very irregular hydrological changes. Most of the part of this study area is being used as agricultural lands, and these lands have a tile drainage system which also makes the hydrology of this area unpredictable because of the rapid drainage of tile drainage. This subwatershed has a developed area that has been used to develop the FSM. The developed area in Ganatsekiagon Creek watershed is known as the Duffin Heights (DH) area. This developed area 
has one SWM pond as the end of the pipe feature, and there are two infiltration trenches as the LIDs in the developed area. the DH area has two types of stormwater collecting pipes; the clean water pipes and the stormwater pipes. The clean water pipes of the norther part of the DH discharge water outside of the development and the clean water pipes of the southern part discharge into the infiltration trenches.

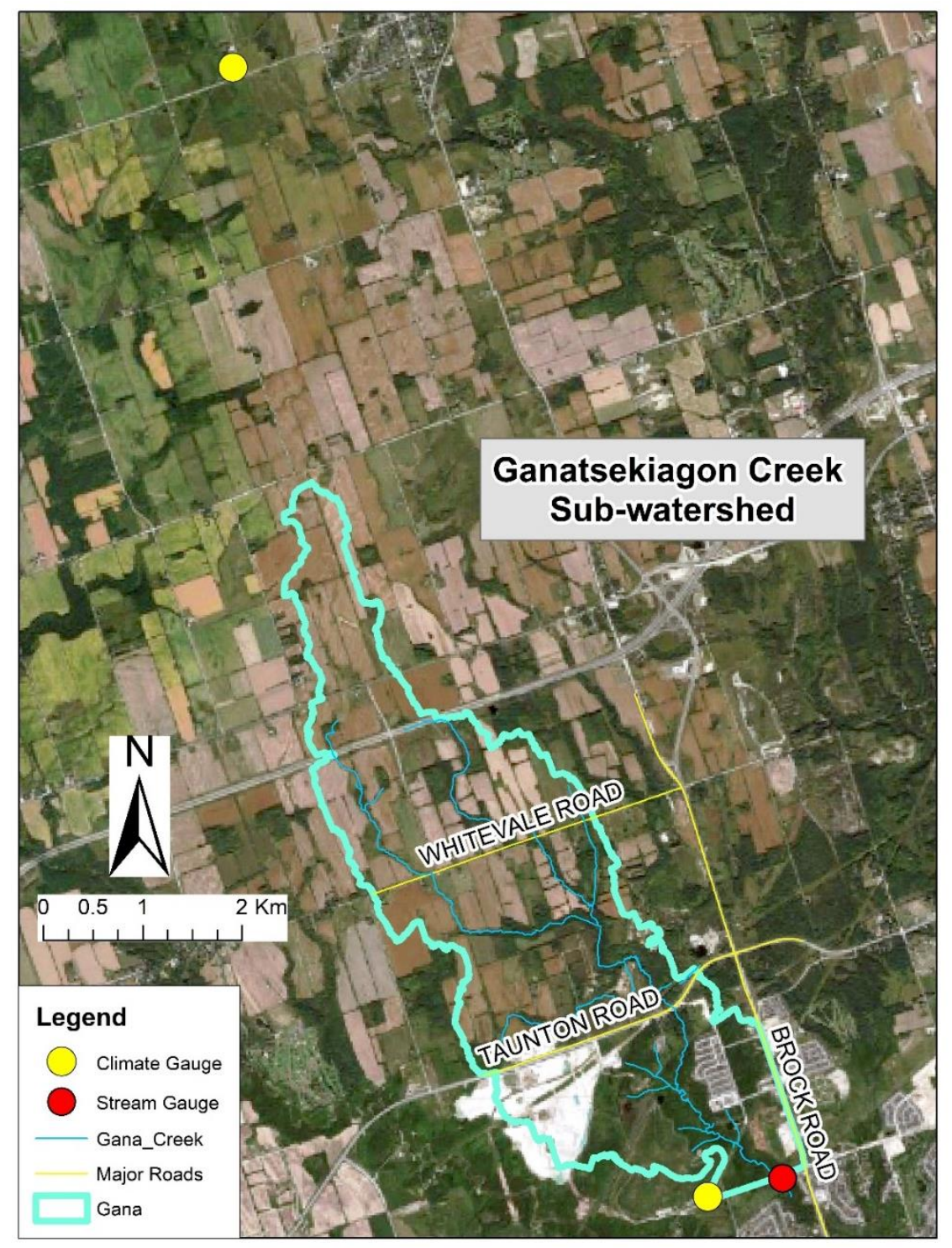

Figure 7: Map of The Study Area 


\subsection{Data Collection}

The topographical data such as DEM, land use, hydrological soil type etc. were collected from the Toronto and Region Conservation Authority (TRCA) for the model setup. Shapefiles of the subwatershed and the channel network of the subwatershed, location of the available stream measuring station and meteorological station, available hydrological data were also collected from the TRCA. The collected hydrological data were used for model calibration and validation. There were only one water level and discharge gauging station in each creek. As there was no precipitation measuring station in this study area, data of two closest rain gauges were collected to use in this research. Figure 7 shows the location of the rain gauges and the steam measuring station. The rain gauge HY009 is at the south-west of the study area, and this station is $0.8 \mathrm{~km}$ away from the Ganatsekiagon Creek's measuring station. On the other hand, rain gauge HY063 is at northeast of the study area, and its distance from the stream's measuring stations is about $12.5 \mathrm{~km}$.

Additionally, the previous hydraulic model (2010) of the study area was collected from TRCA. The collected model had cross-section and alignment of some of the tributary channels, junctions and culverts, which has been used in the model set up for this research. The SWM report and the design drawings of the DH area was also collected from the City of Pickering, which was used to develop the FSM of the DH area. The list of the collected streamflow data and rainfall data is presented in Table 1. 
Table 1: Collected stream and Pond monitoring data

\begin{tabular}{|c|c|c|c|}
\hline Gauge Name/Location & Parameter & $\begin{array}{l}\text { Time } \\
\text { Step }\end{array}$ & Available Period \\
\hline HY028 (Ganatsekiagon) & Water Level and Discharge & $15 \mathrm{~min}$ & 2010/06-2018/01 \\
\hline HY009 & Precipitation & $5 \mathrm{~min}$ & 2009-2017 \\
\hline HY063 & Precipitation & $15 \mathrm{~min}$ & 2009-2014 \\
\hline \multirow{3}{*}{$\begin{array}{l}\text { Duffin Heights SWM } \\
\text { Pond }\end{array}$} & In Pond Water Level & $5 \mathrm{~min}$ & $\begin{array}{c}05 / 09 / 2017- \\
11 / 30 / 2017\end{array}$ \\
\hline & $\begin{array}{c}\text { Pond Inlet Water Level and } \\
\text { Velocity }\end{array}$ & $1 \mathrm{~min}$ & $\begin{array}{l}05 / 09 / 2017- \\
11 / 30 / 2017\end{array}$ \\
\hline & $\begin{array}{c}\text { Pond Outlet Water Level and } \\
\text { Velocity }\end{array}$ & $1 \mathrm{~min}$ & $\begin{array}{l}05 / 09 / 2017- \\
11 / 30 / 2017\end{array}$ \\
\hline
\end{tabular}

\subsubsection{Evapotranspiration}

Average daily evaporation data for each month was collected to provide in the model setup. Average of monthly evapotranspiration values of Potential Evapotranspiration (PET) was calculated using the Canadian climate normal of Oshawa stations for 1981-2010. These PET has 
been corrected for the location of the study area using the adjustment factors of the location from the table by Chow (1959). These data were taken from a water balance study performed by GeoPro Consulting Limited for the city of Pickering in March 2017 (Limited 2017), and values are divided by the number of days in each month. The used evaporation data in this research is shown in Table 2.

Table 2: Average Monthly Evapotranspiration Values

\begin{tabular}{|c|c|c|c|c|}
\hline Month & $\begin{array}{c}\text { Monthly PET } \\
(\mathbf{m m})\end{array}$ & $\begin{array}{c}\text { Adjustment of PET } \\
\text { Factor (Lat 44) from the } \\
\text { table by Chow (1959) }\end{array}$ & $\begin{array}{c}\text { Adj. PET } \\
(\mathbf{m m})\end{array}$ & $\begin{array}{c}\text { Daily PET } \\
(\mathbf{m m})\end{array}$ \\
\hline 1 & 0 & 0.81 & 0 & 0 \\
\hline 2 & 0 & 0.81 & 0 & 0 \\
\hline 3 & 0 & 1.02 & 0 & 0 \\
\hline 4 & 29.3 & 1.13 & 33.2 & 1.11 \\
\hline 5 & 58.2 & 1.27 & 73.9 & 2.38 \\
\hline 6 & 86.3 & 1.28 & 110.4 & 3.68 \\
\hline 7 & 102.5 & 1.30 & 133.3 & 4.3 \\
\hline 8 & 99.3 & 1.20 & 119.1 & 3.84 \\
\hline 9 & 77.1 & 1.04 & 80.2 & 2.67 \\
\hline 10 & 43.8 & 0.94 & 41.2 & 1.32 \\
\hline 11 & 17.9 & 0.80 & 14.3 & 0.48 \\
\hline 12 & 0 & 0.76 & 0.0 & 0 \\
\hline
\end{tabular}

Source: Canadian Climate Normals, 1981 to 2010, Oshawa WPCP station (Lat. 43:52) 


\subsubsection{Baseflow Calculation}

The collected data of the observed streamflow show a significant groundwater contribution to the streams, but groundwater flow was not considered in this research. The baseflow from the observed flow was calculated and added as an inflow to the observing station in the model, to have a balance between the observed flow and the simulated flow. The baseflow was calculated using the digital filter algorithm proposed by Chapman et al. 1996, shown in Equation 1.

Equation 1: $\quad b_{t}=\frac{\text { alpha }}{2-a l p h a} \times b_{t-1}+\frac{1-\text { alpha }}{2-a l p h a} \times Q_{t}$

Here, $b_{t}$ and $b_{t-1}$ are the filtered baseflow at time steps $\mathrm{t}$ and $\mathrm{t}-1$ and $\propto$ is the filtered parameter. Eckhardt 2008, have recommended $\propto=0.925$ for most of the watershed; this recommendation was followed in this research. The base flow obtained using the above equation is shown in Figure 8. 


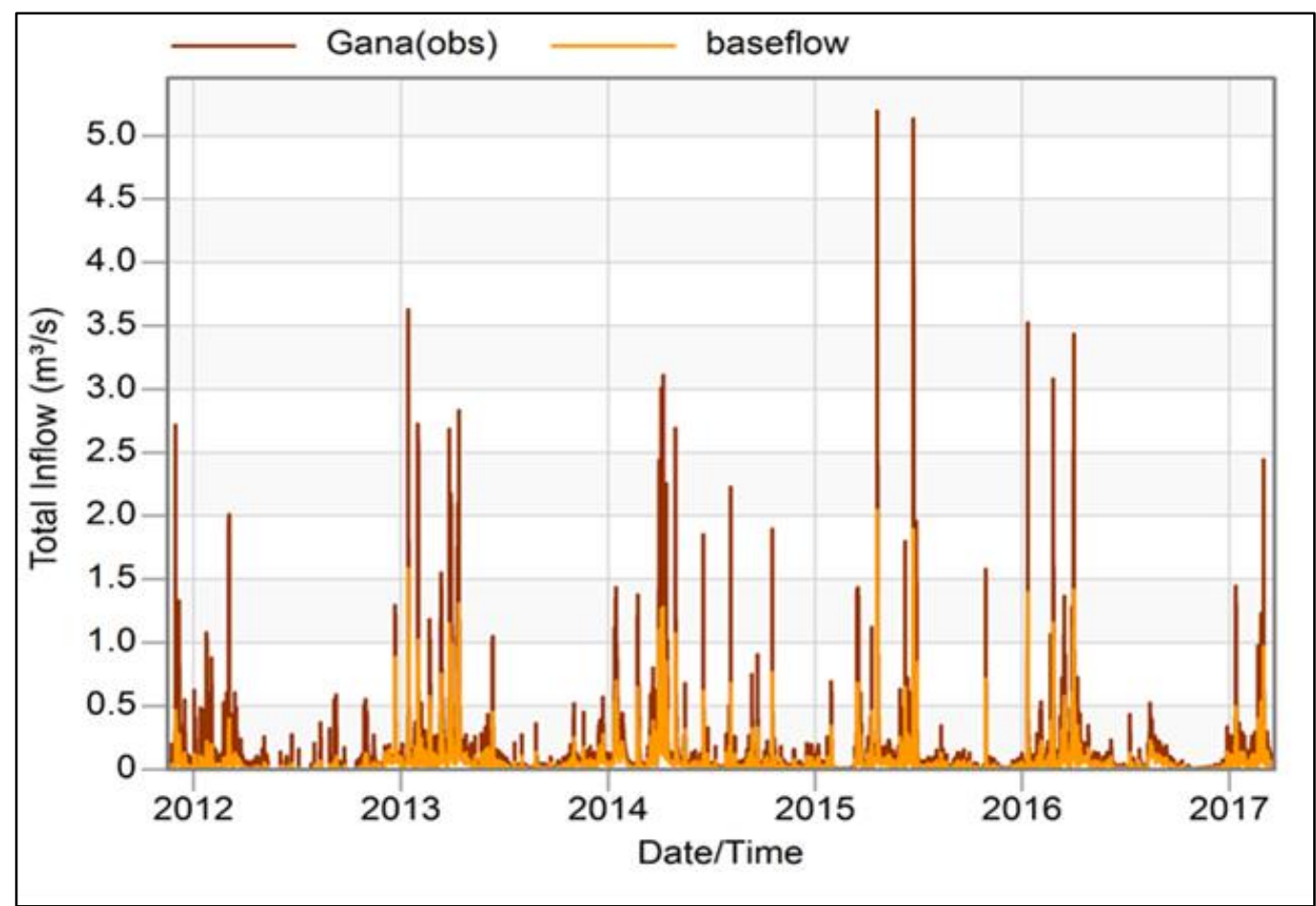

Figure 8: Estimated Baseflow of Urfe and Ganatsekiagon Creek

\subsubsection{Event Analysis}

The developed models had been of Ganatsekiagon sub-watershed was calibrated and validated using the meaningful events selected by analyzing the collected rainfall data and the streamflow data. For the models of the predevelopment scenario, the events from 2011-2015 were used and the events of 2017 were used for the post-development scenarios because the pond monitoring data for DH was available from May 2017 (Table 1), that means DH was developed by May 2017. In the event analysis, the winter season was not considered, due to lack of snow data and the uncertainty related to snow-melt runoff. The selection of appropriate events was difficult because the data analysis of this study area has shown some inconsistency between the rainfall data and the streamflow data. There may be several reasons behind this inconsistency; firstly, there was no 
rainfall station in the study area, and the used rainfall stations were far away from the flow measuring stations, as discussed in stations 4.2. The literature review (section 2.9.3) has shown that the distance between rainfall station and flow measuring station can result in degradation in the model result; because distant rainfall stations cannot capture the spatial and temporal variation of a rainfall event. Secondly, significant beaver activity had been reported in this study area. The streams of the study area have beaver dams, and several incidents have been recorded of washing off and newly constructed beaver dams. These beaver dams result in inconsistency in the rainfall amount and the observed stream flow. Lastly, this study area has tile drainage which also causes a problem in the data consistency, because the agricultural lands are considered as a rural area, but the tile drains have very high efficiency in draining the runoff. Although the impermeability was unchanged, the rapid tile drainage decreased the lag time. Due to the data inconsistency, only six meaningful events were found in the pre-development phase (2011-2015), and the selected events are presented in Table 3. Among these selected events, four were chosen for calibration of the model and the rest of two were used for validation of the model. 
Table 3: Calibration and Validation Events for The Ganatsekiagon Creek Models

\begin{tabular}{|c|c|c|c|c|c|c|c|}
\hline Event ID & $\begin{array}{c}\text { Date \& } \\
\text { Time }\end{array}$ & $\begin{array}{c}\text { Duration } \\
(\mathbf{h})\end{array}$ & $\begin{array}{c}\text { Maximum } \\
\text { Rainfall } \\
(\mathbf{m m} / \mathbf{h r})\end{array}$ & $\begin{array}{c}\text { Total } \\
\text { Rainfall } \\
(\mathbf{m m})\end{array}$ & $\begin{array}{c}\text { Total } \\
\text { Rainfall } \\
\left(\mathbf{m}^{3}\right)\end{array}$ & $\begin{array}{c}\text { Total } \\
\text { Observed } \\
\text { Flow } \\
\left(\mathbf{m}^{3}\right)\end{array}$ & $\begin{array}{c}\text { Runoff } \\
\text { coefficient }\end{array}$ \\
\hline $\begin{array}{c}\text { Calibration } \\
\mathbf{1}\end{array}$ & $\begin{array}{c}5 / 13 / 2011 \\
12: 25: 00 \\
\mathrm{AM}\end{array}$ & 218 & 16.5 & 44.9 & 601,535 & 422,600 & 0.7 \\
\hline $\begin{array}{c}\text { Calibration } \\
\mathbf{2}\end{array}$ & $\begin{array}{c}10 / 26 / 2012 \\
4: 25: 00 \mathrm{PM}\end{array}$ & 218 & 14.5 & 48.7 & 652,322 & 189,700 & 0.3 \\
\hline $\begin{array}{c}\text { Calibration } \\
\mathbf{3}\end{array}$ & $\begin{array}{c}4 / 9 / 2013 \\
3: 05: 00 \mathrm{PM}\end{array}$ & 45 & 12.4 & 23.1 & 308,875 & 173,700 & 0.6 \\
\hline $\begin{array}{c}\text { Calibration } \\
\mathbf{4}\end{array}$ & $\begin{array}{c}4 / 7 / 2015 \\
12: 15: 00 \\
\mathrm{PM}\end{array}$ & 151 & 7.2 & 27.1 & 363,011 & 84,950 & 0.2 \\
\hline $\begin{array}{c}\text { Validation } \\
\mathbf{1}\end{array}$ & $\begin{array}{c}6 / 8 / 2013 \\
7: 55: 00 \mathrm{PM}\end{array}$ & 133 & 16.5 & 28.2 & 378,020 & 96,870 & 0.3 \\
\hline $\begin{array}{c}\text { Validation } \\
\mathbf{2}\end{array}$ & $\begin{array}{c}4 / 19 / 2015 \\
4: 15: 00 \mathrm{PM}\end{array}$ & 44 & 40.3 & 43.0 & 576,209 & 250,700 & 0.4 \\
\hline
\end{tabular}

Analyzing the collected monitoring data of the SWM pond water level and the pond inflowoutflow data (Table 1) some rainfall events were selected. These events were used to evaluate the developed model's performance by comparing the modelled results with the monitoring data. The selected events are presented in Table 4. 
Table 4: Selected Events for Duffin Heights FSM

\begin{tabular}{|c|c|c|c|c|c|c|}
\hline Event & Date & $\begin{array}{c}\text { Duration } \\
\text { (h) }\end{array}$ & $\begin{array}{c}\text { Maximum } \\
\text { Rainfall } \\
(\mathbf{m m} / \mathbf{h r})\end{array}$ & $\begin{array}{c}\text { Total } \\
\text { Rainfall } \\
(\mathbf{m m})\end{array}$ & $\begin{array}{c}\text { Observed } \\
\text { Peak Flow } \\
\text { Rate }\left(\mathbf{m}^{3} / \mathbf{s}\right)\end{array}$ & $\begin{array}{c}\text { Observed } \\
\text { Flow Volume } \\
\left(\mathbf{m}^{3}\right)\end{array}$ \\
\hline 1 & $\begin{array}{c}\text { 5/18/2017 } \\
\text { 5:55:00 PM }\end{array}$ & 1.92 & 37.2 & 9.4 & 0.93 & 696 \\
\hline 2 & $\begin{array}{c}\text { 7/7/2017 } \\
\text { 6:55:00 PM }\end{array}$ & 3.33 & 19.1 & 8.0 & 0.19 & 393 \\
\hline 3 & $\begin{array}{c}\text { 7/20/2017 } \\
\text { 10:00:00 AM }\end{array}$ & 3.83 & 11.4 & 5.1 & 0.09 & 240 \\
\hline 4 & $\begin{array}{c}\text { 7/26/2017 } \\
\text { 6:40:00 PM }\end{array}$ & 17 & 14.5 & 10.4 & 0.17 & 763 \\
\hline 5 & $\begin{array}{c}\text { 8/4/2017 } \\
\text { 4:00:00 PM }\end{array}$ & 3.17 & 23.2 & 10.0 & 0.15 & 438 \\
\hline 6 & $\begin{array}{c}\text { 8/22/2017 } \\
\text { 9:05:00 AM }\end{array}$ & 6.58 & 54.8 & 12.7 & 0.64 & 810 \\
\hline 7 & $\begin{array}{c}\text { 9/3/2017 } \\
\text { 3:45:00 PM }\end{array}$ & 3 & 15.5 & 3.1 & 0.16 & 121 \\
\hline 8 & $\begin{array}{c}\text { 9/4/2017 } \\
\text { 5:30:00 PM }\end{array}$ & 4.5 & 23.7 & 14.7 & 0.21 & 700 \\
\hline 9 & $\begin{array}{c}\text { 9/5/2017 } \\
\text { 1:00:00 PM }\end{array}$ & 2 & 48.5 & 7.1 & 0.63 & 401 \\
\hline
\end{tabular}

The Event analysis of the DH showed that the observed pond inflow hydrograph has a significant delay compared to the inflow hydrograph generated by the model. This delay might be due to the distance of the pond inlet and the rain gage; the distance is about one kilometre. The rainfall was shifted to match the observed flow data and to overcome this timing error for the Duffin Heights 
FSM, assuming that the rain clouds took some time to reach the area of concern from the gauge station. This shifting was done analyzing each event separately.

\subsection{Pre-development model setup}

\subsubsection{Channel setup}

The conduits' and junctions' shapefiles collected from the previously available model were imported in this newly developed model. The consistency of the imported shapefiles was tested using the DEM, and the errors were corrected, and additional conduits and junctions were created according to the DEM to cover the entire study area and to represent the actual flow patterns. The transects of the newly added natural channels were established using the build-in transect creator of the PCSWMM software. The existing culverts of the natural conduits were added and assigned culvert codes to specify the culverts shape and material to specify the entrance and exit loss coefficient and the roughness of each culvert. Finally, all the cross-sections, the connections of the natural channels, the invert elevations, depth of the junctions, and outfalls were checked and updated according to the DEM. According to Bizier (2013), the roughness of the natural channels was set to 0.04 , as the channels have irregular sections and may contain pools. Culvert was modelled based on the shapes obtained from the previously available watershed models.

\subsubsection{Watershed Discretization}

The initial CSM of the pre-development scenario was developed in three different discretization levels by using WDT of PCSWMM. As the most significant parameters of a simulation study, width and flow length of the sub-catchment depend on the discretization level. The literature 
review has shown that the result of the simulation can vary significantly with the resolution of the model. Previous studies have shown that the finely discretized models provide a better match to the observed data but needs longer runtime. Moreover, a properly discretized model can match the observed flow conditions without any calibration of the model. In a previous study, the Duffin Creek watershed model was done considering the entire Ganatsekiagon watershed as one subcatchment. But now in this study as only the Ganatsekiagon sub-watershed was considered as the study area an attempt was made to discretize it more finely, to better represent the heterogeneity of the drained lands. The Ganatsekiagon sub-watershed was delineated using discretization target of $150 \mathrm{ha}, 100 \mathrm{ha}$ and $50 \mathrm{ha}$.

The 150 ha discretization level divided the Ganatsekiagon watershed into nine subcatchments, 100 ha discretization level divided it into 12 subcatchments, while the 50 ha targeted discretization level divided the watershed into 21 subcatchments (Figure 9). As with the 50 ha discretization level the model had 21 subcatchment it was assumed that this number of subcatchment was adding enough complexity to the model with fairly accurate simulation results so, the model with 50 ha discretization level was chosen as the discretization for the further analysis. 


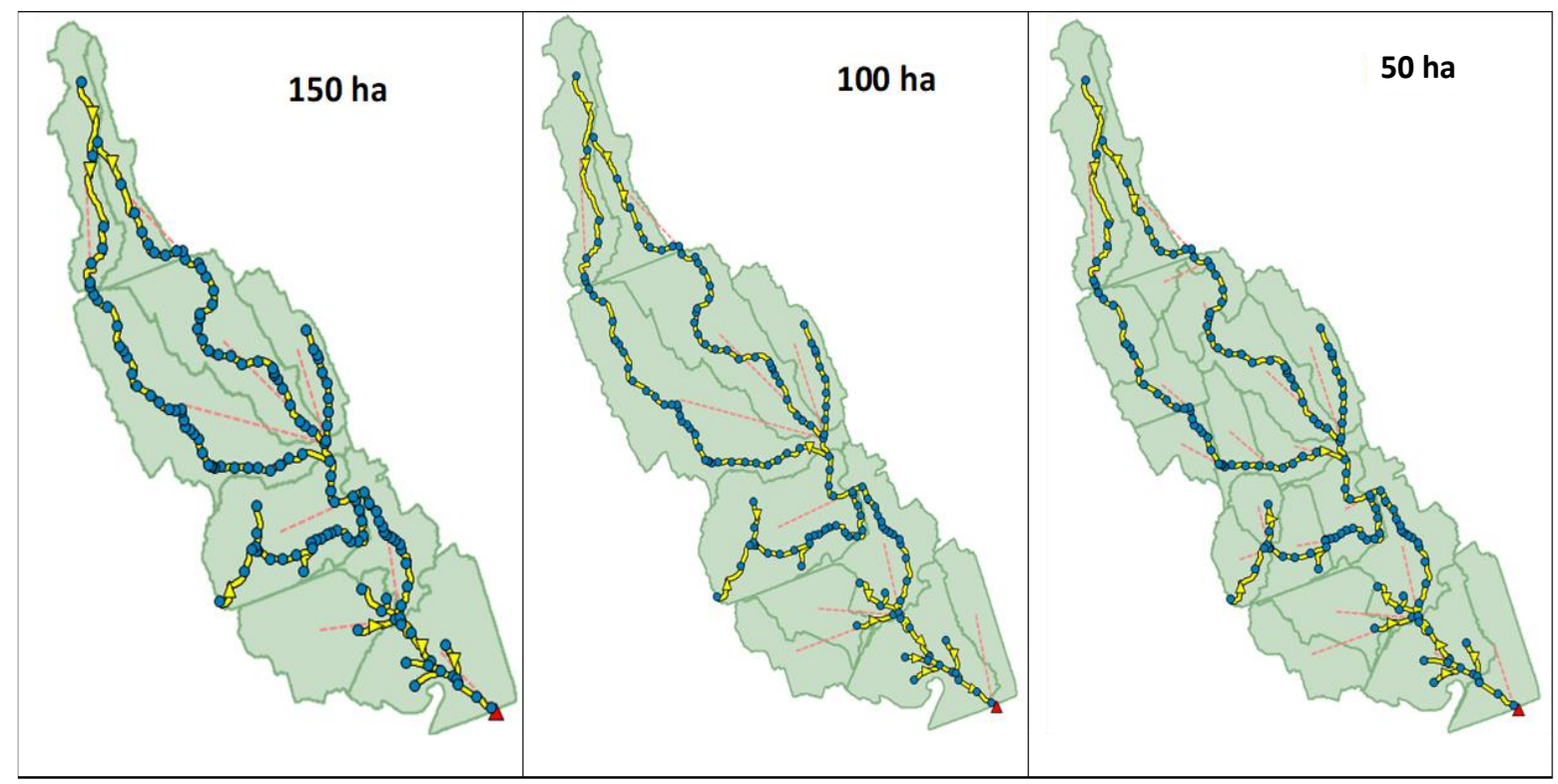

\section{Figure 9: Three Different Levels of Discretization of The Ganatsekiagon Sub-watershed}

\subsubsection{Subcatchment parameters}

After discretizing the watershed, the necessary parameters were assigned to the subcatchments to represent the characteristics of the area. The data of the percentage of the impervious area was obtained from the land use data collected from the TRCA. The percentage of imperviousness of the land use data was also be checked, and in some case, it was corrected manually using the satellite images of the study area. The area weighting tool was used to calculate the total percentage of impervious area in each sub-catchment appropriately.

In this research, Depression storage of the permeable area was assumed based on the land use and the guideline given in the PCSWMM manual (Table 5). The Manning's n, according to the surface cover, were obtained from the land cover data. The area weighting tool was used to calculate Depression storage (Dstore) for the permeable and impermeable area of the subcatchments and 
Manning's $\mathrm{N}$ for the permeable area. Generally, the impermeable area is mainly of smooth asphalt, so Manning's N was assumed 0.01 as guided by Rossman and Huber 2016.

Table 5: Estimated Dstore for Permeable and Impermeable Areas

\begin{tabular}{|l|c|c|}
\hline \multicolumn{1}{|c|}{ Land Use } & Dstore Permeable & Dstore Impermeable \\
\hline Cemetery & 5 & 1.875 \\
\hline Commercial & $3.75-4$ & 1.875 \\
\hline Conservation lands & 8 & 2.5 \\
\hline Firms & 5 & 2.5 \\
\hline Golf Course & 5 & 1.25 \\
\hline Hydro Corridor & 8 & 2.5 \\
\hline Industrial & $3.75-5$ & 1.875 \\
\hline Open Space & 6 & 2.5 \\
\hline Park & 3.75 & 1.875 \\
\hline Residential Low & 3.75 & 1.875 \\
\hline Rural residential & 4 & 2 \\
\hline Transportation & 4 & 1.25 \\
\hline natural & 8 & 2.5 \\
\hline
\end{tabular}

(Source: PCSWMM Manual)

$\mathrm{CN}$ is the most critical parameter in this research. The GIS data of hydrological soil type, land use and natural cover data collected from TRCA was used to estimate the $\mathrm{CN}$ for each subcatchment. In this model, it was assumed that $100 \%$ of the runoff from the impervious area, was routed over the permeable area. In SWMM for CN infiltration method, the impermeable areas are ignored, as no infiltration can occur in impermeable areas. $\mathrm{CN}$ number was estimated to represent the characteristics of the porous regions only. 
The rainfall data were assigned by selecting the appropriate rain gauge for each subcatchment. For this process, Thiessen Polygon was created by using the rain gauge HY009 and HY063.

\subsubsection{General Model Settings}

The $\mathrm{CN}$ method was chosen as the infiltration method in the model. Rainfall and flow routing were selected as the process of modelling for this study. Dynamic wave approach was chosen as the routing method in this as backwater effects are expected to occur in the outlet of the SWM ponds and at road-crossing culverts. For the hydrologic routing, the time step was chosen 5 min for the wet period, but for the dry period, 15 min time step was considered; as no rain is expected in the dry period. The routing time step for the dynamic wave method was fixed at 4 seconds to avoid instability problems and ensure small continuity errors.

\subsubsection{Sensitivity test of the model}

The sensitivity test of the model was done for the input parameters, and the results show the model's runoff volume was sensitive to the subcatchment width, flow length, slope, depression storage and $\mathrm{CN}$; while the shape of the hydrograph was sensitive to the roughness and drying time of the surface soil.

The sensitivity test shows that the model was significantly sensitive to the CNs, and sensitivities for all the other parameters were negligible compared to the CN's sensitivity. Therefore, the model was calibrated and validated for $\mathrm{CN}$ only. 


\subsubsection{Calibration and Validation of The Pre-development Model}

SRTC tool was used for sensitivity analysis of the catchment parameters before calibration and as discussed in the previous section $\mathrm{CN}$ was identified as the most sensitive catchment parameter for this model.

The calibration performance was measured using the Nash Sutcliffe Efficiency (NSE) calculated by the SRTC. The equation used to calculate the NSE is given below.

$$
N S E=1-\frac{\sum\left(y_{\text {obs }}^{i}-y_{\text {model }}^{i}\right)^{2}}{\sum\left(y_{o b s}^{i}-\overline{y_{o b s}}\right)^{2}} \quad \text { Equation } 2
$$

Here, $\overline{y_{o b s}}=$ mean of the observed values

NSE can be any value from $-\infty$ to 1 . The value of 1 represents the perfect match of the modelled result, to the observed data (Nash and Sutcliffe 1970).

$\mathrm{CN}$ was calibrated for each event, to have the NSE closest to one. The $\mathrm{CN}$ was increased to $50 \%$, $35 \%, 54 \%$ and $22 \%$ for the calibration events 1 to 4 respectively (Table 3), to calibrate the model. Then the calibrated CNs of each event were applied to the validation events to identify the best match to the observed data. Both the validation events results showed that $22 \%$ increase of $\mathrm{CN}$ resulted in the best matching model to the observed data; thus, the model with a $22 \%$ increased $\mathrm{CN}$ was finalized as the calibrated model. The results of the calibration process are presented in Figure 10, Figure 11, Figure 12 and Figure 13. The results of the validation process are shown in Figure 14 and Figure 15. In the mentioned figures the legend "Current" is representing the result without calibrated CN. 


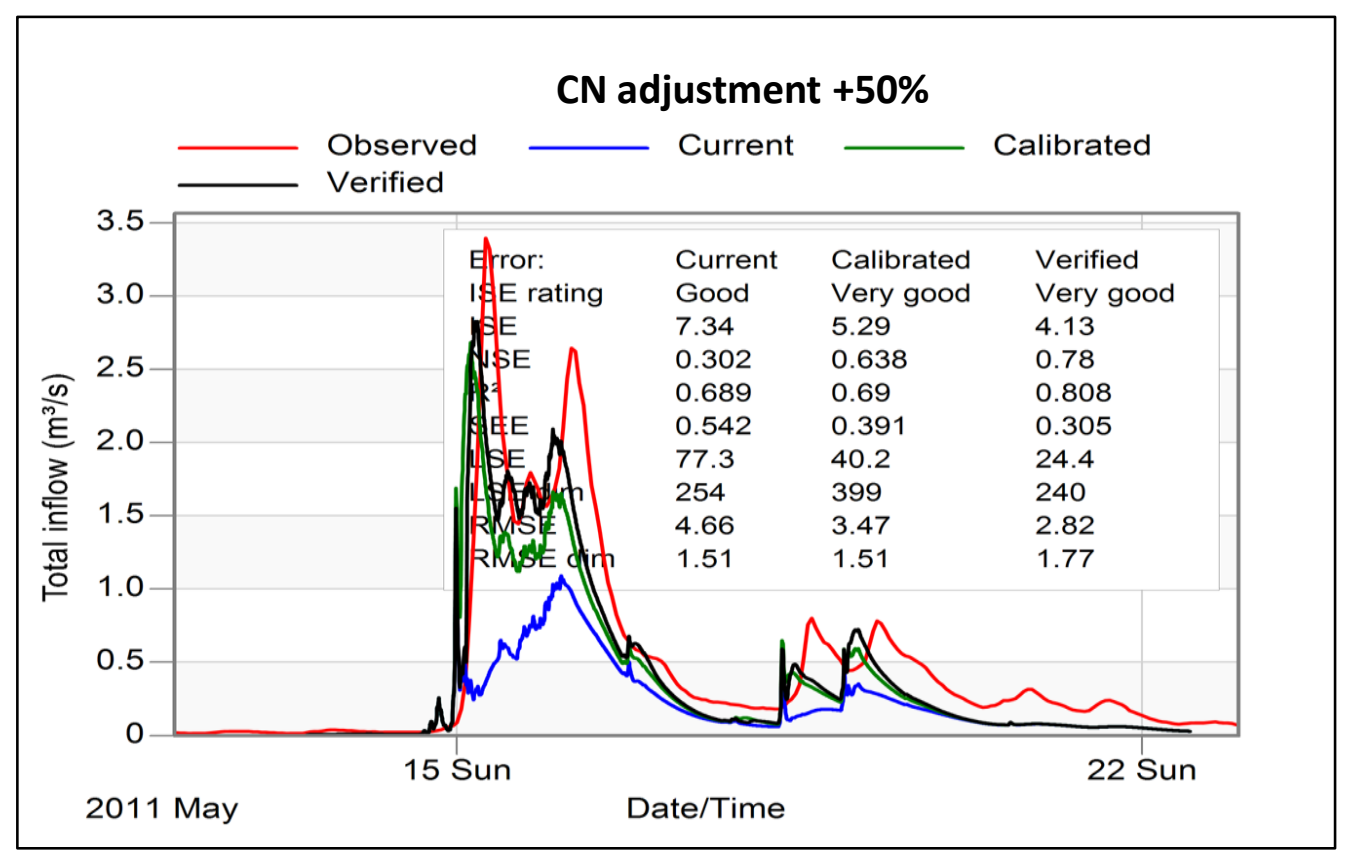

Figure 10: Calibration result of Event 1

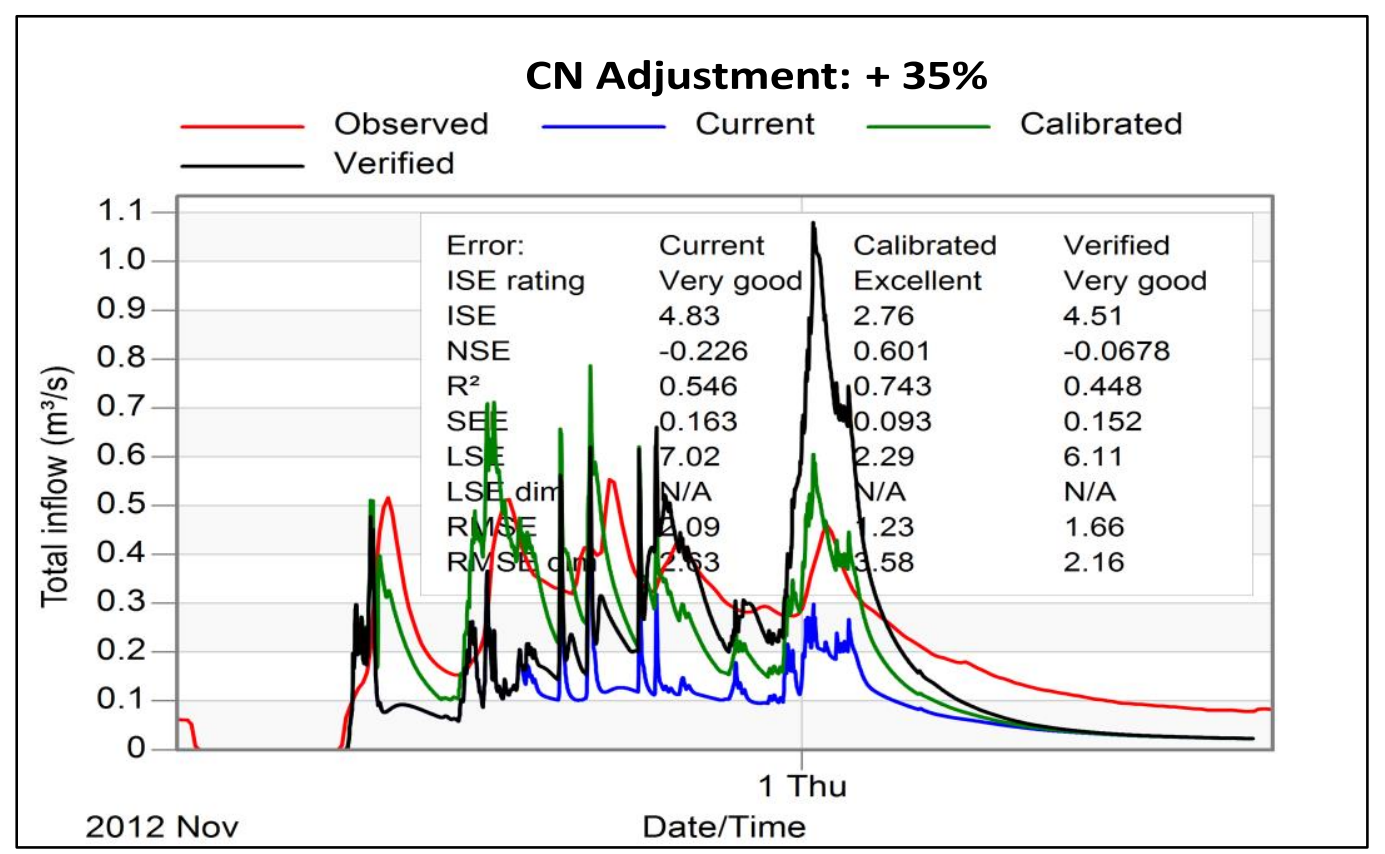

Figure 11: Calibration result of Event 2 


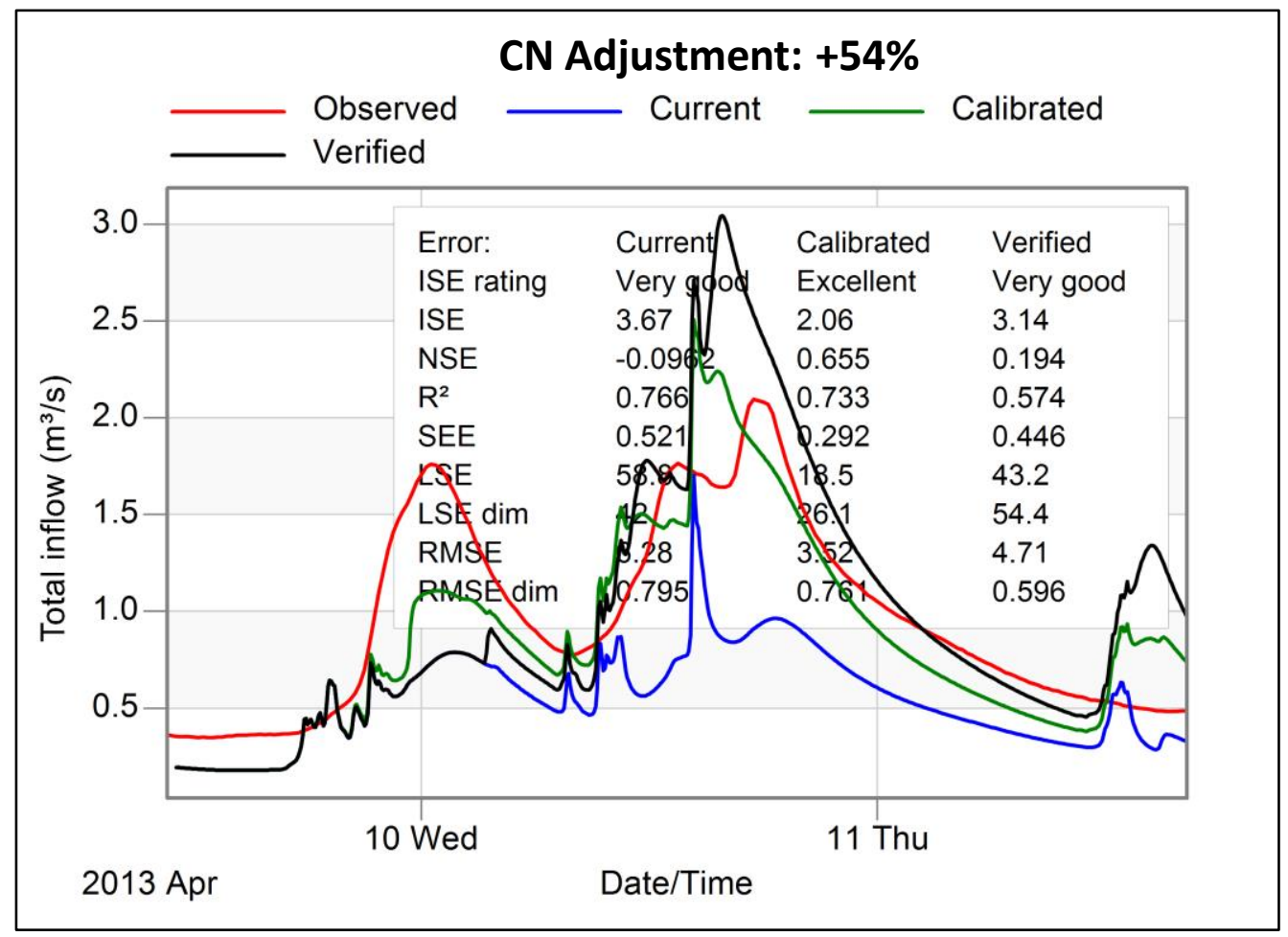

Figure 12: Calibration result of Event 3

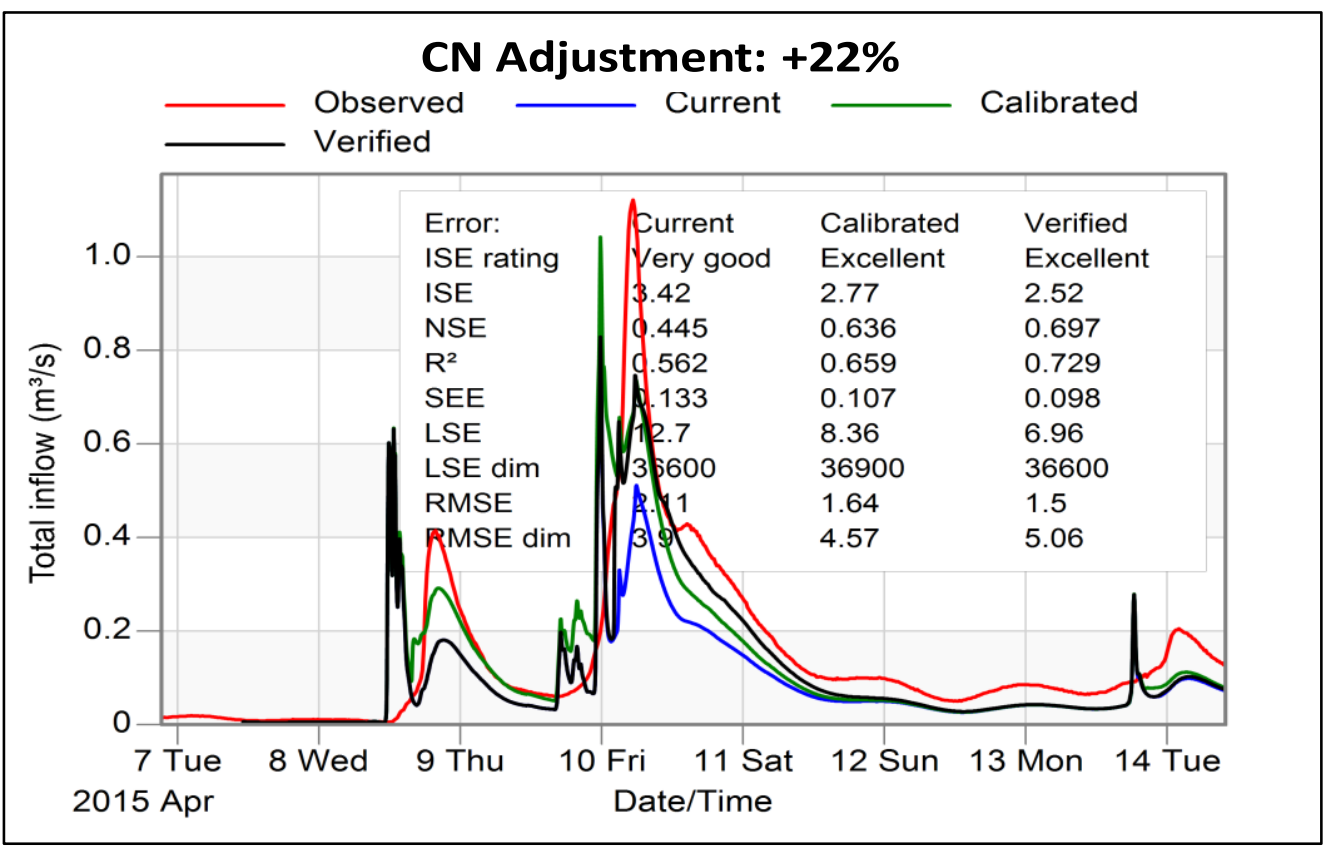

Figure 13: Calibration result of Event 4 


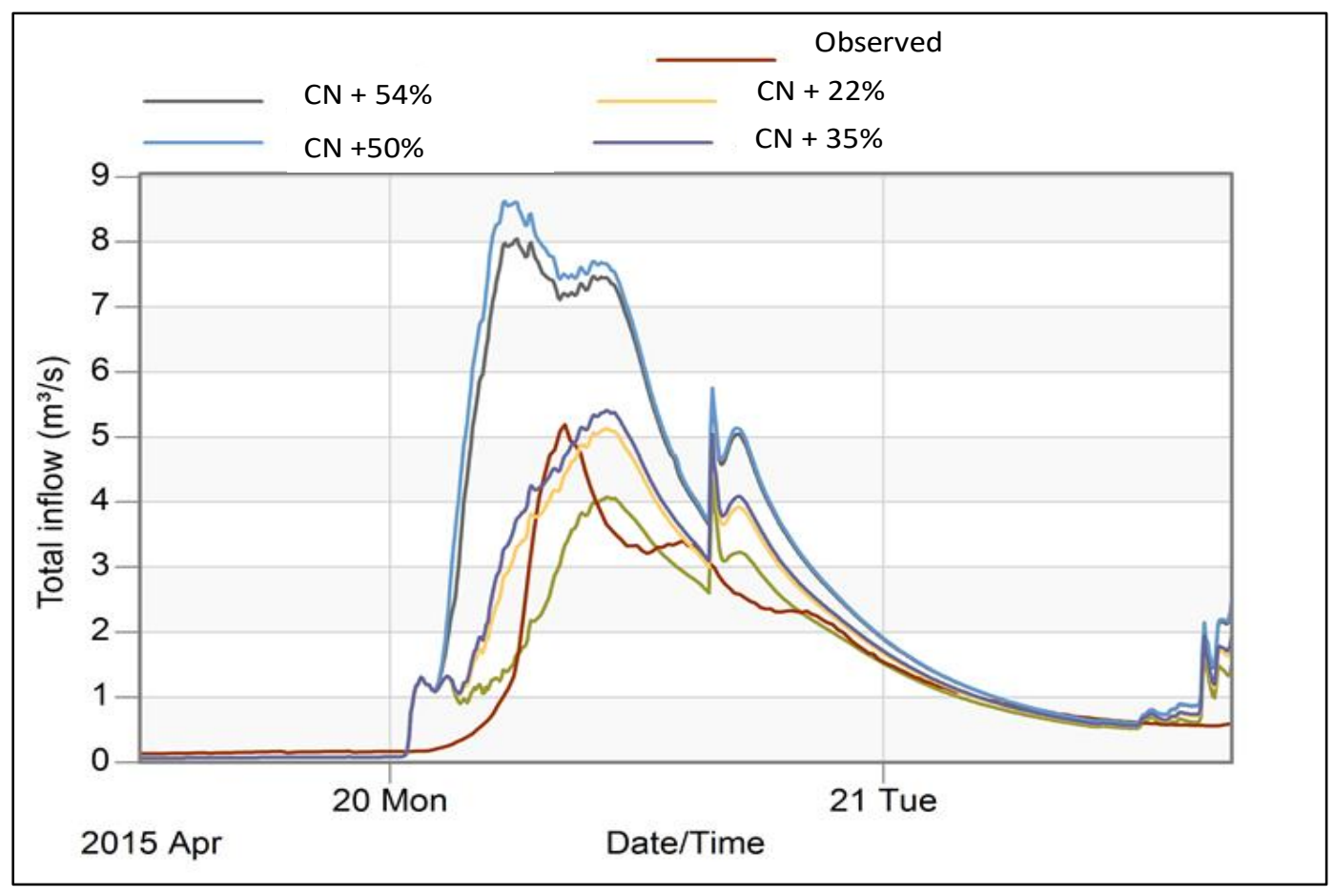

Figure 14: Validation result of Event 5

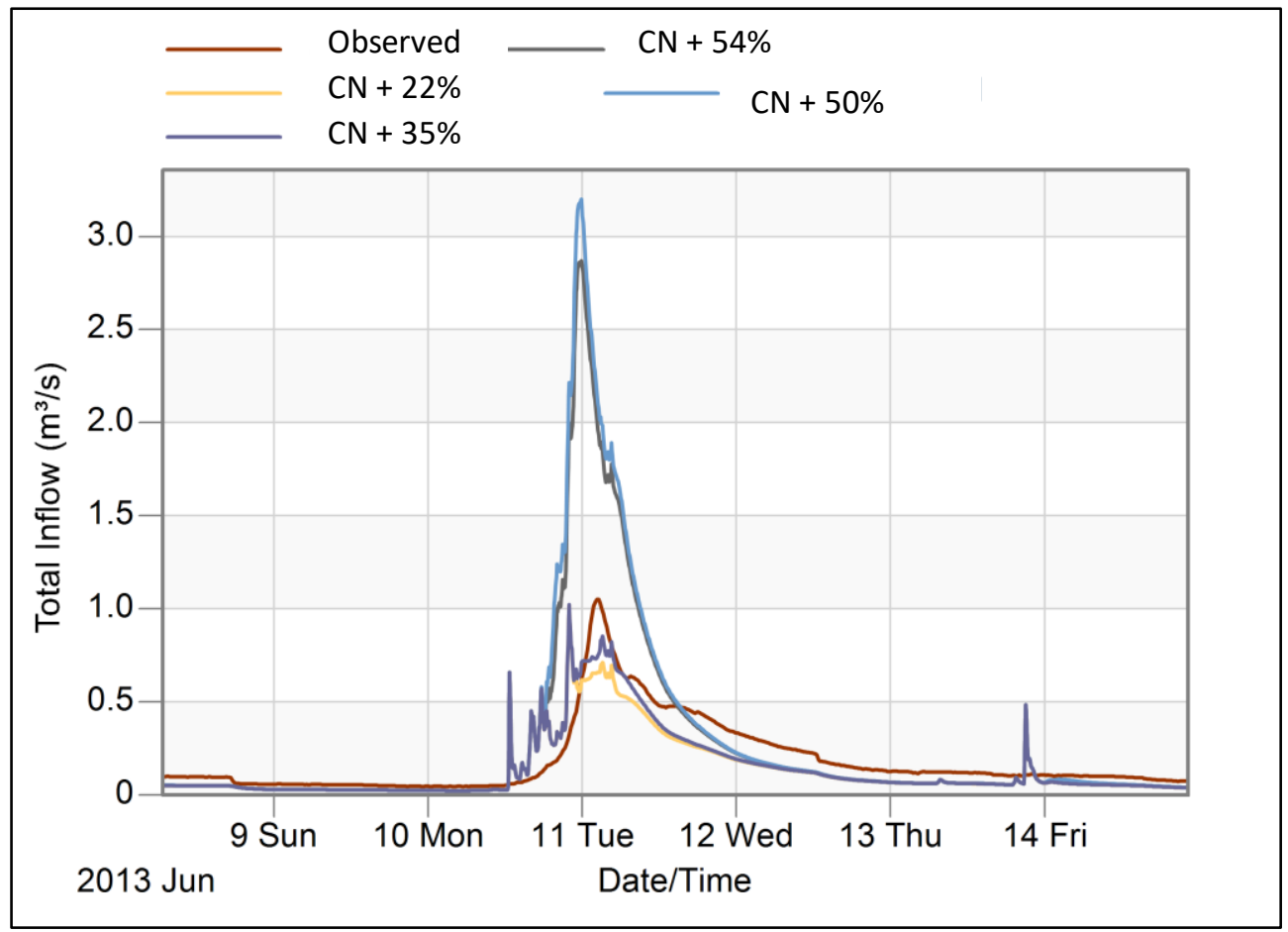

Figure 15: Validation result of Event 6 


\subsection{Post-development Modelling at a Coarse Scale}

The CSM of the post-development scenario was created by incorporating the post-development changes in the developed portion of the watershed. The subcatchment containing the developed area $(\mathrm{DH})$, in the calibrated pre-development model was split to separate exactly the same area as the DH areas from the rest of the watershed. The DH area has an SWM pond, and this pond was created in the model according to the SWM report collected from the City of Pickering. Following the SWM report, the impervious percentage of the developed area has also been changed to $57 \%$ for the $\mathrm{DH}$ area. The pond of $\mathrm{DH}$ has been created with all the detailing, such as forebay and main ponds stage-area curve, weirs and orifices dimensions and position, the outfall of the pond to the streams; all these details have been collected for the SWM report collected for the City of Pickering. The rest of the post-development model was unchanged from the pre-development model. The developed portion of the post-development model in CSM is presented in Figure 16. 


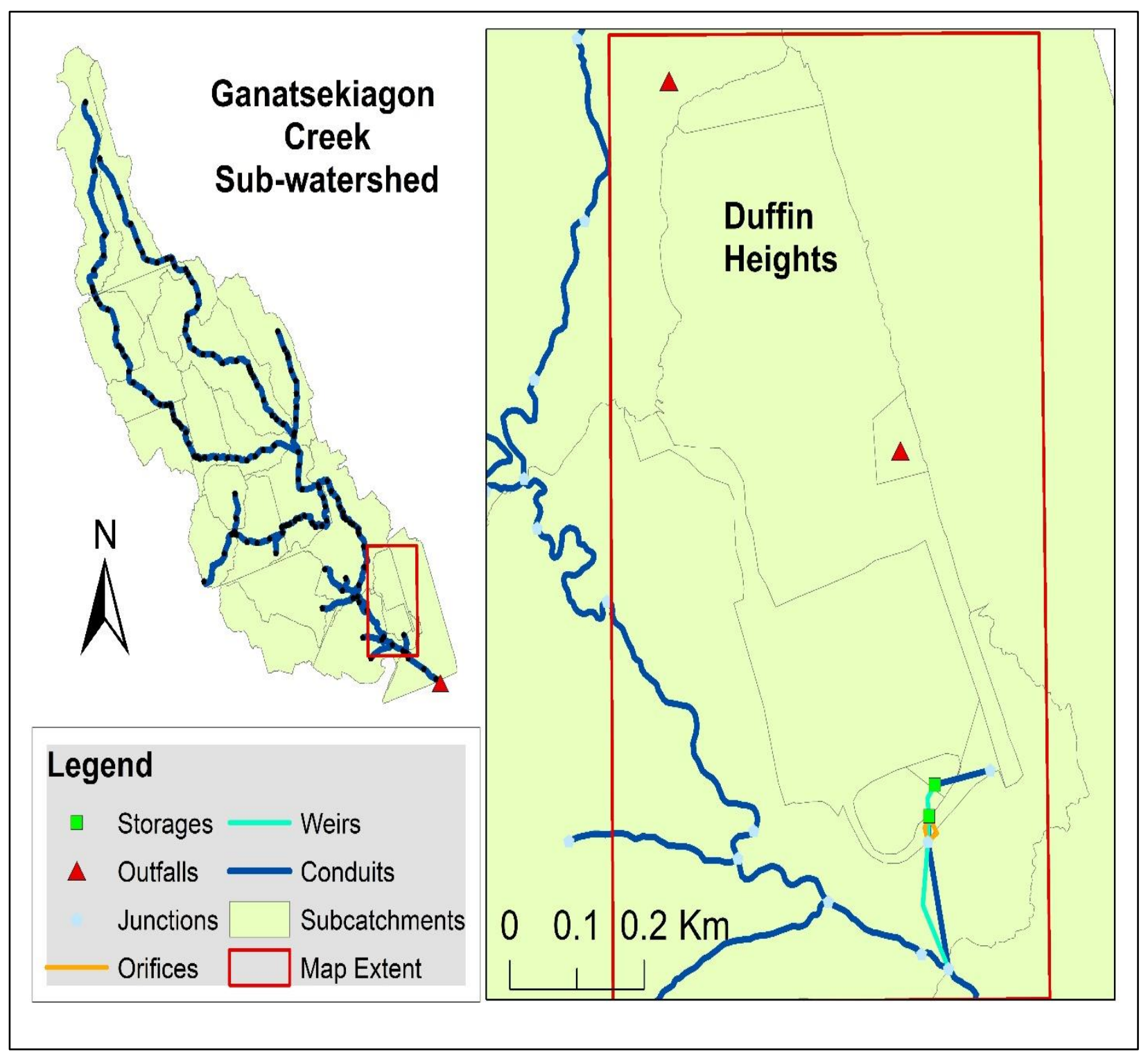

Figure 16: Duffin Heights in CSM 


\subsection{Fine-Scale Models for Developed Area}

A fine-scale post-development model for only the developed area of DH was prepared. For the preparation of the FSM, the subcatchments area, shape, stormwater pipe size, slope, flow direction and the details of the LIDs were incorporated from the collected design drawings of the developed area manually. The invert elevation was determined using the DEM of that area. The details data of the SWM ponds was used from the SWM reports of the DH area, collected from the City of Pickering.

In the developed area, there were two types of pipes collecting the stormwater. One is termed as "stormwater" pipe, which is collecting the rainwater from roads and overland flows and the other type is termed as "clean water" pipes, which is collecting the rainwater from roofs of the residential area. The clean water from the Lebovic West Lands are discharged outside of the developed area, but the Cougs Subdivision's clean water collectors have the outfalls into two infiltration tranches

under the roads. The stormwater pipes are releasing into the SWM ponds, which is located on the south-west of the developed area (Figure 17). 


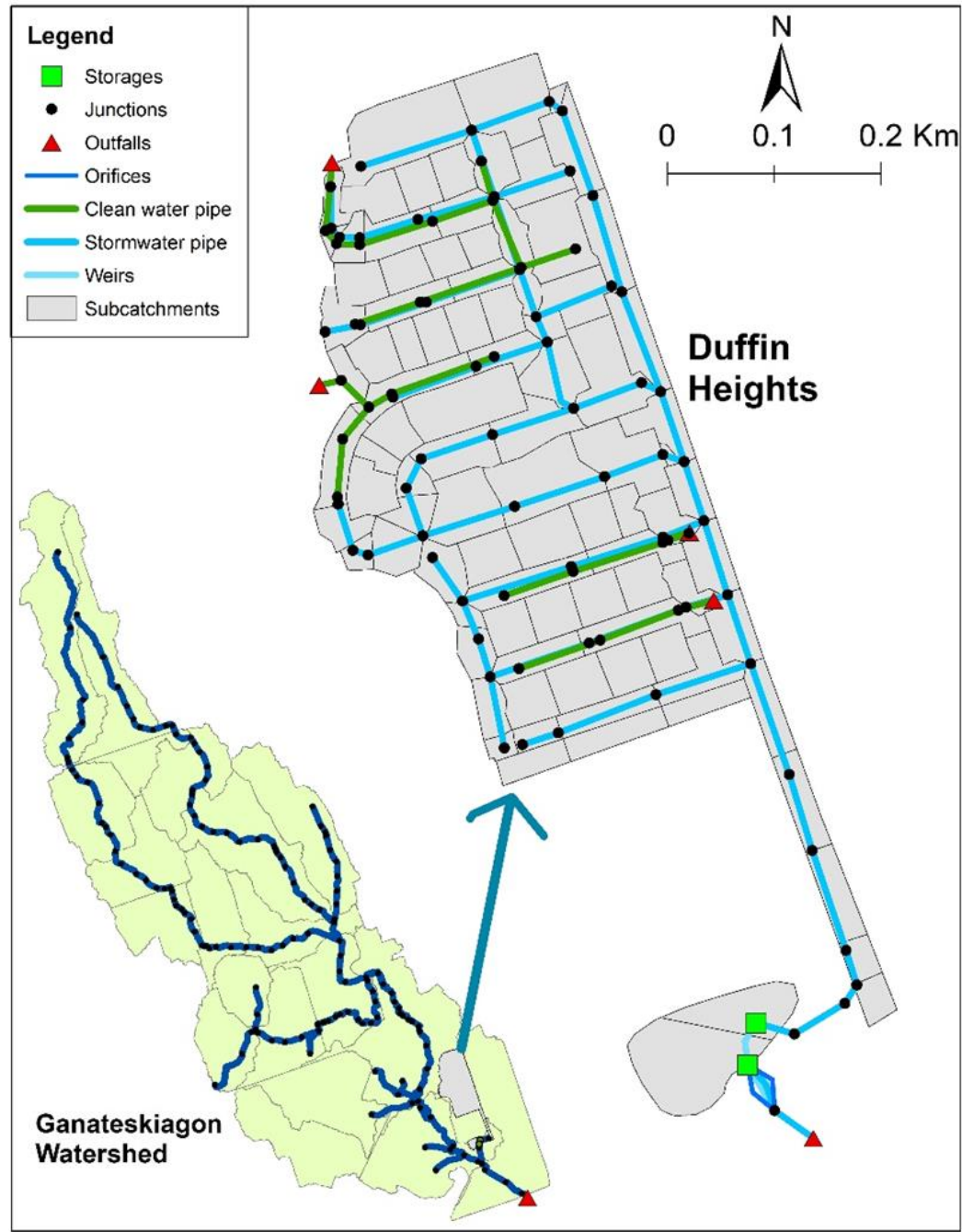

Figure 17: Detailed Post-development Model of The Duffin Heights in Fine-Scale

Sensitivity analysis was done for the model calibration and the analysis show that calibration is not improving the results anymore. The reason behind this may be, the FSM consists of very fine parameters to represent the real scenario, and further improvement is not resulting in any noticeable change. 


\subsection{Multi-scale Model (MSM)}

After developing the FSM of the developed area, it was incorporated into the calibrated predevelopment model by replacing the coarse-scale developed area. Thus, the developed area had detailed fine-scale parameters, but the rest of the undeveloped area had parameters of coarse-scale. This combined model has been termed as a Multi-scale Model. Figure 18 presents the difference between a MSM and a CSM. The purpose of developing an MSM was to understand the effect of the development and the associated BMPs on the downstream portion of the watershed.

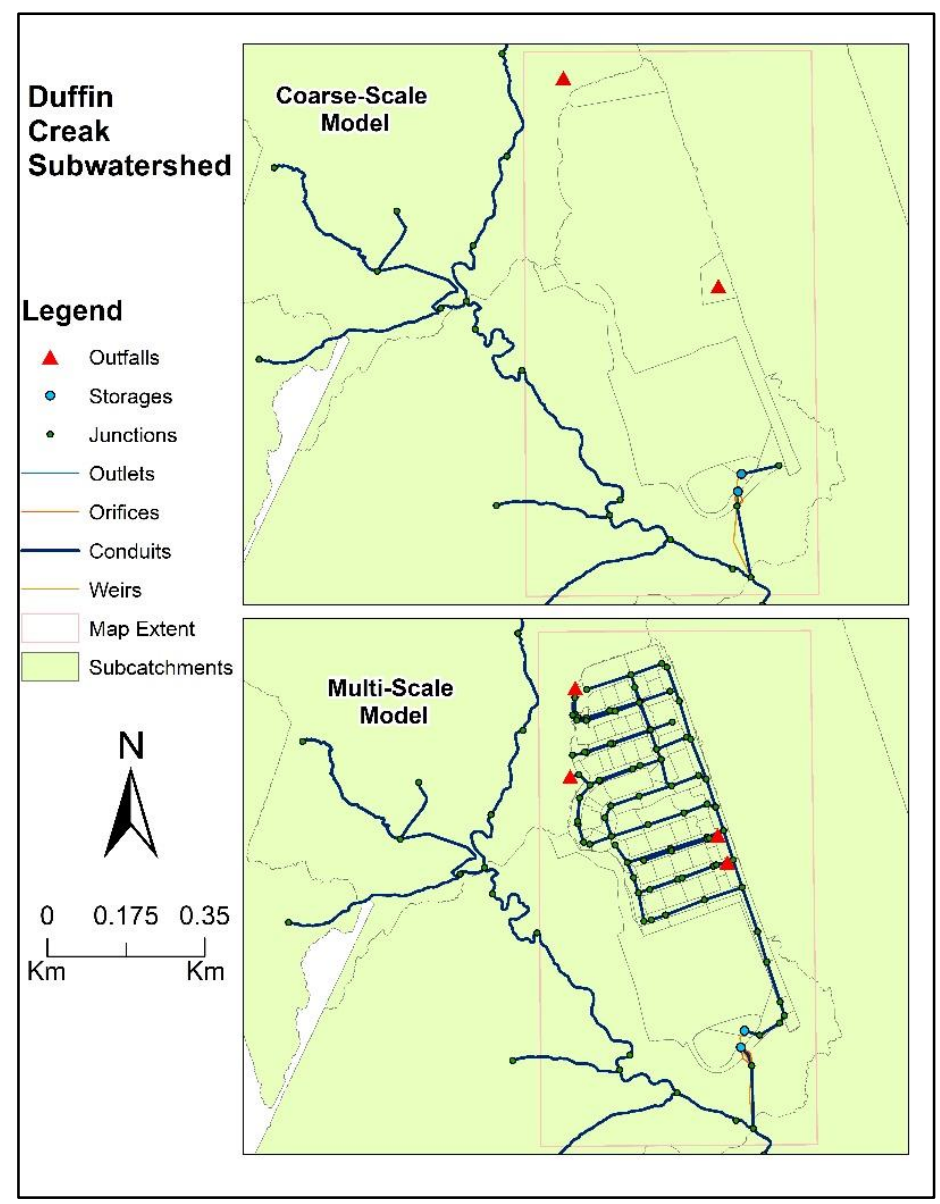

Figure 18: Difference of a Multi-scale and a Coarse-scale Model of the Ganatsekiagon Creek Sub-watershed 


\subsection{Performance Evaluation}

As the extent of existing development in the subwatershed is almost negligible, the results may not show a prominent change in the MSM and CSM. It is expected that a large amount of land development will result in a significant change in the flow condition of the creek. The collected data from the TRCA show that the approved land development in this sub-watershed will be resulting in about $40 \%$ development of the total sub-watershed, as shown in Figure 19. This section presents the analysis of some future expected development scenario with different BMP measures.

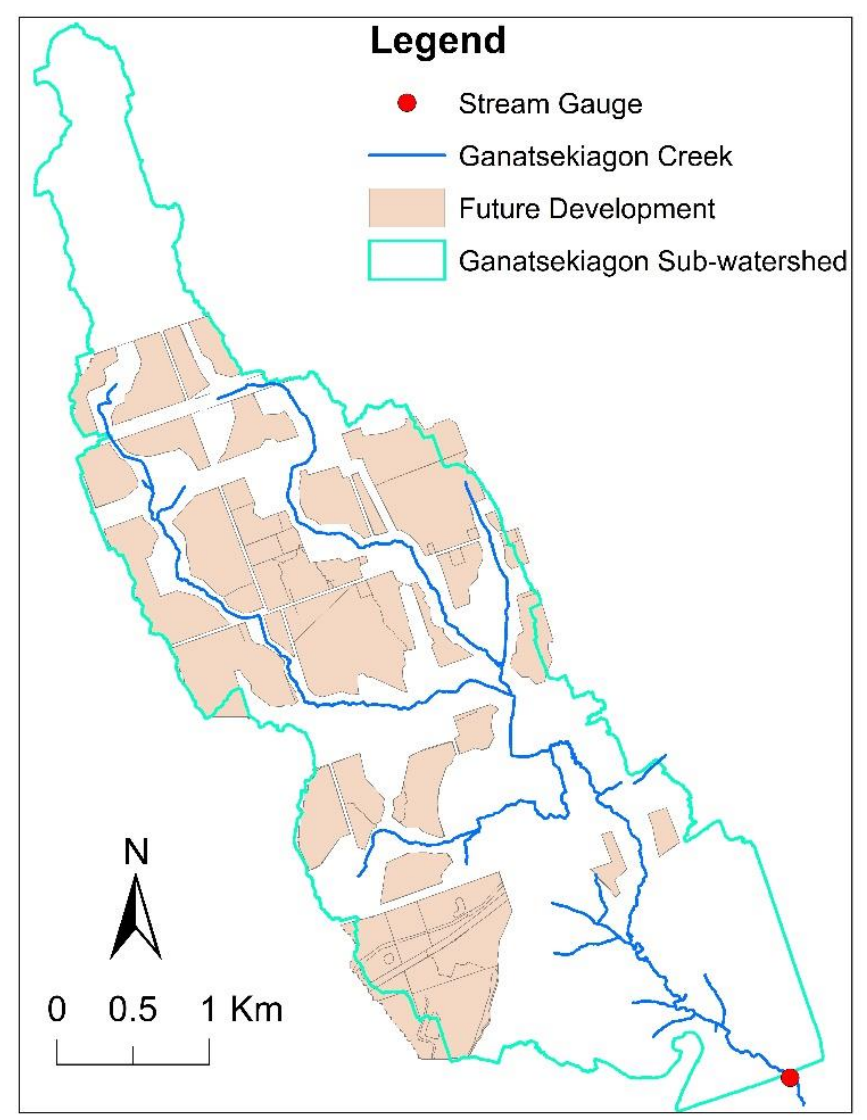

Figure 19: Map of The Approved Future Development Projects in The Subwatershed 
The approved land developments data indicate that about 480 ha out of the 1400 ha area of the sub-watershed is approved for future land development. Figure 19 shows the location of the approved development projects in the sub-watershed area. Based on these expected future developments, several scenarios were considered, corresponding to different development levels within the approved areas, and analyzed to compare the results of the pre-development, CSM and MSM models. In addition, scenarios were also developed to consider the presence of different BMP options in the developed lands. The list of all the scenarios are presented in Table 6, and the details of each scenario are provided in Sections 4.7.1 and Error! Reference source not found..

\section{Table 6: List of The Scenarios}

\begin{tabular}{|c|c|}
\hline Scenario & Description \\
\hline Scenario 1 & Pre-Development \\
\hline Scenario 2 & $25 \%$ Coarse-Scale \\
\hline Scenario 3 & $25 \%$ Multi-Scale \\
\hline Scenario 4 & $50 \%$ Coarse-Scale \\
\hline Scenario 5 & $50 \%$ Multi-Scale \\
\hline Scenario 6 & $80 \%$ Coarse-Scale \\
\hline Scenario 7 & $80 \%$ Multi-Scale \\
\hline
\end{tabular}




\begin{tabular}{|c|c|}
\hline Scenario & Description \\
\hline Scenario 9 & $100 \%$ Multi-Scale \\
\hline Scenario 10 & $100 \%$ development without any pond \\
\hline Scenario 11 & $100 \%$ development without LID \\
\hline Scenario 12 & $100 \%$ development without any BMP \\
\hline
\end{tabular}

\subsubsection{Future developments}

The total area of the approved future development is about 480ha within the Ganatsekiagon subwatershed. The performance of the developed MSM will be evaluated by creating the expected future development scenarios. These development scenarios were created assuming that all the future developments will be same as the developed area of DH. So, the developed area of DH was used as a dice to create future expected development scenarios. Four levels of future developments were assumed and for each level of development CSM and MSM was developed. The details of the scenario assumptions are presented below.

\subsubsection{25\% of Future Development}

This scenario has been created, considering that $25 \%$ of the approved future development has been implemented in the sub-watershed area, and the developments have the same features as the DH. The area of the DH is about 20 ha so for $25 \%$ of the future development 6 new developed area has 
been installed in the model in the location of the approved future developments (Figure 20). These further developed areas have the same LID and Pond as the DH area, in the model. Both the CSM and MSM has been created considering this scenario to compare the result with the predevelopment condition.

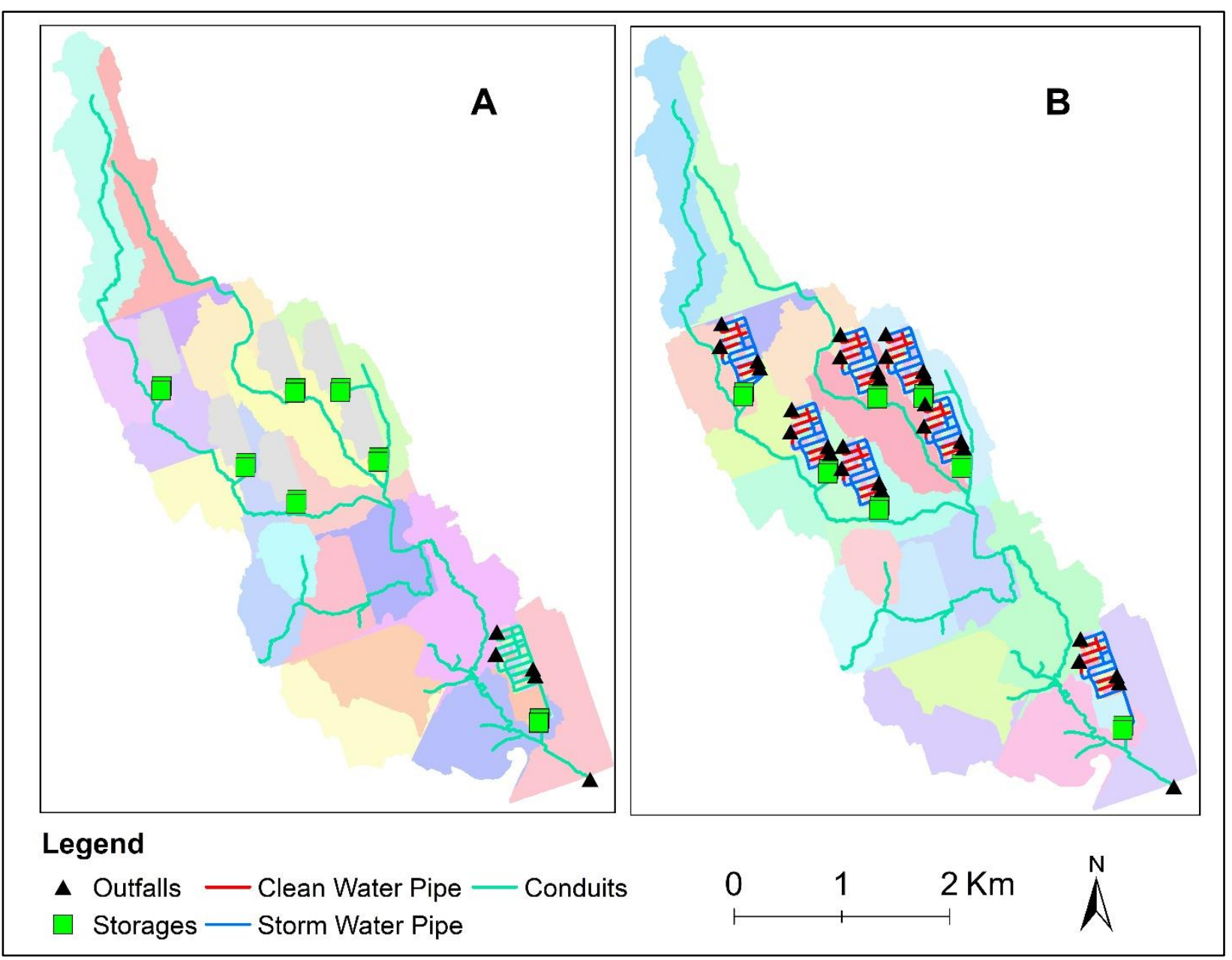

Figure 20: Models of the 25\% of Future Development Scenario A) Coarse and B) Multi Scale 


\subsubsection{2 $\mathbf{5 0 \%}$ of Future Developments}

In this scenario, 12 new developed areas were set up, to represent $50 \%$ implementation of future developments. All these new developments have the same LID and SWM pond at the end of the pipe to manage the increased overland flow due to the increased developments. All the new development was setup similar to the DH development and placed on the same locations of the proposed future developments. Figure 21, is showing the maps of the CSM and MSM of the 50\% of future development scenario.

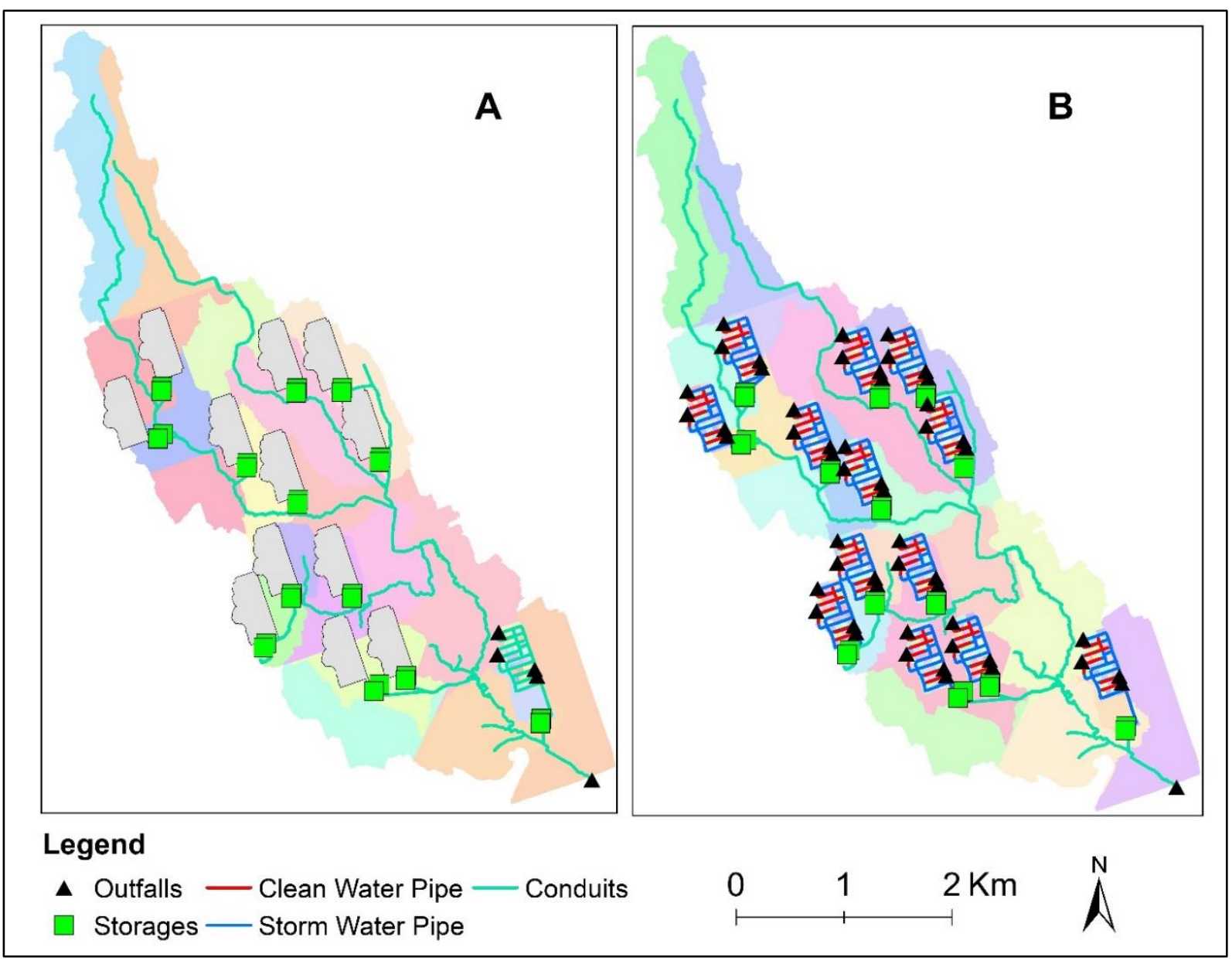

Figure 21: Models of the 50\% of Future Development Scenario A) Coarse and B) Multi Scale 


\subsubsection{3 $80 \%$ of Future Developments}

This scenario consists of 19 developed area in the sub-watershed model to replicate $80 \%$ of the future expected developments. In some cases, the developed area was outside of the previously defined sub-watershed because, after development, those areas were discharging the runoff into the Ganatsekiagon creek. The CSM and the MSM of this $80 \%$ of future development scenario are presented in Figure 22.

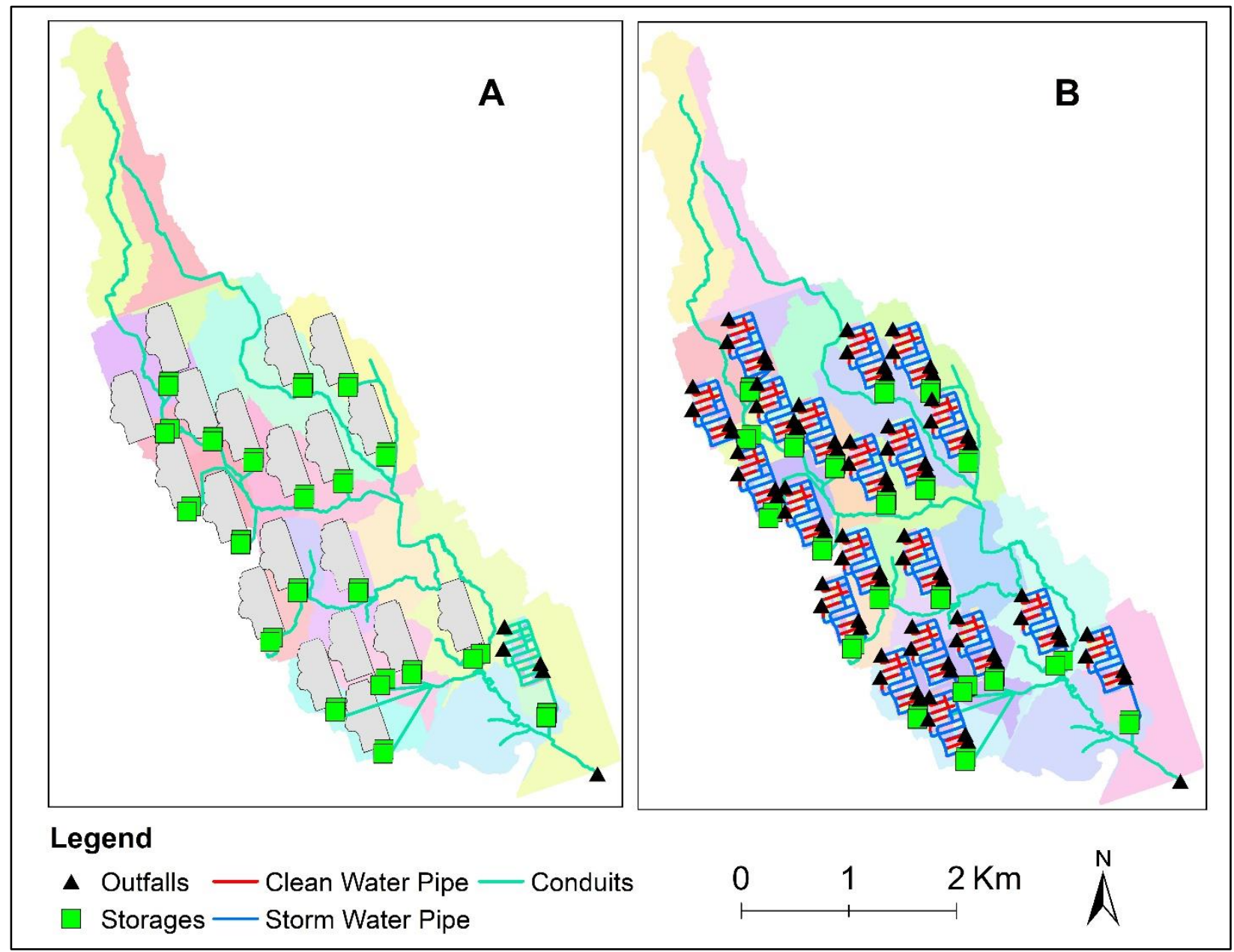

Figure 22: Models of the $80 \%$ of Future Development Scenario A) Coarse and B) Multi Scale 


\subsubsection{4 $\mathbf{1 0 0 \%}$ of Future Developments}

In this scenario, 24 new developments were set up on the same place of the approved development projects, to simulate the $100 \%$ of future development scenario. All of the new developments have the same BMPs as the DH. Figure 23, presents in the CSM and MSM of the $100 \%$ of the future development scenario.

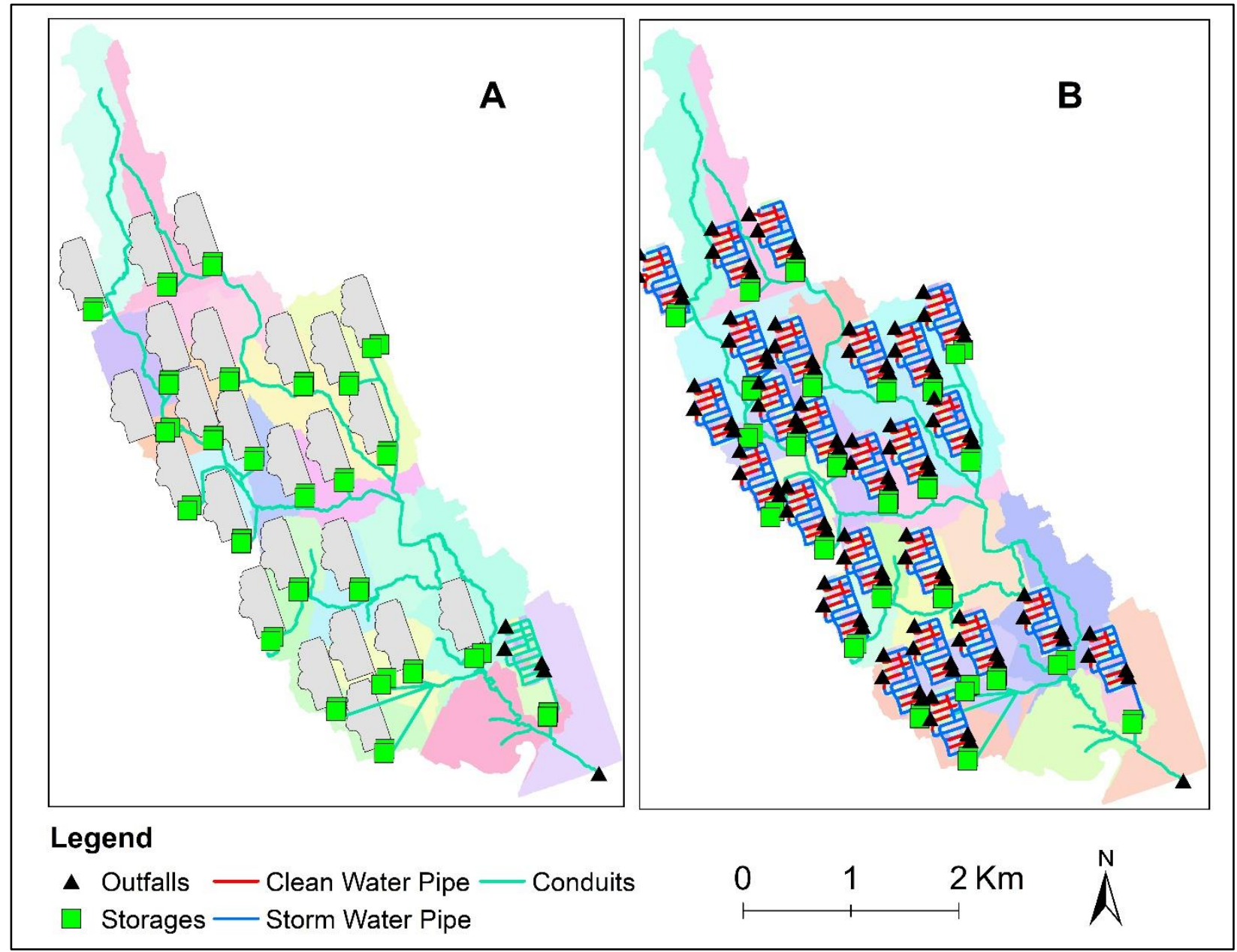

Figure 23: Models of the $100 \%$ of Future Development Scenario A) Coarse and B) Multi Scale 


\subsubsection{Best Management Practices}

As the previous studies indicated that different BMPs have a different effect on changing the FV and PFR associated with the development. Some scenarios were also developed to understand the specific effect of the LID and the SWM pond on the PFR and the FV of the model results. The developed scenarios are presented below.

\subsubsection{Future Development Without LID}

A scenario has been created to see the effects of the developments without LIDs. In this scenario, the $100 \%$ future development was replicated without any LID features. All the stormwater runoff and clean-water were collected by the stormwater pipes and discharged into the SWM ponds of the developed areas. The SWM ponds eventually discharge the runoff into the Creek with a delay, to reduce the peak flow. The difference in the with and without LID is presented in Figure 24. 


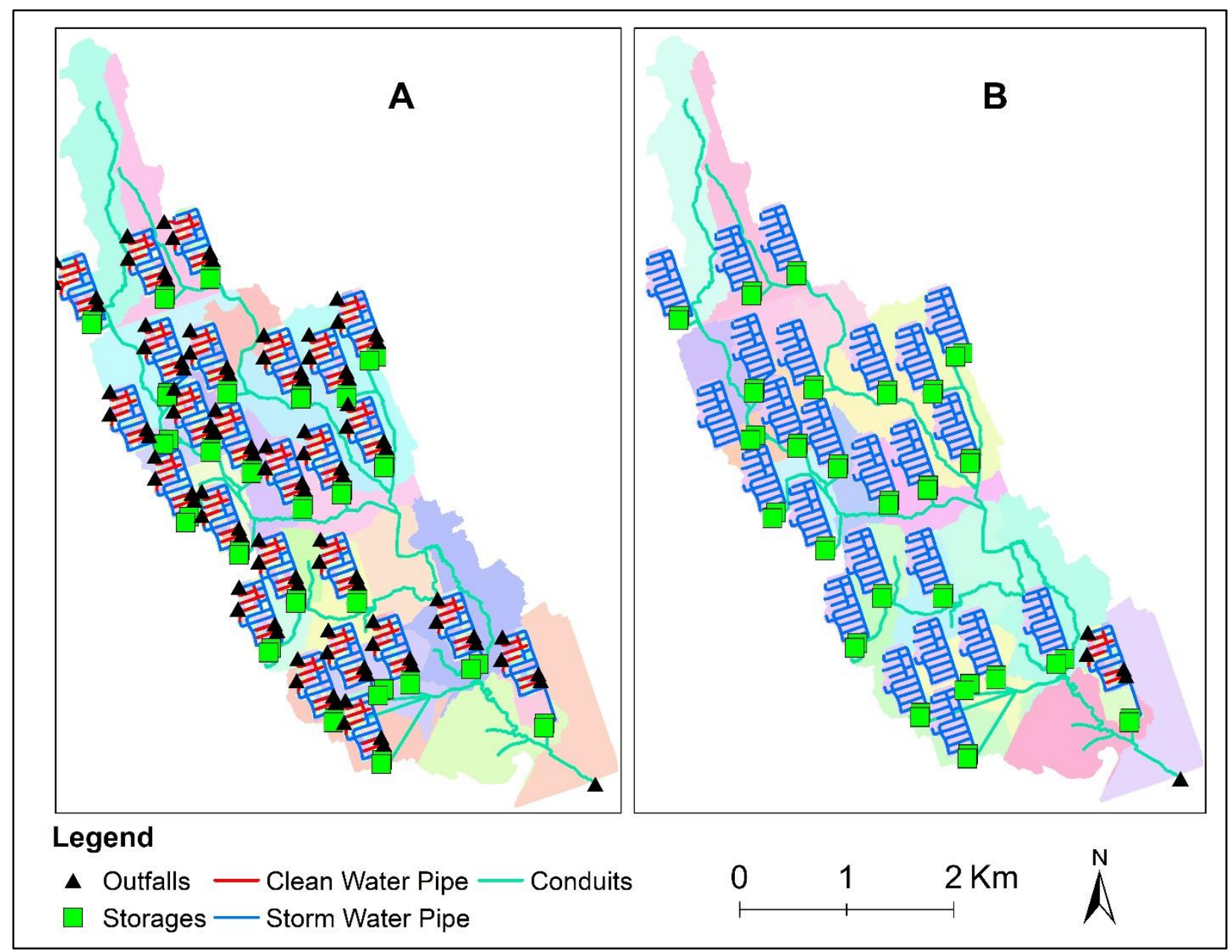

Figure 24: Multi Scale Model of The $100 \%$ of Future Development A) with and B) without LID Scenarios

\subsubsection{Future Development Without SWM Ponds}

In this scenario, $100 \%$ of the future developments have been set up without any SWM ponds. The clean water of the developed area is collected by the clean water pipes and discharged into the LIDs, and the stormwater runoff has been collected by the stormwater pipes and directly discharged into the creek. Figure 25, is presenting the difference in the with and without pond scenario. 


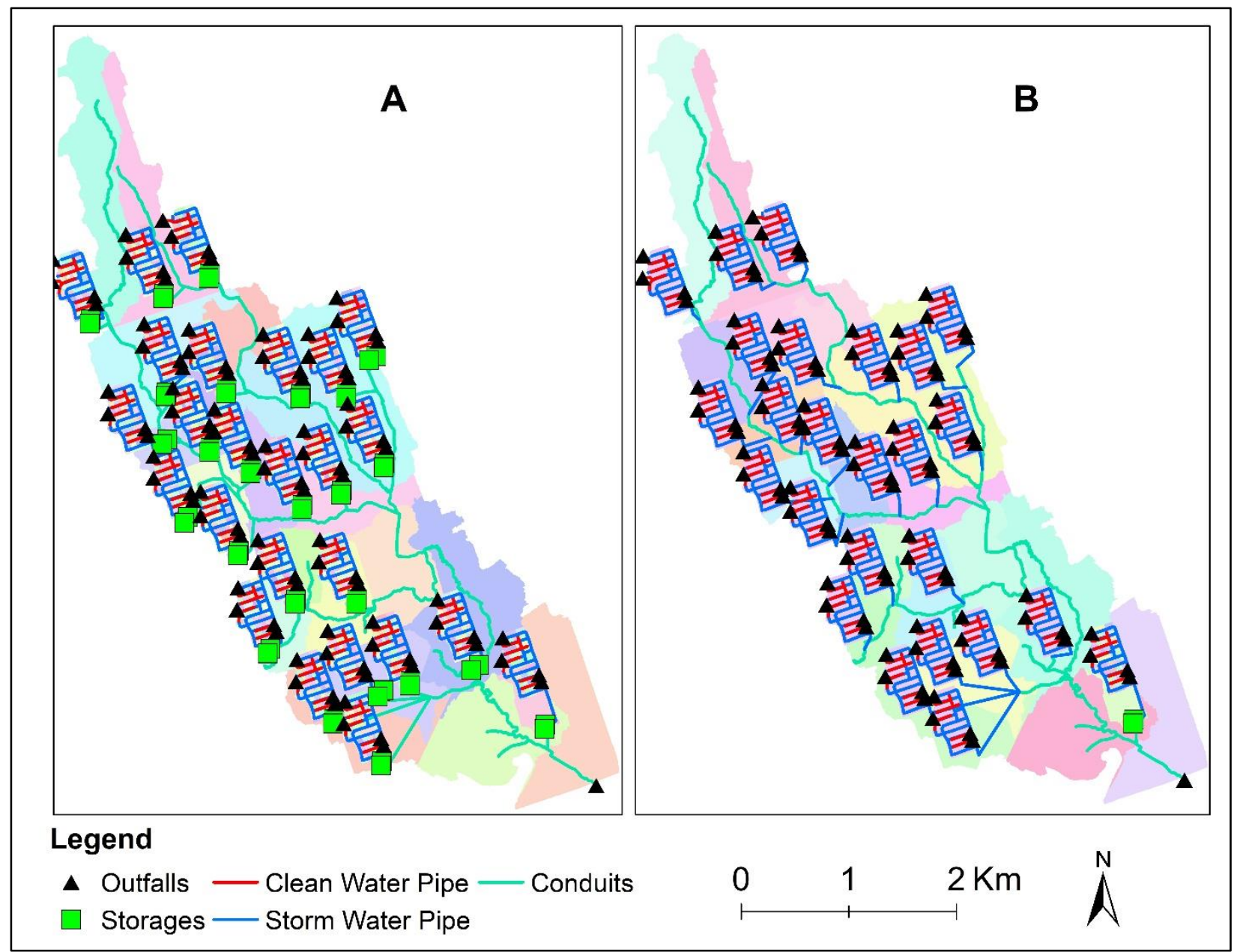

Figure 25: Multi Scale Model of the $100 \%$ of Future Development A) With and B) Without SWM Pond Scenarios

\subsubsection{Future Development Without Any BMPs}

This scenario has been created to understand the effects of BMPs in the developed area. In this scenario, no LID nor SWM pond was setup. All the stormwater and clean water has been collected by the Stormwater pipes and directly discharged into the Creek. Figure 26 presents the difference between the model of with and without BMPs scenario. 


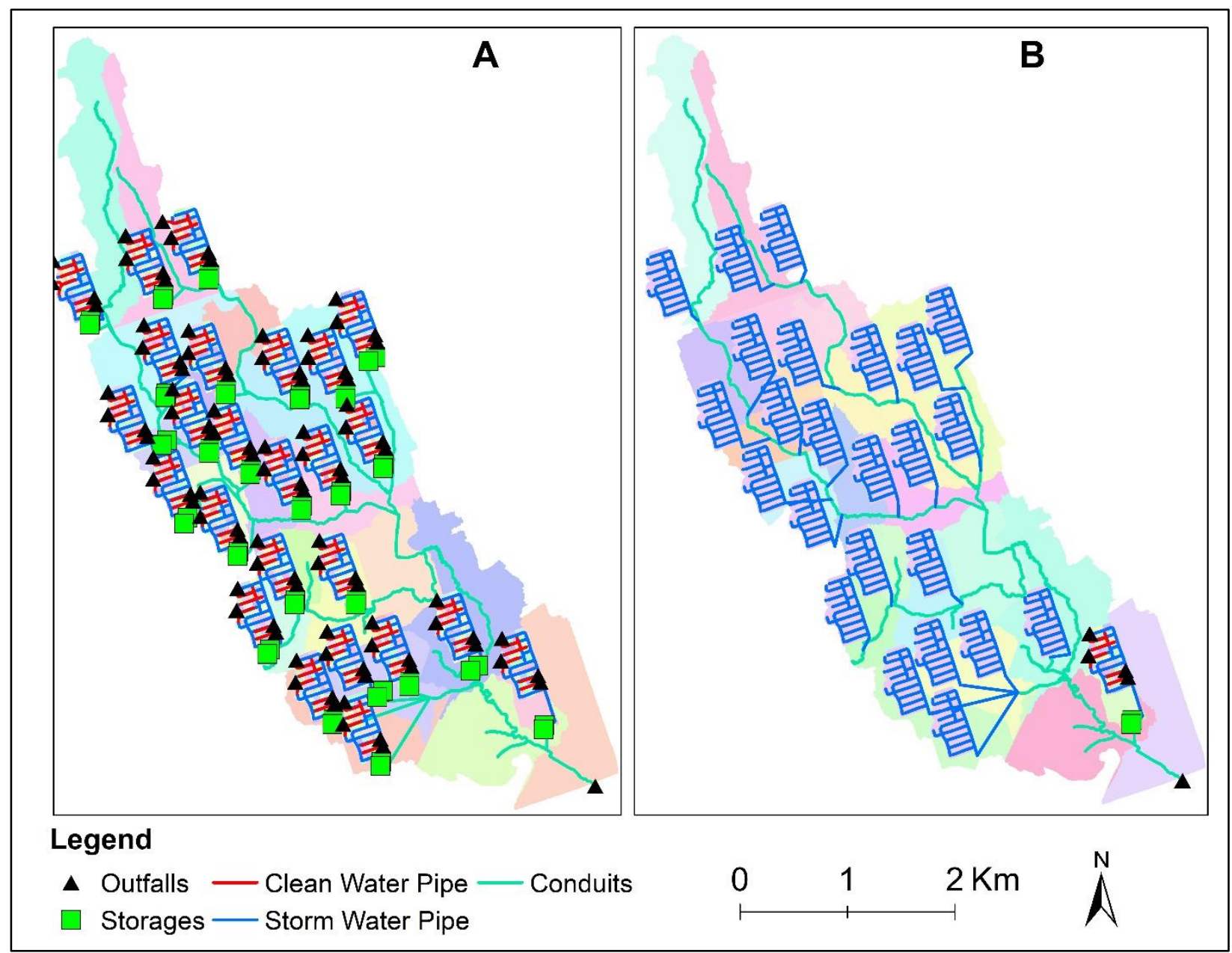

Figure 26: Multi Scale Model of the $100 \%$ of Future Development A) With and B) Without BMPs Scenarios 


\section{Results and Discussions}

This chapter presents the performance of the developed CSM, FSM and the MSM. The results of the developed model are first presented, and the model results are compared with the predevelopment condition as well as the observed data to show the performance of the models. Then the results of the expected future development scenarios and the scenarios with and without BMPs are presented to show the effect of development on the downstream part of the watershed and the rationale of using the MSM instead of CSM.

\subsection{Calibrated Pre-development Model's Performance}

The performances of the finally chosen calibrated pre-development model for all the selected events presented in Table 3 were analyzed. The hydrographs of the performance of the model from the events are presented in Figure 27. The shape of the hydrographs of the simulation shows a good match to the observed streamflow hydrographs. though the peak and the volume do not match accurately but considering the limitation of rainfall data availability in the watershed and the problem of beaver dams, the simulation results can be considered acceptable. 


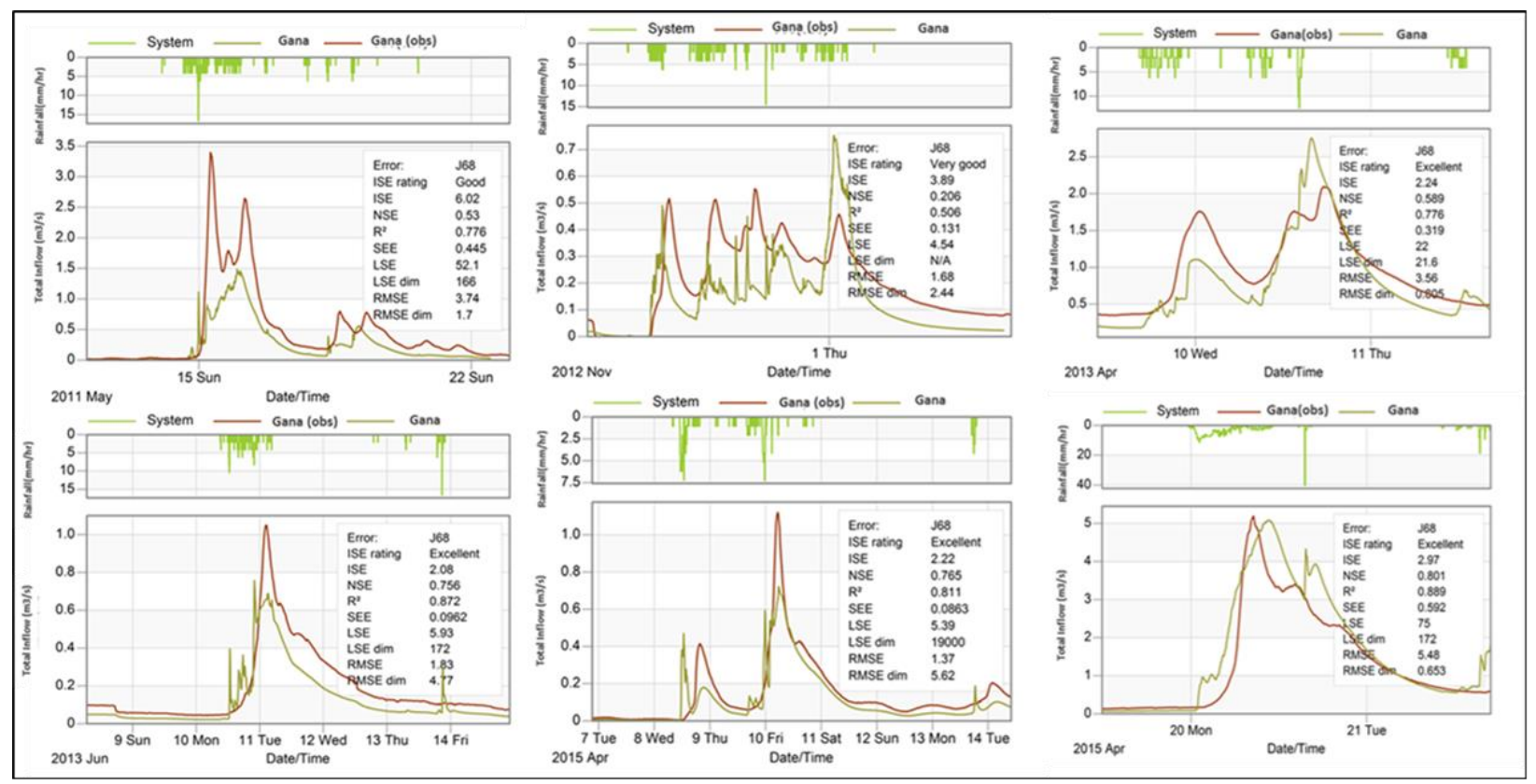

Figure 27: Performance of the Calibrated Ganatsekiagon Creek Sub-watershed Model in All the Selected Events

\subsection{Calibrated Post-development CSM's Performance}

The performance of post-development models was evaluated, for the selected events of 2017. By analyzing the rainfall and observed streamflow, some events were chosen to evaluate the performance of the post-development models. The results of the performance evaluation are presented in Figure 28. Like the pre-development model, the results of this performance evaluation of the post-development CSM is also showing that the simulated hydrograph is matching the shape of the observed hydrograph. 


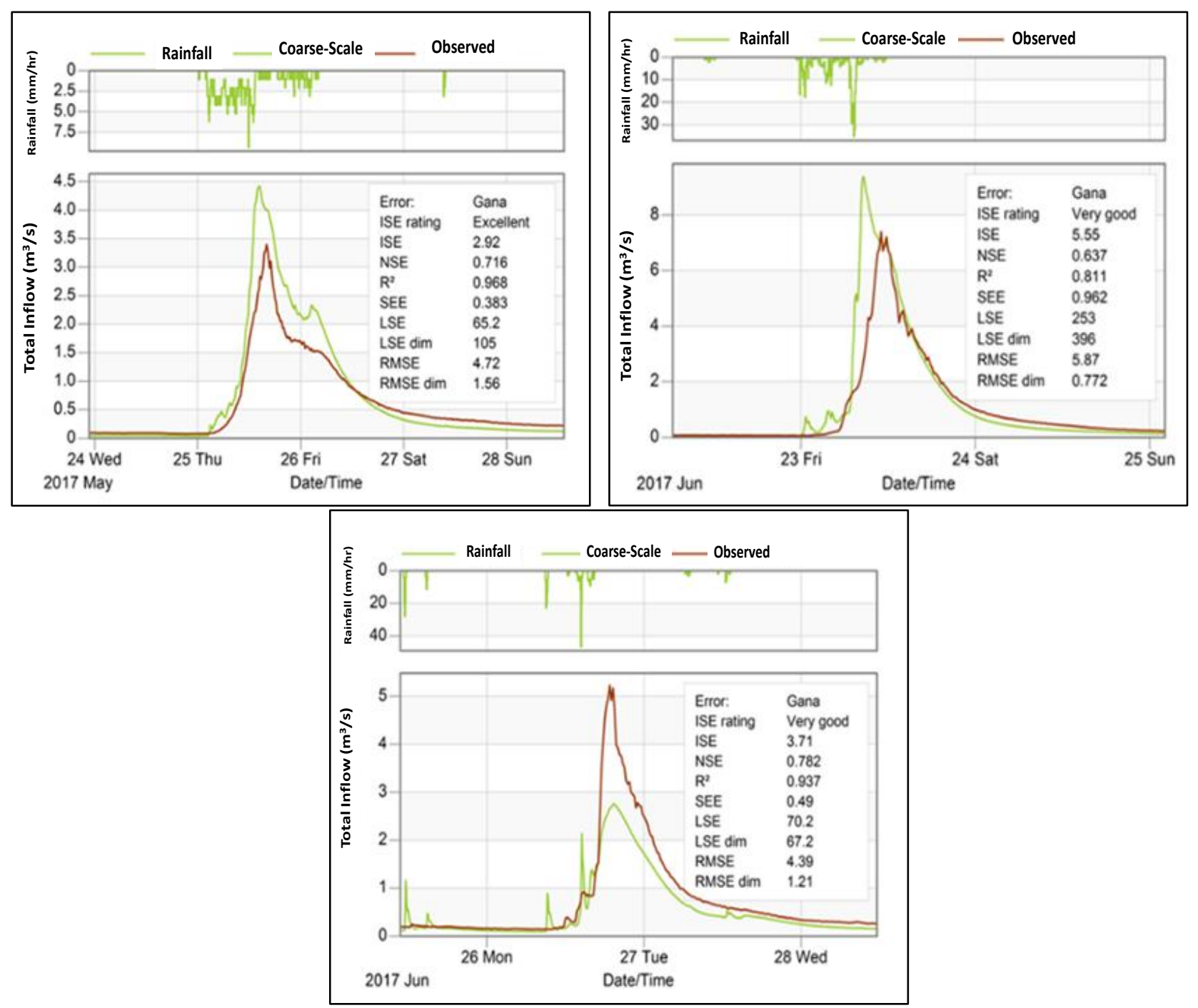

Figure 28: Performance Evaluation of the Ganatsekiagon Creek Sub-watersheds Postdevelopment Model

\subsection{Comparison of Coarse-scale Pre and Post-development Models}

The performance of pre and post-development models were compared for the previously selected pre-development events for calibration (Table 3) and post-development events. The results of the comparisons are presented in Table 7. The results indicate a slight increase in FV at the creek and minimal changes in PFR with the current level of development with BMPs in place. 
Table 7: Comparison of Pre- development and CSM Ganatsekiagon Creek Sub-watershed Models

\begin{tabular}{|c|c|c|c|}
\hline Parameter & Pre-Dev & CSM & $\begin{array}{c}\text { Difference in Results } \\
(\%)\end{array}$ \\
\hline \multicolumn{4}{|c|}{ Event of May13, 2011} \\
\hline $\mathrm{PFR}\left(\mathrm{m}^{3} / \mathrm{s}\right)$ & 1.4 & 1.4 & 1.45 \\
\hline $\mathrm{FV}\left(\mathrm{m}^{3}\right)$ & 200,400 & 203,400 & 1.50 \\
\hline \multicolumn{4}{|c|}{ Event of Oct. 27, 2012} \\
\hline PFR $\left(\mathrm{m}^{3} / \mathrm{s}\right)$ & 0.7 & 0.8 & 9.42 \\
\hline $\mathrm{FV}\left(\mathrm{m}^{3}\right)$ & 114,100 & 158,100 & 38.56 \\
\hline \multicolumn{4}{|c|}{ Event of April 09, 2013} \\
\hline $\operatorname{PFR}\left(\mathrm{m}^{3} / \mathrm{s}\right)$ & 2.7 & 2.7 & 1.14 \\
\hline $\mathrm{FV}\left(\mathrm{m}^{3}\right)$ & 148,800 & 164,700 & 10.69 \\
\hline \multicolumn{4}{|c|}{ Event of June 08, 2013} \\
\hline $\operatorname{PFR}\left(\mathrm{m}^{3} / \mathrm{s}\right)$ & 0.7 & 0.8 & 15.50 \\
\hline $\mathrm{FV}\left(\mathrm{m}^{3}\right)$ & 78,750 & 89,830 & 14.07 \\
\hline \multicolumn{4}{|c|}{ Event of April 7, 2015} \\
\hline PFR $\left(\mathrm{m}^{3} / \mathrm{s}\right)$ & 2.9 & 3.0 & 3.74 \\
\hline $\mathrm{FV}\left(\mathrm{m}^{3}\right)$ & 212,500 & 225,000 & 5.88 \\
\hline \multicolumn{4}{|c|}{ Event of April 19, 2015} \\
\hline $\operatorname{PFR}\left(\mathrm{m}^{3} / \mathrm{s}\right)$ & 4.9 & 4.9 & -0.63 \\
\hline $\mathrm{FV}\left(\mathrm{m}^{3}\right)$ & 292,200 & 291,600 & -0.21 \\
\hline \multicolumn{4}{|c|}{ Post-development Events: 2017} \\
\hline \multicolumn{4}{|c|}{ Event of May 24, 2017} \\
\hline & Pre-Dev & Post-Dev & \\
\hline $\operatorname{PFR}\left(\mathrm{m}^{3} / \mathrm{s}\right)$ & 4.3 & 4.3 & -0.18 \\
\hline $\mathrm{FV}\left(\mathrm{m}^{3}\right)$ & 258,500 & 267,500 & 3.48 \\
\hline \multicolumn{4}{|c|}{ Event of June 25, 2017} \\
\hline PFR $\left(\mathrm{m}^{3} / \mathrm{s}\right)$ & 2.8 & 2.8 & -0.14 \\
\hline $\mathrm{FV}\left(\mathrm{m}^{3}\right)$ & 117,700 & 118,800 & 0.93 \\
\hline \multicolumn{4}{|c|}{ Event of June 22, 2017} \\
\hline $\operatorname{PFR}\left(\mathrm{m}^{3} / \mathrm{s}\right)$ & 9.1 & 9.0 & -0.98 \\
\hline $\mathrm{FV}\left(\mathrm{m}^{3}\right)$ & 271,100 & 271,700 & 0.22 \\
\hline
\end{tabular}




\subsection{Comparison of CSM and FSM for Developed Area}

The FSM was compared with the post-development CSM using the rainfall events presented in Table 4. The results of this comparison show that the CSM is under-predicting both PFR and the FV (Figure 29). The results of the Comparison of CSM and FSM clearly show that FSMs are producing better results.

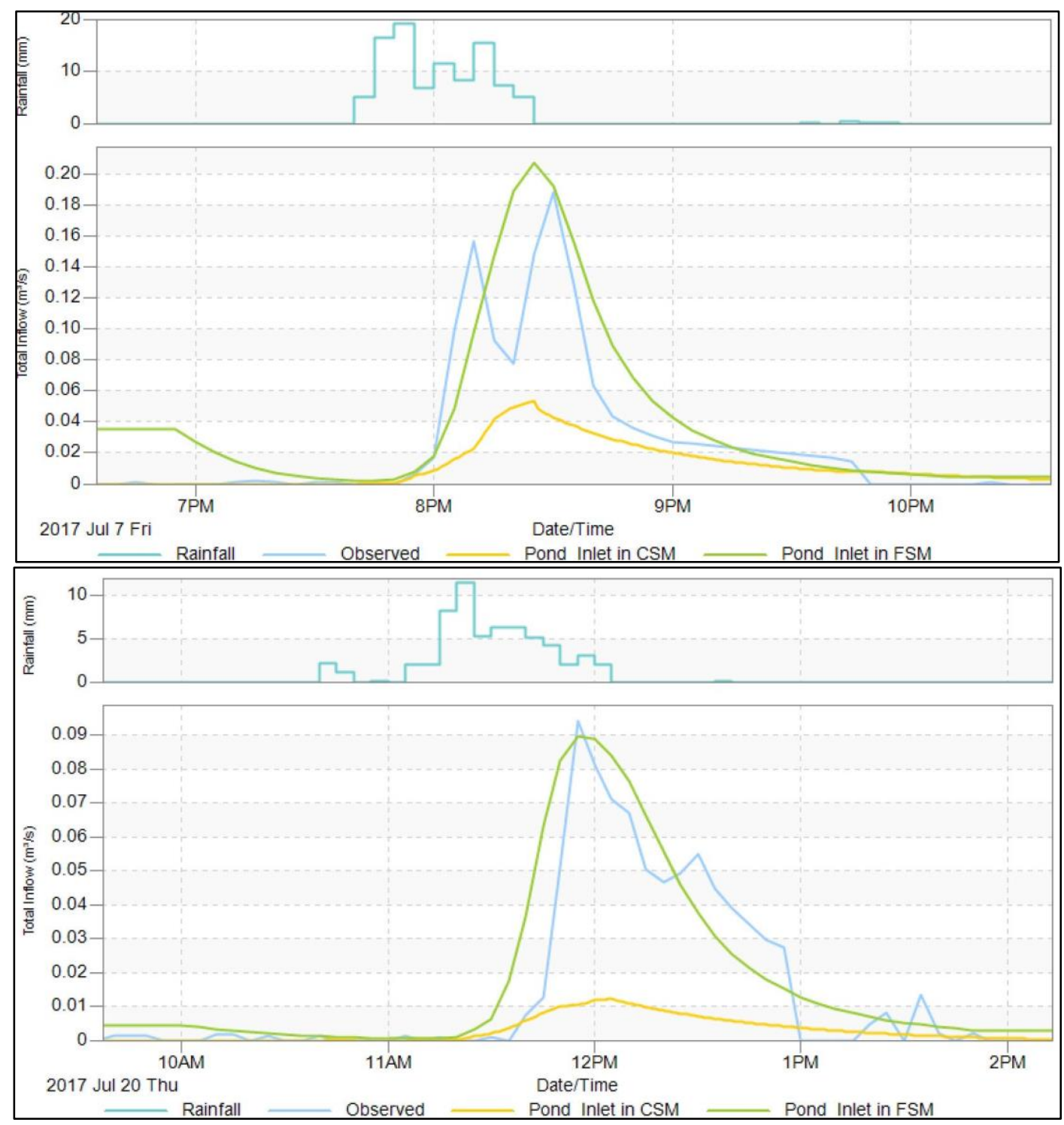

Figure 29: Comparison of Coarse-scale and Fine-scale Post-development Model of Duffin Heights area 


\subsection{Evaluation based on observed data}

In this section, the results of the comparison of the FSM and CSM has been shown with the performance evaluation at the pond inlet. At the pond inlet, the results of FSM and MSM is the same because the pond receives the runoff of the developed area only, and in FSM and MSM the developed area is the same. The performance of MSM and CSM were compared at the outfall point of the sub-watershed separately. In this section, the comparison of the modelled results and the observed data is presented to show the difference in the simulated results of the same area with different scales.

\subsubsection{Comparison at Pond Inlet}

The performance of the FSM was compared to CSM at the pond inlet. The location of the pond inlet is shown in Figure 18. Figure 30 \& Figure 31 are presenting the comparison of PFR, and the FV resulted from the simulation of CSM and FSM. For this analysis, the same events were used as listed in Table 4. In all the events, the CSM is under predicting the PFR. Though none of the FSM or CSM are showing an accurate match to the observed flow data of the pond inlet, the FSM is showing better match in terms of PFR. For example, for the event 2 and 3, the observed PFR is matched well by the FSM results. The FVs of those events are also showing similar results. However, PFR and FV determined by the CSM show lower magnitude compared to the observed data. 


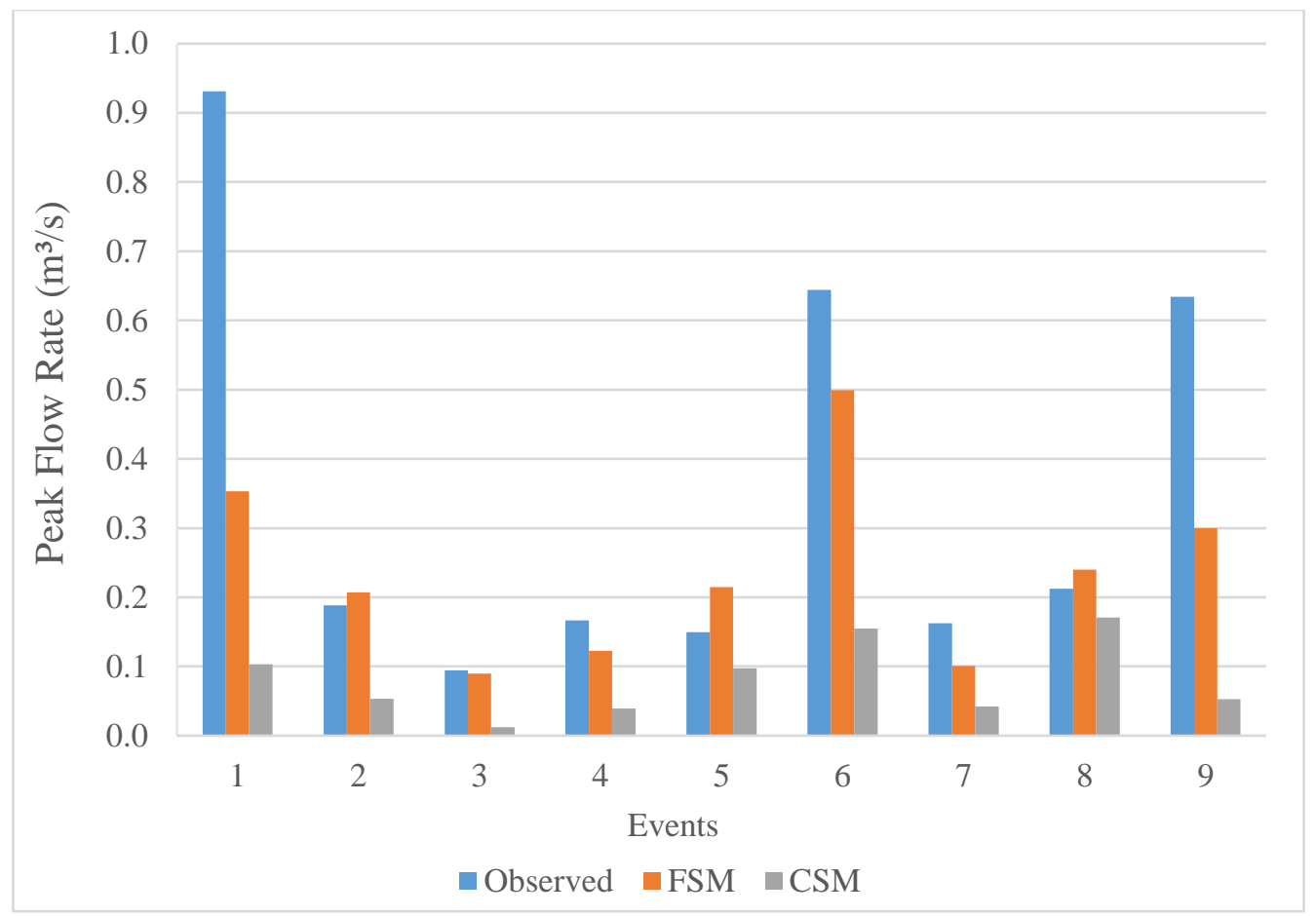

Figure 30: Comparison of Modelled Peak Flow Rate at Duffin Heights SWM Pond Inlet

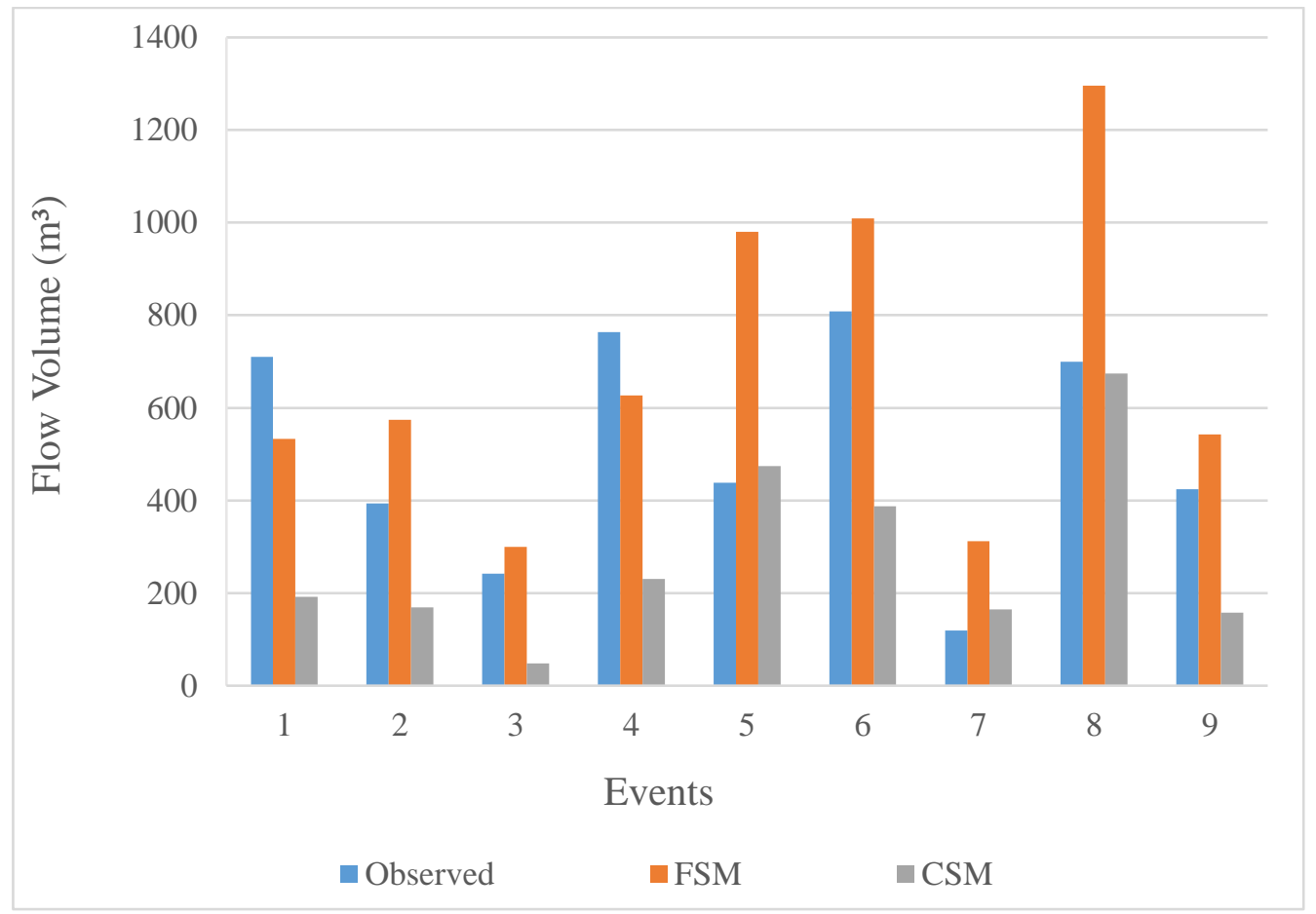

Figure 31: Comparison of Modelled Flow Volume at Duffin Heights SWM Pond Inlet 


\subsubsection{Comparison at Watershed Outfall}

The performance of MSM was evaluated at the outfall point of the watershed, by comparing the results of MSM with the pre-development Model and the CSM. Analyzing the Creek discharge monitoring data, some meaningful events were selected for the comparison of the FV and the PFR, from the MSM and CSM, with the monitored data. The selected events are presented in Table 8.

Table 8: Selected Post Development Events (2017) for The Ganatsekiagon Creek Subwatershed

\begin{tabular}{|c|c|c|c|c|c|c|}
\hline Event & Date & $\begin{array}{c}\text { Duration } \\
(\mathbf{h})\end{array}$ & $\begin{array}{c}\text { Maximum } \\
\text { Rainfall } \\
(\mathbf{m m} / \mathbf{h r})\end{array}$ & $\begin{array}{c}\text { Total } \\
\text { Rainfall } \\
(\mathbf{m m})\end{array}$ & $\begin{array}{c}\text { Peak Flow } \\
\text { Rate (m } \mathbf{3} \mathbf{s})\end{array}$ & $\begin{array}{c}\text { Flow } \\
\text { Volume } \\
\left(\mathbf{m}^{\mathbf{3}}\right)\end{array}$ \\
\hline 1 & $\begin{array}{c}5 / 24 / 2017 \\
7: 55: 00 \mathrm{AM}\end{array}$ & 92.2 & 9.3 & 44 & 3.4 & 238,200 \\
\hline 2 & $\begin{array}{c}6 / 22 / 2017 \\
4: 50: 00 \mathrm{PM}\end{array}$ & 132.7 & 46.5 & 78 & 7.4 & 458,900 \\
\hline 3 & $\begin{array}{c}7 / 6 / 2017 \\
12: 20: 00 \mathrm{PM}\end{array}$ & 60.5 & 19.0 & 8 & 4.6 & 80,600 \\
\hline 4 & $\begin{array}{c}7 / 11 / 2017 \\
8: 20: 00 \mathrm{PM}\end{array}$ & 209.6 & 34.1 & 43 & 7.4 & 304,800 \\
\hline
\end{tabular}

The analysis of the models of Ganatsekiagon Creek Sub-watershed shows that for the selected events, the hydrographs of the Pre-dev. Model, the CSM and the MSM are almost the same (Figure 32). So, maybe the development of the Duffin heights does not have any adverse effect on the subwatersheds system. However, it should be noted that the developed area is less than $2 \%$ of the whole watershed area. So, this it is the effect of less than $2 \%$ of land-use change may not be 
significant enough to be captured by any model. And the change of that small area may result in a negligible effect on the creek flow to be seen in a hydrograph.

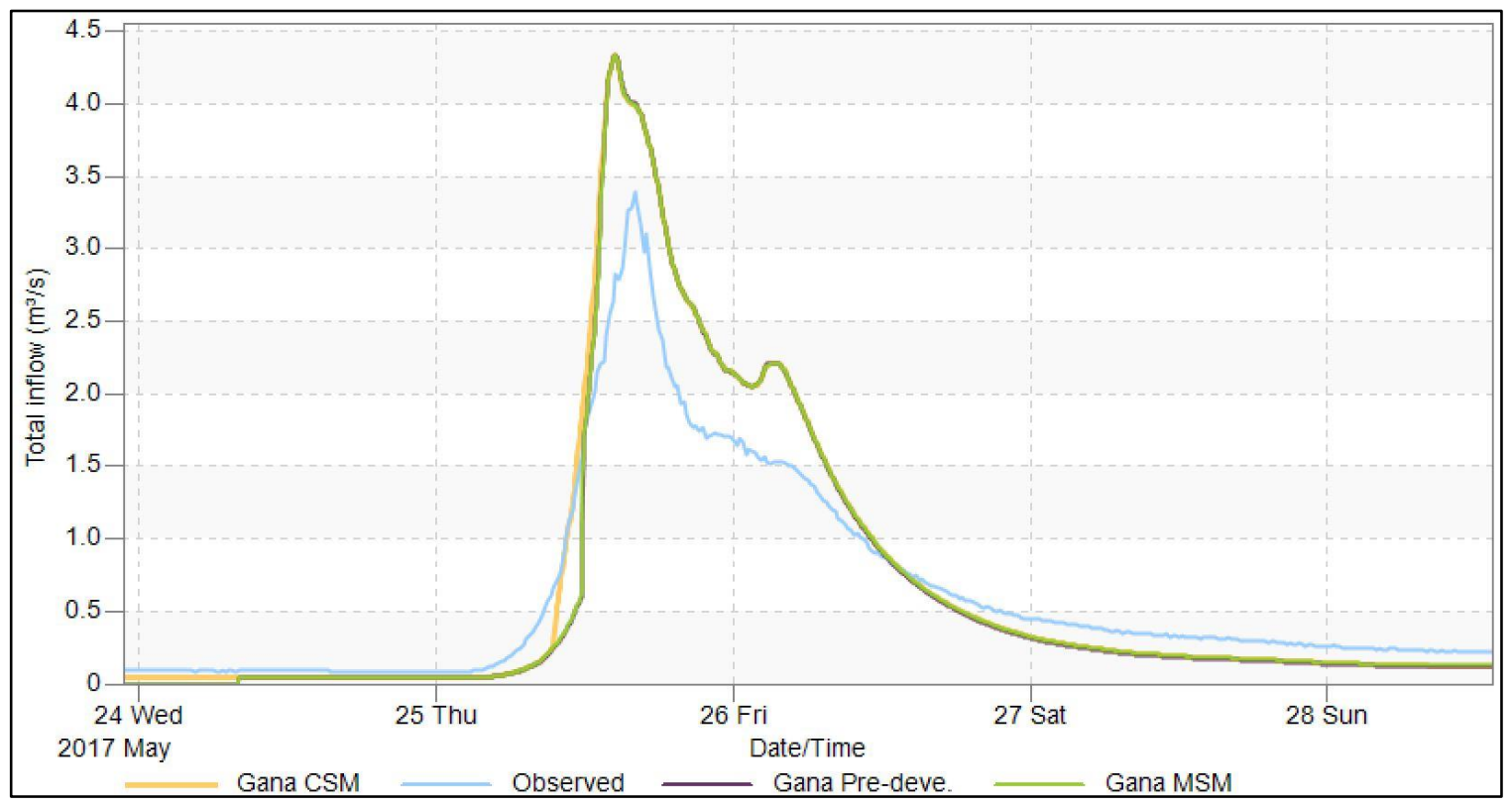

Figure 32: Event Comparison Results of Pre-development Model, CSM, and MSM of the Post-Development scenario of Ganateskiagon Creek Watershed

The comparison of the PFR of the models shows that the change between the predevelopment, coarse-scale and Multi-scale post-development are very negligible (Table 9), since, the developed area is less than $2 \%$ of the entire sub-watersheds area, the insignificant change in peak discharge rate is logical. The results also show an increase in the total flow volume from the pre-development scenario to the Post development models for Ganateskiagon creek models (Table 10), and MSM is showing higher total inflow than the CSM. 
Table 9: Comparison of Peak Flow Rate from The Models at The Ganatsekiagon Creek

\begin{tabular}{|c|c|c|c|c|}
\hline Events & Observed & Pre-Dev. Model & CSM & MSM \\
\hline 1 & 3.398 & 4.345 & 4.339 & 4.341 \\
\hline 2 & 7.403 & 9.098 & 9.024 & 9.041 \\
\hline 3 & 4.590 & 1.335 & 1.345 & 1.348 \\
\hline 4 & 7.389 & 2.854 & 2.856 & 2.865 \\
\hline
\end{tabular}

Table 10: Comparison of Total Flow Volume from the Models at the Ganatsekiagon Creek

\begin{tabular}{|c|c|c|c|c|}
\hline Event & Observed & Pre-Dev. Model & CSM & MSM \\
\hline $\mathbf{1}$ & 248,800 & 262,900 & 265,200 & 265,600 \\
\hline $\mathbf{2}$ & 474,100 & 413,600 & 420,700 & 422,200 \\
\hline $\mathbf{3}$ & 84,730 & 46,070 & 48,890 & 49,360 \\
\hline $\mathbf{4}$ & 318,900 & 169,400 & 172,200 & 176,800 \\
\hline
\end{tabular}

The results of the comparison of the predevelopment model, CSM and MSM are showing an increasing trend of the FV. However, as mentioned above, the development was less than $2 \%$ of the total sub-watershed area, which causes only a little increase in the FV. These results indicate that extensive land development may result in a more distinct change in the model results. 


\subsection{Results of the Future Development Scenarios}

The of the FV and the PFR resulted from the simulation of the future development scenarios was compared, to understand the effect of the development levels on the sub-watershed system with both coarse-scale and the Multi-scale model. For these scenarios' simulation, some AES design storm was used. The details of the events are presented in Table 11.

Table 11: List of the Selected Design Storms for the Simulations

\begin{tabular}{|c|c|c|c|}
\hline Events & $\begin{array}{c}\text { Rainfall Duration } \\
(\mathbf{h r})\end{array}$ & $\begin{array}{c}\text { Return Period } \\
(\mathbf{y r})\end{array}$ & $\begin{array}{c}\text { Rainfall Depth } \\
(\mathbf{m m})\end{array}$ \\
\hline $\mathbf{1}$ & 1 & 2 & 23.8 \\
\hline $\mathbf{2}$ & 12 & 2 & 41.1 \\
\hline $\mathbf{3}$ & 1 & 5 & 32.6 \\
\hline $\mathbf{4}$ & 12 & 5 & 53.2 \\
\hline $\mathbf{5}$ & 1 & 10 & 38.5 \\
\hline $\mathbf{6}$ & 12 & 10 & 61.3 \\
\hline
\end{tabular}

\subsubsection{Peak Flow Rate (PFR)}

The comparison of the PFR is presented in Figure 33, which shows that for the short duration events (Event 1,3,5), the CSMs are showing a lower PFR than the pre-development scenario, but the MSMs are showing a slight increase in the PFR. This is because for the events of the lowduration period have less amount of rainfall and in pre-development scenario, the infiltration 
capacity was sufficient to convert most of the water from rainfall into infiltration. But with increased development, the infiltration capacity decreased, and in the MSMs the CN was assigned according to the land use of well discretize subcatchments, so the infiltration capacity of MSMs was less than the grossly parameterized CSMs. For example, the pre-development scenario of event 1 converts $91 \%$ of the rainfall into infiltration whereas the CSM and MSM with $80 \%$ development are converting only $83 \%$ and $75 \%$ of rainwater into infiltration respectively because of the changed infiltration capacity. With the decreased infiltration, stormwater runoff increased and as the MSM has more defined flow paths as pipes which conveys the water faster with higher PFR. The results also show that the $100 \%$ future development models are showing considerably higher PFR because, with the $100 \%$ future development, it is assumed that some area from neighbouring watersheds will be developed in such a way that those will discharge into the channels of Ganatsekiagon watershed, which is increasing the PFR. 

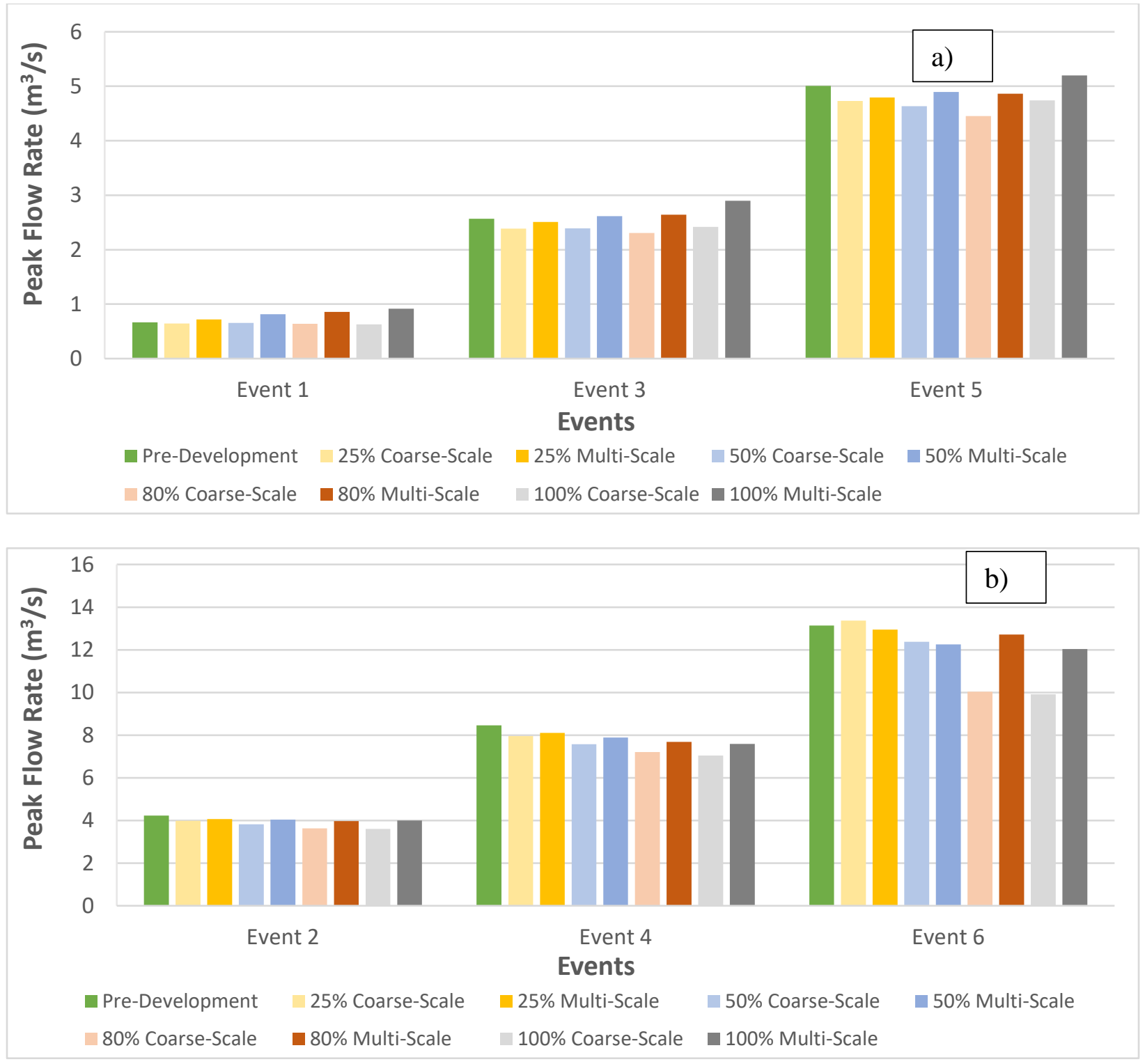

Figure 33: Comparison of Maximum Flow Rate in the Future Development Scenarios with a) Short Duration b) Long Duration Events

On the other hand, all the long duration events (Event 2,4, and 6) are showing a lower PFR than the pre-development scenario, in both the CSMs and MSMs. Because the long duration events generate significantly higher rainfall in comparison to the infiltration capacity of the predevelopment scenario. So, in pre-development scenario, the long duration events cause a higher PFR. But with the developments, though the infiltration capacity decreased, the developments also 
incorporate LID and SWMFs which was able to reduce the PFR in comparison to the predevelopment scenario and with a higher rate of development the PFR reduction increases. In the event 6, which has the highest amount of rainfall over a longer time, shows very less PFR in the CSMs of the $80 \%$ and $100 \%$ development scenario. This lower PFR are representing the longer time of concentration. As CSMs does not have defined flow paths like stormwater pipes, the time of concentration was too long in the CSMs with a higher level of developments. Though the PFR with $100 \%$ future development is showing about $1 \mathrm{~m}^{3} / \mathrm{s}$ PFR reduction from the predevelopment condition in Event 6, which indicates the BMPs are very effective in PFR reduction for large events.

As the CSMs and the MSMs are showing a considerable difference in the PFR. So, the PFR with CSM and MSM has been compared at 7 points of the conveyance system (Figure 34) with $80 \%$ of the expected future development to understand the propagation of the PFR in the models. 


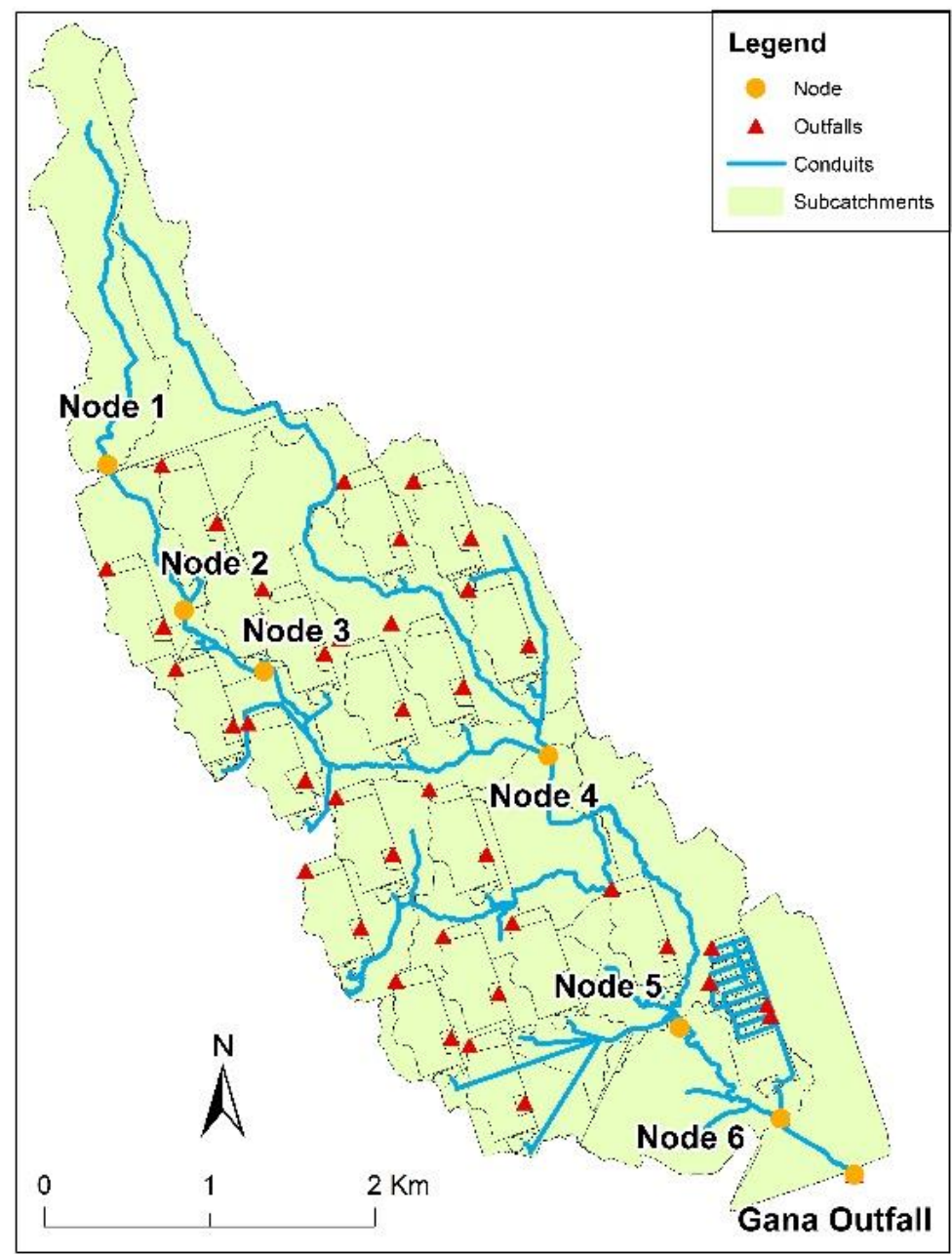

\section{Figure 34: Map Showing of the Nodes to Compare the Peak Flow Rate Propagation}

The comparison of the PFR propagation shows that with development, the CSM is not showing any significant difference from the pre-development scenario (Figure 35). However, with MSM, as the $\mathrm{CN}$ was assigned according to the specific land use of the finely discretized subcatchments of the developed area, the PFR was significantly higher at every point of the conveyance system except the Node 1. MSM and CSM do not show any change from the pre-development scenario at Node 1 because there was no development introduced at the upstream of Node 1. This results also shows that, in MSM the peak flow occurs sooner than the CSM and the pre-development scenario. 
Additionally, these results indicate the catchments response time to the precipitation is quite short in this sub-watershed as the results do not show any delayed peak at the outfall. With a different shape of the subcatchment, the response time may change with the same sub-watershed characteristics.

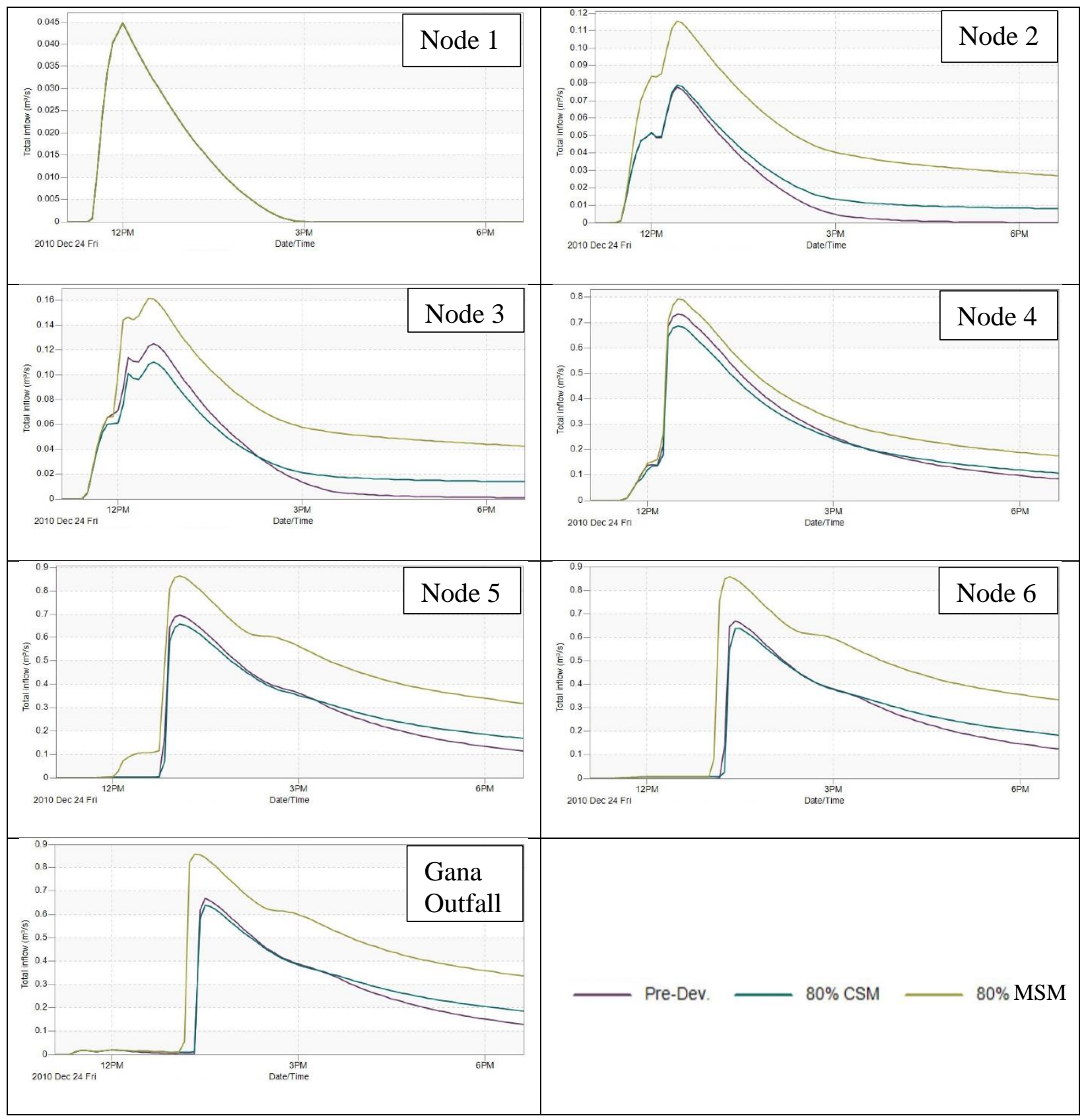

Figure 35: Comparison of the Peak Flow Rate Propagation from the CSM and MSM with 80\% Future Development 


\subsubsection{Flow Volume (FV)}

The comparison of the FV shows that with a higher percentage of developments, the FV is increasing (Figure 36). For all the events, all the development scenarios are generating more runoff than the pre-development scenario, and the $100 \%$ future development is showing the highest FV as expected. This comparison of the FV also shows that the CSMs are always showing lower FV than the MSMs. The difference between the CSM and MSM is more prominent in the smaller events. The reason behind this difference is that the MSM has more detailed parameters, and it routs the stormwater through the defined channels. The results indicate that the LID measure in comparison to the development extend was not sufficient because the LIDs are expected to reduce the FV, and only two LIDs were set up in each developed area with a small contributing area. Installation of more LID measures is expected to change the results significantly. 

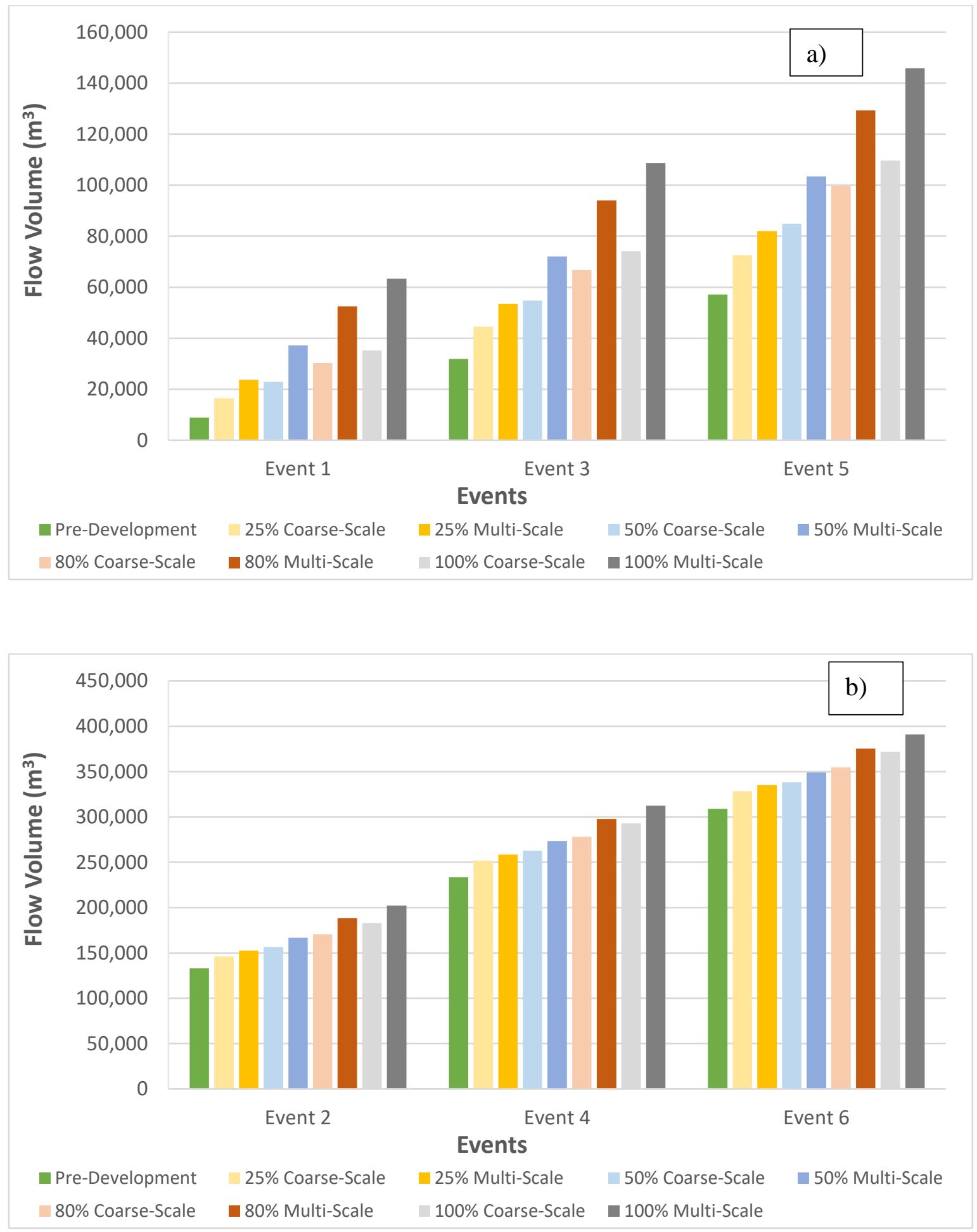

Figure 36: Comparison of the FV in Different Future Development Scenarios with a) short duration and b) Long Duration Events 


\subsection{Results of the BMPs Scenarios}

All the three above scenarios with and without BMPs was compared with the assuming $100 \%$ of the future development and was compared with the scenario having all the LID and SWM pond in coarse and Multi-scale. The same designed storms mentioned in Table 11, was used for the simulation of the scenarios. From the results of the analysis, the FV and the PFR was compared to understand the effects of the BMPs in the sub-watershed.

\subsubsection{Flow Volume}

The results show that for all the events, the FV from the models of the without any pond scenarios is showing a significant decrease from the models with ponds (Figure 37). The reason behind this decrease is that the SWM ponds do not infiltrate any water, so these are not a flow control measure. On the other hand, in the without pond scenarios in the location of the pond was set up as a natural area with normal infiltration characteristics, so these scenarios had more infiltration than the with pond scenarios.

The comparison results also show that the without LID scenario is showing the highest FV for all the events, though a developed area had only two LID features in the model. These results indicate that the LIDs are the main BMPs to control the FV. 

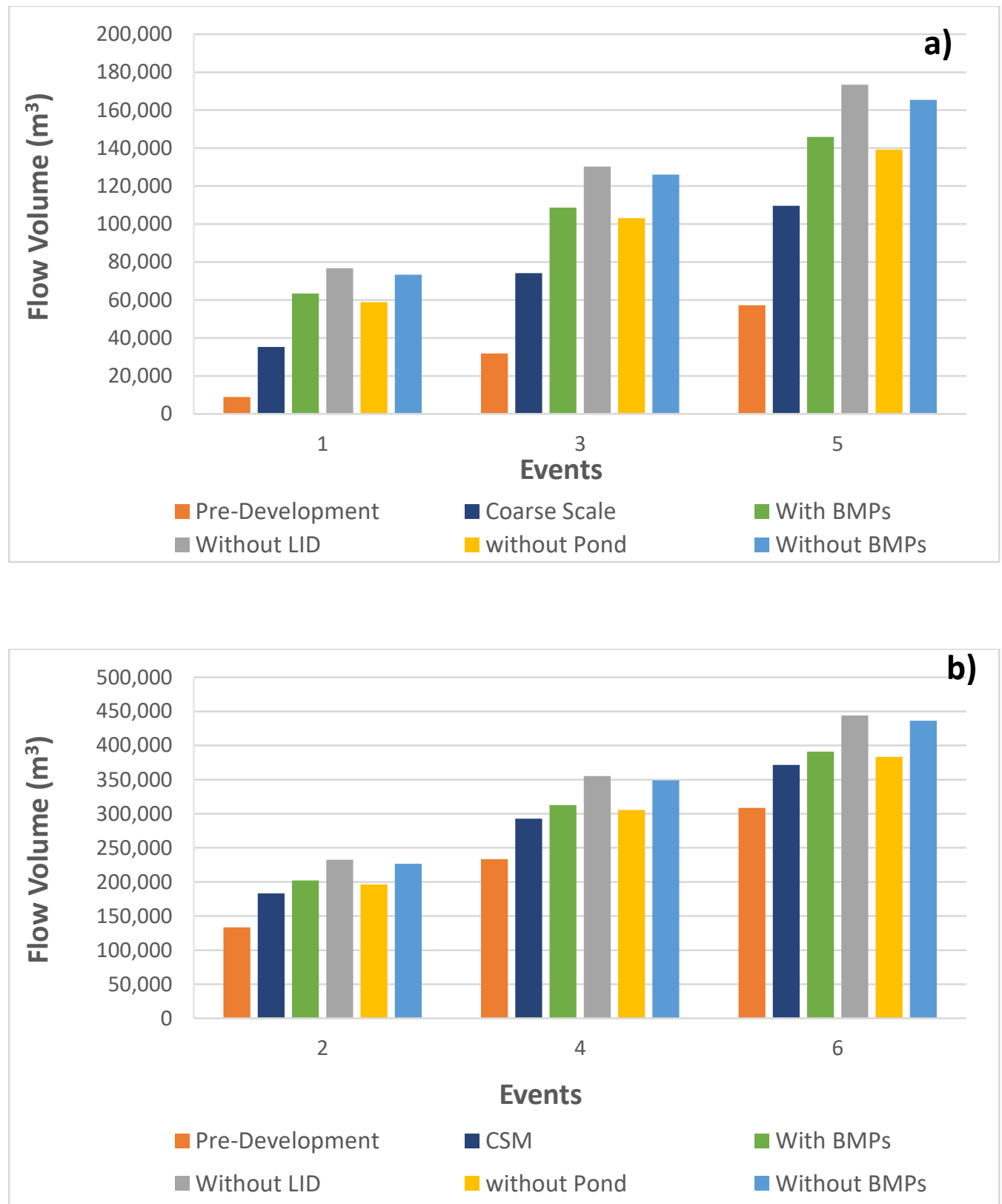

Figure 37: Comparison of The Flow Volume of All the BMPs Scenario with a) Short Duration and b) Long Duration Events 


\subsubsection{Peak Flow Rate}

The results of the PFR shows that there is no noticeable difference in between the with and without LID scenarios (Figure 38), which indicates that, the LID has an insignificant effect on the PFR reduction. However, the scenarios with and without SWM pond shows a significant difference in the PFR. This difference indicates SWM pond reduces the PFR generated from the increased imperviousness significantly, in all small and large events. This results also show that the difference between the scenario of with BMPs and without LID is very low compared to the difference between the without-pond (with LID) and without any BMPs scenario, though they are supposed to represent the effectiveness of LID. The reason behind this difference in result is that the without LID scenario had the ponds to store the additional flow and those ponds reduced the peaks, but in the without BMPs scenario there was no pond to store the additional flow. Due to the absent of LIDs and that additional flow was added with the flow generated in the without pond scenario and raised the PFR higher than the without pond scenario. The results also show that in the without-pond scenarios the PFRs of the short duration events have a higher value than the long duration events. Because in the long duration events though the rainfall amount is more, it is distributed over a long period which results in lower PFRs than the short duration events. 


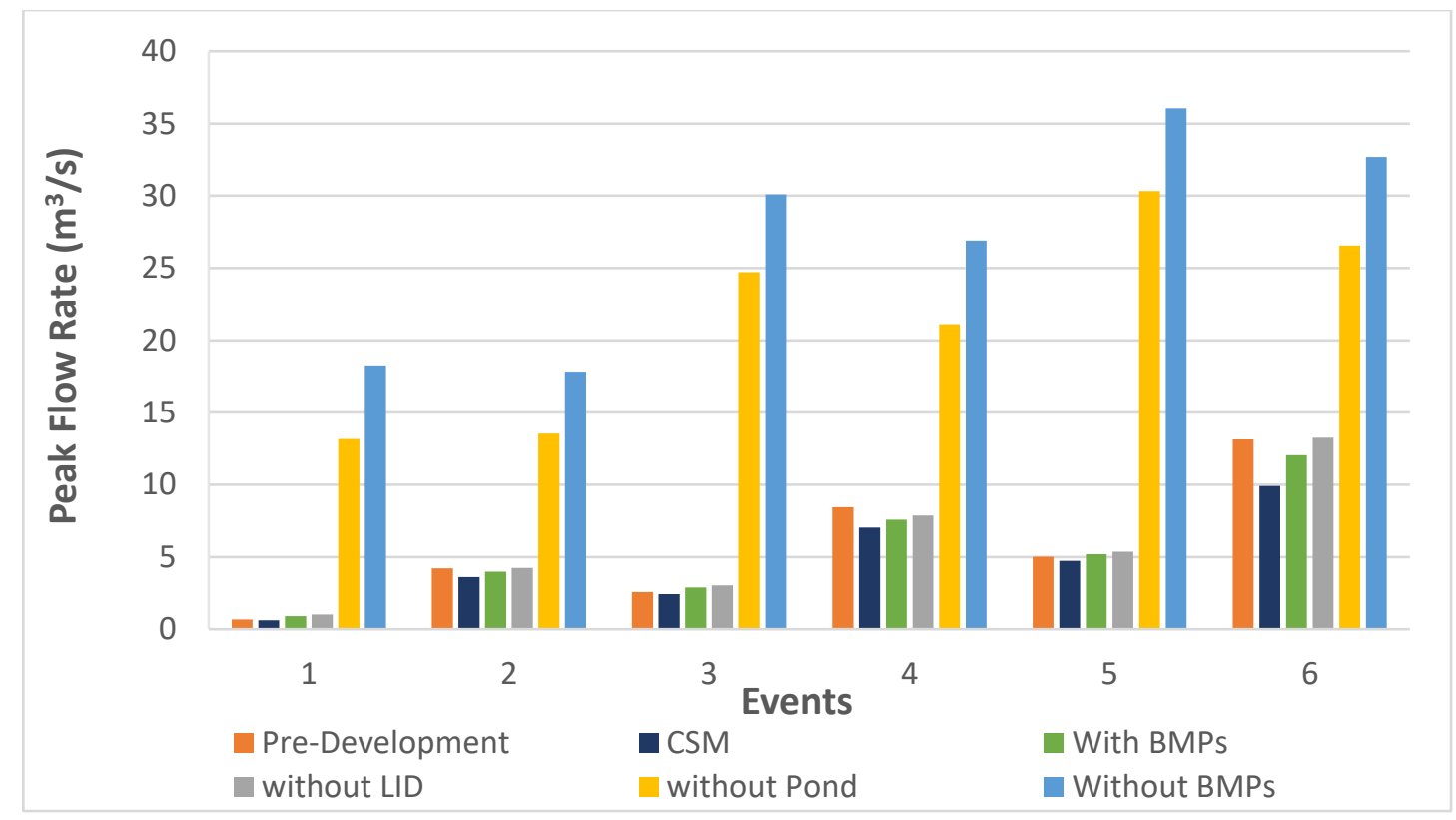

Figure 38: Comparison of the Peak Flow Rate of the BMPs Scenario

The results of the FV and the PFR show that the scenario with all the BMPs has significantly lower PFR and a slightly lower FV than the scenario without BMPs. Moreover, the BMPs have even decreased the FV and PFR from the larger events than the Pre-Dev. scenario. And in smaller events, the FV and PFR have increased a little. This increase in smaller events and a decrease in larger events also indicates that the calculation of the effect of BMPs is not always a simple arithmetic calculation. The scenario of without LID shows a significant increase in the FV. Though in this sub-watershed only two LIDs installed in each developed area, dealing with a very less area with an increased number of LID and it contributed area may change the result significantly. And the without pond scenario shows a significant increase in the PFR so, the ponds are working effectively to reduce the PFR. 


\section{Summary and Conclusions}

\subsection{Summary}

In stormwater management modelling, two spatial scales are used in current practice. The government agencies use the CSMs for the plan and policies but for the land development projects, the FSMs are prepared for the developed area and associated BMPs. These FSMs only shows the effect of the development on the outfalls of the developed area. The effects on the downstream part of the watershed cannot be evaluated from these FSMs. Additionally, the newly developed areas contain multiple BMPs and the cumulative effects of the BMPs are not simple additives. Transferring the results of the FSMs into the CSMs is not easy and presents problems related to parameterizations. This scale difference makes the evaluation process of the BMPs complicated and time-consuming. The main objective of this research study was to develop a methodology to integrate the FSM of a developed area and a CSM of an undeveloped area, to minimize the problems related to transferring the result from one scale to another. The developed methodology was also implemented in an urbanizing watershed as a case study. Several hypothetically assumed future development scenarios and scenarios with and without different BMPs was also tested with the developed methodology with several design storm events.

\subsection{Key Findings}

The developed methodology of a Multi-scale modelling is successfully linking the FSM for the developed area and the CSM for the rest of the sub-watershed. This modelling methodology will be useful to evaluate the effects of the proposed development and the associate BMPs on the 
downstream channels with more confidence. The result of the scenario simulation shows that with the increase of development percentage the FV is increasing and the PFR is decreasing.

The results of the comparison of CSM and the MSM in this research show, the MSM always generates a larger amount of FV and larger PFR. As the Multi-scale model has well-defined parameters according to the land use of the smaller sub-catchments and comparatively accurate flow-paths, the result of the MSM can be considered more accurate.

The results of future development scenarios show that with the increased developments, the FV is increasing, which is unexpected. Because in general, the development should be done in such a way that the FV does not increase in comparison of the pre-development scenario. One Plausible reason behind the increased FV can be that the number of LIDs is not sufficient for controlling the huge flow generated from increased imperviousness.

The result of the with- and without-BMPs scenarios for this study area have shown that the withLIDs scenarios are showing a noticeable decrease in the FV than the without-LIDs scenario, but the with-LID scenarios could not decease the FV than the pre-development condition. The reason behind these may be, the developed area only has two LIDs with a considerably small contributed area. So, a developed area with many LID and lower groundwater table may show a different result. This comparison also indicates pond has no effect in terms of FV control.

The comparison of the PFR of the future development scenarios of this study area shows that, for the larger events PFR is showing a decreasing trend with the development. The with- and withoutBMPs scenarios show that the without-pond scenarios have significantly higher PFR than the 
scenarios with-pond. So, ponds are acting effectively in controlling the PFR for long-duration events in this sub-watershed.

\subsection{Limitations and Future Recommendations}

In this study, the water quantity difference between the pre-development and the post-development scenario has been compared, ignoring the water quality part assuming the SWM pond was sufficient to maintain the allowable TSS range. Only the PFR and the FV has been considered to compare the water quantity. The other two important performance measures for the water quantity analysis, the time to peak and the lag time, was not considered in this research.

Sufficient data of groundwater level was not available, so in this research, groundwater contribution has not considered. Though the analysis of the data of the study area also revealed that the groundwater table in this area is high and has a considerable contribution to the streamflow. So, to calibrate the model, a baseflow has been added in the model as an inflow to the measuring node.

A large amount of undeveloped portions of the study area is an agricultural area with tile drainage. These tile drainage does not permit enough time for the infiltration of the stormwater and drains very quickly to the natural streams. These tile drainages can not be incorporated in the predevelopment model due to lack of information about the drainage alignment. Due to these tile drainages, the streamflow of the predevelopment condition was considerably high. In the calibration process of the pre-development, model, this high amount of observed streamflow was 
simulated in the model by increasing the $\mathrm{CN}$ of the area. Because the calibration was done only for the $\mathrm{CN}$ in this research.

There are several beaver dams in this area, which makes it really challenging to select events for the calibration of the models. Because of there were several large rainfall events, but the streamflow was not consistent with the rainfall maybe because the beaver dams trapped the flow in some sections, so the streamflow measuring station did not get the expected flow. And in some case with a small rainfall event, there was a larger FV that may be occurred due to a failure of a beaver dam.

In this research study, only the events from May to October was selected for the calibration and validations. The flow condition of the winter months was not included in this study to avoid the complexity of winter hydrology though in winter season the combination of snowmelt and rain water can result a huge flow volume in the streams. 


\section{References}

Ahiablame, L. M., Engel, B. A., and Chaubey, I. (2012). “Effectiveness of low impact development practices: Literature review and suggestions for future research." Water, Air, and Soil Pollution, 223(7), 42534273.

Anselin, L. (2010). "Thirty years of spatial econometrics." Papers in Regional Science, John Wiley \& Sons, Ltd (10.1111), 89(1), 3-25.

Aquafor Beech Ltd. (2013). “2012 Duffins Creek hydrology update: Final report.” 130.

Arnold, C. L., and Gibbons, C. J. (1996). “Impervious Surface Coverage: The Emergence of a Key Environmental Indicator." Journal of the American Planning Association, Taylor \& Francis Group , $62(2), 243-258$.

Bizier, P. (Ed.). (2013). Gravity Sanitary Sewer Design and Construction. Gravity Sanitary Sewer Design and Construction, American Society of Civil Engineers, Reston, VA.

Booij, M. J. (2003). "Determination and integration of appropriate spatial scales for river basin modelling." Hydrological Processes, 17(13), 2581-2598.

Booth, D. B., Karr, J. R., Schauman, S., Konrad, C. P., Morley, S. a, Larson, M. G., and Burges, S. J. (2005). "Reviving Urban Streams: Land Use, Hydrology." Journal Of The American Water Resources Association, 98195(5), 1351-1364.

Chapman, T. G., Maxwell, I. A., and Institution of Engineers, A. (1996). Baseflow separation - comparison 
of numerical methods with tracer experiments. NATIONAL CONFERENCE PUBLICATION- INSTITUTION OF ENGINEERS AUSTRALIA NCP, Institution of Engineers, Australia.

Damodaram, C., Giacomoni, M. H., Prakash Khedun, C., Holmes, H., Ryan, A., Saour, W., and Zechman, E. M. (2010). "Simulation of combined best management practices and low impact development for sustainable stormwater management." Journal of the American Water Resources Association, 46(5), 907-918.

Dannowski, R. (2013). "Handbook of Water Sensitive Planning and Design." Journal of Environment Quality, Lewis Publishers, 33(1), 409.

DeBusk, K. M., and Wynn, T. M. (2011). "Storm-Water Bioretention for Runoff Quality and Quantity Mitigation." Journal of Environmental Engineering, 137(9), 800-808.

Dreelin, E. A., Fowler, L., and Ronald Carroll, C. (2006). “A test of porous pavement effectiveness on clay soils during natural storm events." Water Research, 40(4), 799-805.

Eckhardt, K. (2008). "A comparison of baseflow indices, which were calculated with seven different baseflow separation methods." Journal of Hydrology, 352(1-2), 168-173.

Elliott, A. H., Trowsdale, S. A., and Wadhwa, S. (2009). "Effect of Aggregation of On-Site Storm-Water Control Devices in an Urban Catchment Model." Journal of Hydrologic Engineering, 14(9), 975-983.

Fletcher, T. D., Mitchell, V. G., Deletic, A., Ladson, T. R., and Séven, A. (2007). “Is stormwater harvesting beneficial to urban waterway environmental flows?" Water Science and Technology, 55(4), 265-272. 
Garcia-Fresca, B., and Sharp, J. M. (2005). “Hydrogeologic considerations of urban development: Urbaninduced recharge." Reviews in Engineering Geology XVI: Humans as Geologic Agents, Geological Society of America, 123-136.

Ghosh, I., and Hellweger, F. L. (2011). "Effects of Spatial Resolution in Urban Hydrologic Simulations." Journal of Hydrologic Engineering, 17(1), 129-137.

Guan, M., Sillanpää, N., and Koivusalo, H. (2015). “Modelling and assessment of hydrological changes in a developing urban catchment." Hydrological Processes, 29(13), 2880-2894.

Hager, J., Hu, G., Hewage, K., and Sadiq, R. (2018). "Performance of low-impact development best management practices: a critical review." Environmental Reviews, 27(1), 17-42.

Hellmers, S., and Fröhle, P. (2017). "Integrating local scale drainage measures in meso scale catchment modelling." Water (Switzerland), 9(2).

Hoghooghi, N., Golden, H. E., Bledsoe, B. P., Barnhart, B. L., Brookes, A. F., Djang, K. S., Halama, J. J., McKane, R. B., Nietch, C. T., and Pettus, P. P. (2018). “Cumulative effects of Low Impact Development on watershed hydrology in a mixed land-cover system." Water (Switzerland), 10(8), 1-20.

Huff, F. A., and Changnon, S. A. (1972). "Climatological Assessment of Urban Effects on Precipitation at St. Louis." Journal of Applied Meteorology, 11(5), 823-842.

Hunt, W. F., Smith, J. T., Jadlocki, S. J., Hathaway, J. M., and Eubanks, P. R. (2008). “Pollutant Removal and Peak Flow Mitigation by a Bioretention Cell in Urban Charlotte, N.C." Journal of Environmental 
Engineering, 134(5), 403-408.

Ichiba, A., Gires, A., Tchiguirinskaia, I., Schertzer, D., Bompard, P., and Veldhuis, M. C. Ten. (2018). "Scale effect challenges in urban hydrology highlighted with a distributed hydrological model." Hydrology and Earth System Sciences, 22(1), 331-350.

Jakeman, A. J., and Hornberger, G. M. (1993). "How much complexity is warranted in a rainfall-runoff model?" Water Resources Research, 29(8), 2637-2649.

Jefferson, A. J., Hopkins, K. G., Fanelli, R., Avellaneda, P. M., and Mcmillan, S. K. (2017). "Stormwater management network effectiveness and implications for urban watershed function: A critical review." (August), 4056-4080.

Joksimovic, D., and Alam, Z. (2014). "Cost efficiency of Low Impact Development (LID) stormwater management practices." Procedia Engineering, Elsevier B.V., 89(Lid), 734-741.

Kaykhosravi, S., Khan, U., and Jadidi, A. (2018). “A Comprehensive Review of Low Impact Development Models for Research, Conceptual, Preliminary and Detailed Design Applications." Water, 10(11), 1541.

Khin, M. M. L. (2015). “Development of Detailed Distributed Urban Drainage Models Using Remote Sensing and GIS Data." Ryerson University.

Kokkonen, T. S., Jakeman, A. J., Young, P. C., and Koivusalo, H. J. (2003). “Predicting daily flows in ungauged catchments: Model regionalization from catchment descriptors at the Coweeta Hydrologic 
Laboratory, North Carolina." Hydrological Processes, 17(11), 2219-2238.

Krebs, G. (2017). "Spatial Resolution and Parameterization of an Urban Hydrological Model.”

Krebs, G., Kokkonen, T., Setälä, H., and Koivusalo, H. (2016). “Parameterization of a hydrological model for a large, ungauged urban catchment." Water (Switzerland), 8(10), 1-24.

Krebs, G., Kokkonen, T., Valtanen, M., Koivusalo, H., and Setälä, H. (2013). “A high resolution application of a stormwater management model (SWMM) using genetic parameter optimization." Urban Water Journal, 10(6), 394-410.

Krebs, G., Kokkonen, T., Valtanen, M., Setälä, H., and Koivusalo, H. (2014). "Spatial resolution considerations for urban hydrological modelling." Journal of Hydrology, Elsevier B.V., 512, 482-497.

Kuczera, G., and Mroczkowski, M. (1998). “Assessment of hydrologic parameter uncertainty and the worth of multiresponse data." Water Resources Research, 34(6), 1481-1489.

Leimgruber, J., Krebs, G., Camhy, D., and Muschalla, D. (2018). “Sensitivity of model-based water balance to low impact development parameters." Water (Switzerland), 10(12).

Lerner, D. N. (1990). “Groundwater recharge in urban areas." Atmospheric Environment. Part B. Urban Atmosphere, Elsevier, 24(1), 29-33.

Li, C., Fletcher, T. D., Duncan, H. P., and Burns, M. J. (2017). “Can stormwater control measures restore altered urban flow regimes at the catchment scale?" Journal of Hydrology, 549, 631-653. 
Limited, G. C. (2017). Water Balance Study.

Liu, H. (2016). “Long-term Performance Modelling of Etobicoke Exfiltration System.” Ryerson University.

Liu, H., Tolson, B. A., Craig, J. R., and Shafii, M. (2016). “A priori discretization error metrics for distributed hydrologic modeling applications." Journal of Hydrology, Elsevier B.V., 543, 873-891.

Liu, Y., and Gupta, H. V. (2007). "Uncertainty in hydrologic modeling: Toward an integrated data assimilation framework." Water Resources Research, 43(7), 1-18.

Ludwig, R., May, I., Turcotte, R., Vescovi, L., Braun, M., Cyr, J. F., Fortin, L. G., Chaumont, D., Biner, S., Chartier, I., Caya, D., and Mauser, W. (2009). "The role of hydrological model complexity and uncertainty in climate change impact assessment." Advances in Geosciences, 21, 63-71.

Nash, J. E., and Sutcliffe, J. V. (1970). "River flow forecasting through conceptual models part I - A discussion of principles." Journal of Hydrology, 10(3), 282-290.

Ontario, G. of. (2018). Watershed Planning in Ontario.

Ontario Ministry of the Environment. (2003). Stormwater management planning and design manual. MOE.

Palla, A., Berretta, C., Lanza, L. G., and La Barbera, P. (2008). “Modelling storm water control operated by green roofs at the urban catchment scale." 11th International Conference on Urban Drainge. Edinburgh, 1-10. 
Pennino, M. J., McDonald, R. I., and Jaffe, P. R. (2016). "Watershed-scale impacts of stormwater green infrastructure on hydrology, nutrient fluxes, and combined sewer overflows in the mid-Atlantic region." Science of the Total Environment, The Authors, 565, 1044-1053.

Petrucci, G., and Bonhomme, C. (2014). "The dilemma of spatial representation for urban hydrology semidistributed modelling: Trade-offs among complexity, calibration and geographical data." Journal of Hydrology, Elsevier B.V., 517, 997-1007.

Petrucci, G., Rioust, E., Deroubaix, J. F., and Tassin, B. (2013). "Do stormwater source control policies deliver the right hydrologic outcomes?" Journal of Hydrology, 485, 188-200.

Rossman, L. A. (2017). “Storm Water Management Model Reference Manual Volume II - Hydraulics." U.S. Environmental Protection Agency, II, 190.

Rossman, L. A., and Huber, W. C. (2016). "Storm Water Management Model Reference Manual. Volume I - Hydrology (Revised). EPA/600/R-15/162A." I, 231.

Salvadore, E., Bronders, J., and Batelaan, O. (2015). "Hydrological modelling of urbanized catchments: A review and future directions." Journal of Hydrology, Elsevier B.V., 529(P1), 62-81.

Sample, D. J., Heaney, J. P., Wright, L. T., and Koustas, R. (2001). “Geographic Information Systems, Decision Support Systems, and Urban Storm-Water Management." Journal of Water Resources Planning and Management, 127(3), 155-161.

Schueler, T. R. (1994). "The Importance of Imperviousness." Watershed Protection Techniques, 1(3), 1-12. 
Shepherd, J. M. (2006). "Evidence of urban-induced precipitation variability in arid climate regimes." Journal of Arid Environments, Academic Press, 67(4), 607-628.

Shepherd, J. M., Pierce, H., Negri, A. J., Shepherd, J. M., Pierce, H., and Negri, A. J. (2002). "Rainfall Modification by Major Urban Areas: Observations from Spaceborne Rain Radar on the TRMM Satellite." Journal of Applied Meteorology, 41(7), 689-701.

Soil Conservation Service. (1986). "Urban hydrology for small watersheds (technical release 55)." Washington (DC): US Department of Agriculture, 164.

Taha, H. (1997). Urban climates and heat islands: albedo, evapotranspiration, and anthropogenic heat. Energy and Buildings.

Toronto Population. (2019). “Toronto Population 2019." <http://worldpopulationreview.com/worldcities/toronto-population/> (May 8, 2019).

TRCA. (2009). Don River Watershed Plan - Aquatic System: Report on Current Conditions.

TRCA. (2019). "Watershed Features - Etobicoke \& Mimico - Toronto and Region Conservation Authority (TRCA)." <https://trca.ca/conservation/watershed-management/duffins-creek/watershedfeatures/> (May 20, 2019).

United Nations. (2018). "World Urbanization Prospects: The 2018 Revision." <https://population.un.org/wup/Country-Profiles/\%3E> (May 8, 2019).

Di Vittorio, D., and Ahiablame, L. (2015). “Spatial Translation and Scaling Up of Low Impact Development 
Designs in an Urban Watershed." Journal of Water Management Modeling, 1-9.

Walsh, C. J., Roy, A. H., Feminella, J. W., Cottingham, P. D., Groffman, P. M., li, R. P. M. A. P. M. O., and li, R. P. M. A. P. M. O. (2005). "The urban stream syndrome : current knowledge and the search for a cure Source: Journal of the North American Benthological Society, Vol . 24 , No . 3 ( Sep ., 2005 ), Published by : The University of Chicago Press on behalf of the Society for Freshwate." The North American Benthological Society, 24(3), 706-723.

Wikipedia.

(n.d.).

"Wikipedia."

<https://upload.wikimedia.org/wikipedia/commons/4/46/Natural_\%26_impervious_cover_diagra ms_EPA.jpg> (Jun. 12, 2019).

Xiao, Q., McPherson, E. G., Simpson, J. R., and S.L.Ustin. (2006). "Hydrologic processes at the urban residential scale." Wiley InterScience, 21(1), 2174-2188. 